VALIDATING THE FUNCTIONS OF IDENTITY SCALE: ADDRESSING METHODOLOGICAL AND CONCEPTUAL MATTERS

\author{
A Thesis \\ Presented to \\ The Faculty of Graduate Studies \\ of \\ The University of Guelph
}

by

TONI E. SERAFINI

In partial fulfillment of requirements

for the degree of

Doctor of Philosophy

August, 2006

CToni E. Serafini, 2006 


$\begin{array}{ll}\begin{array}{l}\text { Library and } \\ \text { Archives Canada }\end{array} & \begin{array}{l}\text { Bibliothèque et } \\ \text { Archives Canada }\end{array} \\ \begin{array}{l}\text { Published Heritage } \\ \text { Branch }\end{array} & \begin{array}{l}\text { Direction du } \\ \text { Patrimoine de l'édition }\end{array} \\ \begin{array}{l}\text { 395 Wellington Street } \\ \text { Ottawa ON K1A 0N4 }\end{array} & \begin{array}{l}\text { 395, rue Wellington } \\ \text { Ottawa ON K1A ON4 } \\ \text { Canada }\end{array} \\ \end{array}$

Your file Votre référence ISBN: 978-0-494-20944-8 Ourfile Notre référence ISBN: 978-0-494-20944-8

NOTICE:

The author has granted a nonexclusive license allowing Library and Archives Canada to reproduce, publish, archive, preserve, conserve, communicate to the public by telecommunication or on the Internet, loan, distribute and sell theses worldwide, for commercial or noncommercial purposes, in microform, paper, electronic and/or any other formats.

The author retains copyright ownership and moral rights in this thesis. Neither the thesis nor substantial extracts from it may be printed or otherwise reproduced without the author's permission.
AVIS:

L'auteur a accordé une licence non exclusive permettant à la Bibliothèque et Archives Canada de reproduire, publier, archiver, sauvegarder, conserver, transmettre au public par télécommunication ou par l'Internet, prêter, distribuer et vendre des thèses partout dans le monde, à des fins commerciales ou autres, sur support microforme, papier, électronique et/ou autres formats.

L'auteur conserve la propriété du droit d'auteur et des droits moraux qui protège cette thèse. $\mathrm{Ni}$ la thèse ni des extraits substantiels de celle-ci ne doivent être imprimés ou autrement reproduits sans son autorisation.
In compliance with the Canadian

Privacy Act some supporting forms may have been removed from this thesis.

While these forms may be included in the document page count, their removal does not represent any loss of content from the thesis.
Conformément à la loi canadienne sur la protection de la vie privée, quelques formulaires secondaires ont été enlevés de cette thèse.

Bien que ces formulaires aient inclus dans la pagination, il n'y aura aucun contenu manquant. 


\section{ABSTRACT \\ VALIDATING THE FUNCTIONS OF IDENTITY SCALE: ADDRESSING METHODOLOGICAL AND CONCEPTUAL MATTERS}

Toni E. Serafini

University of Guelph, 2006
Advisor:

Dr. Scott B. Maitland

Based on Eriksonian theory and research on identity formation, Adams and Marshall (1996) proposed that there are five basic functions of identity. These include provision of: (a) the structure for understanding who one is; (b) meaning and direction through commitments, values and goals; (c) a sense of personal control and free will; (d) consistency, coherence and harmony between values, beliefs and commitments; and (e) the ability to recognize potential in the form of future possibilities and alternative choices. Serafini and Adams (2002) operationalized the constructs by creating the Functions of Identity Scale (FIS). Various studies have examined the validity of the FIS (e.g., Serafini, Maitland, \& Adams, 2003).

The current study addressed perceived gaps in previous work within the framework of continued revision and validation of the FIS. In order to address concerns, the study had four main goals: to revise the Control subscale and establish its construct validity; to assess the structural validity of a five-factor model; to establish the external validity of each of the subscales; and to test the structural relationships between the functions of identity and other identity constructs (i.e. identity statuses and identity styles). Confirmatory Factor Analysis (CFA) and Structural Equation Modelling (SEM) 
were employed with a sample of 422 female and 107 male undergraduate students from two universities in Southern Ontario.

Conceptual revisions to the Control function involved a shift in emphasis from locus of control to personal control and self-regulation. The original FIS scale items were also revised to increase clarity and readability (5.5 grade reading level). Results of CFA supported the construct validity of the revised five-factor measurement model containing 15 items and the new Personal Control factor. The external validity of each of the subscales was also established and several predictive relationships between the functions of identity and identity statuses and identity styles were supported. Rigorous validity testing, strong psychometric properties, low reading level, brevity, utility in both research and clinical domains, and a noncategorical approach to measuring identity consolidation make the FIS an attractive complement or alternative to other identity measures currently in use. 


\section{ACKNOWLEDGEMENTS}

This dissertation marks the end of a significant chapter in my life and I have not gotten here alone. My sincere thanks and admiration go to my committee members who have demonstrated unyielding flexibility and support: My Advisor, Dr. Scott Maitland, who stepped in with grace and caring when my 'PhD-World' seemed to be falling apart. Your strength, gentleness and unfaltering confidence in me have meant more than words can express. You have truly been an incredible support and mentor. Thank you, thank you, thank you!! Dr. Clare MacMartin, thank you for creating an environment where I could grow and build my confidence, and for gently and caringly supporting me in all my personal and professional struggles. You are a treasure. Dr. Ian Newby-Clark, your call for me to "be adventurous" as I wrote my discussion was the catalyst for getting it done. It enabled me to tap a different part of myself and to truly give myself to the process thank you. Dr. Gerald Adams, you started me on this journey and have remained with me in spirit. Thank you for all the memorable experiences!

My colleagues, friends and family together have forged my "rock," the foundation on which I have garnered continued strength and perseverance, especially when my resources felt completely depleted. Geoff, Anne-Marie, and Yuiko, the PhD Candidates who went before me and from whose experiences I learned so much. Yuiko, meeting you and sharing our short time together has touched me deeply - I will never forget your kind and gentle ways of encouraging and supporting and the laughter and silly times we shared. Anne-Marie, we have shared so much (beyond birthdays!), yet have spent little physical time together. The strength of our connection and experiences together binds us in lasting friendship. And my dear Geoff, my cohort. You and I have traversed the often 
muddy $\mathrm{PhD}$ waters together and have finally reached land! You have often been my lifeboat. I cannot articulate how blessed I feel to have met you and to have shared this experience with you. Who would have thought back in "Theorizing" class that we would have become such good friends? Thank you for sharing "you" with me and for accepting me for all that I am.

My dear women-friends have been incredible these past years. Vicki, we met at the outset of my doctoral studies and have shared what seems like a lifetime of friendship. We have laughed together, played together and cried together. Thanks for being my pal and my cheerleader! Sarah, we, too, have shared some parallel experiences and a long history. You are an inspirational woman and I treasure you. Karen, Lesley, Louise and Veena, your support and understanding have been invaluable. You have patiently waited and unquestioningly supported. My whole circle of dear women-friends, knowing you has given me strength and broadened my understanding of identity, in all life's stages. Thank you all for your love, support and unfaltering faith. I carry you all in my heart, always.

My dear family has stood by for years while I continued to be a "student" and move towards this goal. I have held your support and faith in my heart throughout. Mom and Dad, you believed in me even when you didn't quite understand what I was doing, and you never pressured me to just "get married," or "get a job" and be done with it. I know you have sacrificed in doing so and I hank you (yes, now I am ready to retire!). Franca, my dear sister. You have been my staunchest supporter in many ways, often dealing with my hysterical phone messages and challenging the negative voices in my head. Thanks, Sista, you are the best sister and friend any woman could ask for! 
The PhD journey also revealed an unforeseen treasure, my Andrzej. You came into my life at an unexpected time and you have brought me so much joy and so much "life"! With you, I have developed different parts of myself and have enjoyed many adventures. You have broadened my world and have reminded me, time and time again, that life continues to unfold outside the boundaries of academia. You have understood me, supported me, challenged me and comforted me. I love you with all my heart and I thank you for all that you have brought to my life.

Finally, I would like to acknowledge and thank the participants who gave their time and energy to my research and the Social Sciences and Humanities Research Council (SSHRC) who supported this research through a Doctoral Fellowship. 


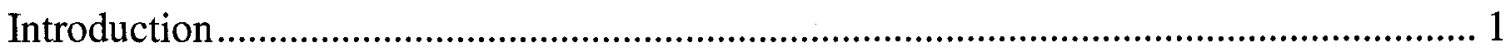

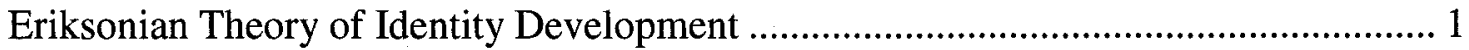

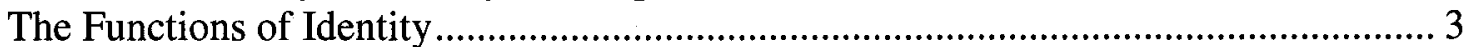

The Functions of Identity Scale (FIS): Scale Construction (Study 1) and Preliminary

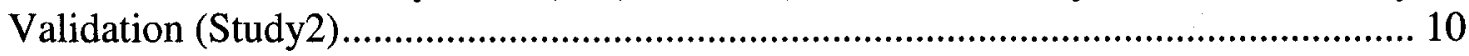

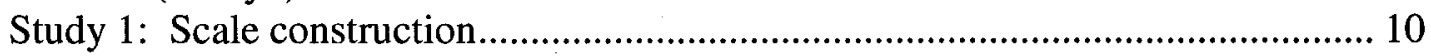

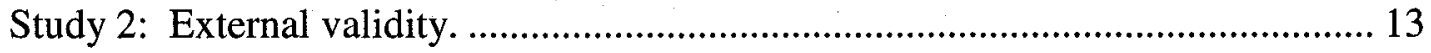

Study 3: Validation of the Functions of Identity Scale via CFA and SEM............ 17

The Functions of Identity: The Role of Personal Control in Self-Regulation ............. 21

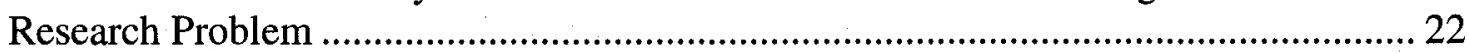

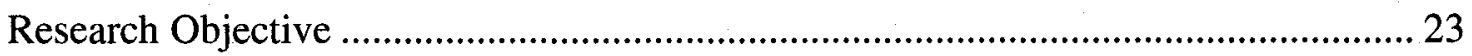

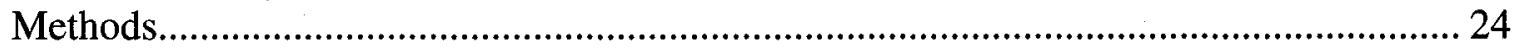

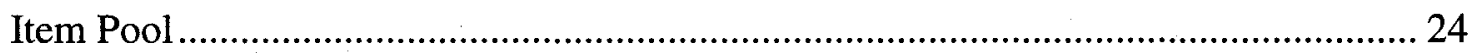

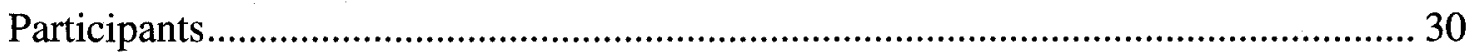

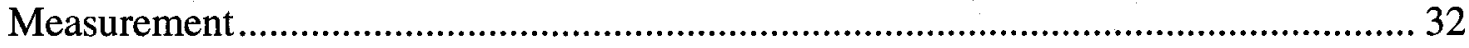

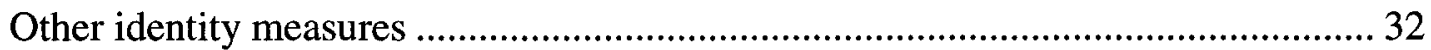

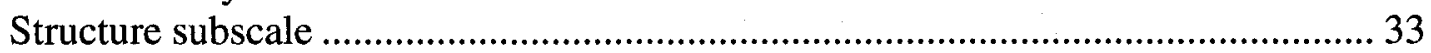

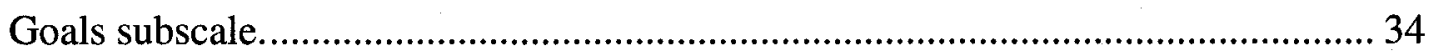

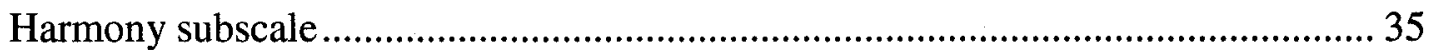

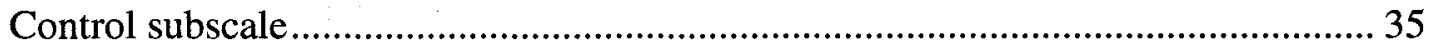

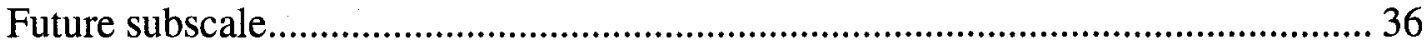

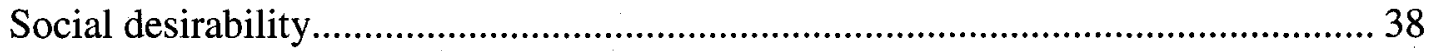

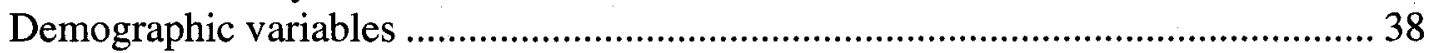

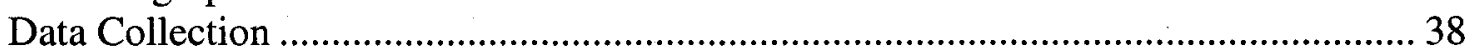

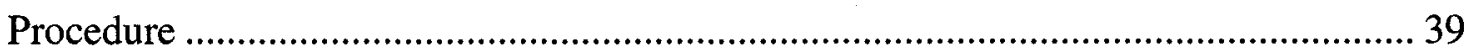

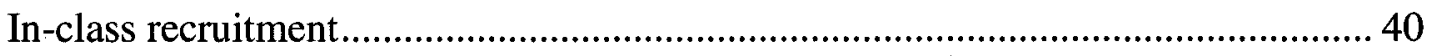

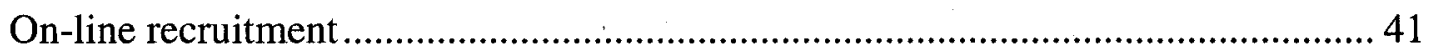

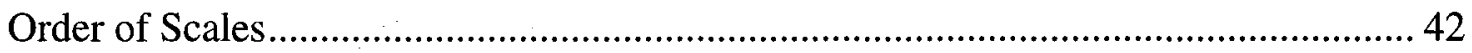

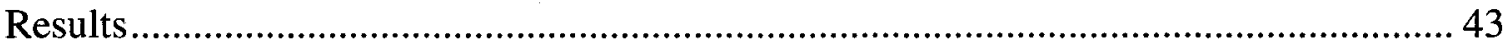

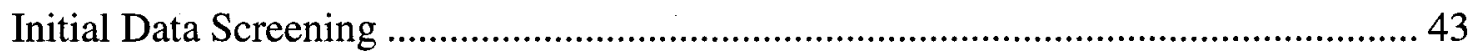

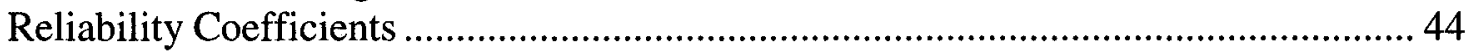

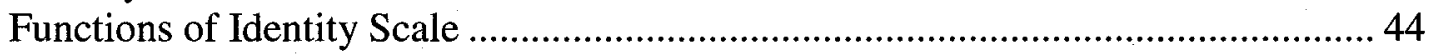

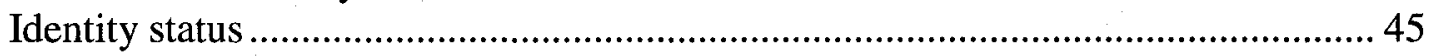

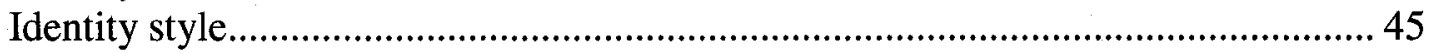

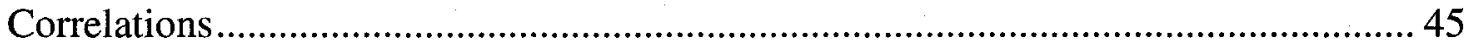

Correlations among the Functions of Identity subscales .................................... 45

Correlations between identity status and the functions of identity ....................... 48

Correlations between identity styles and the functions of identity ........................50

Correlations between identity statuses and identity styles.....................................51

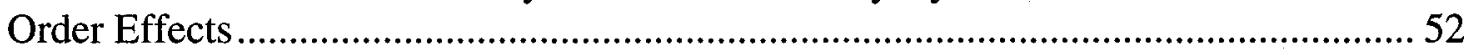

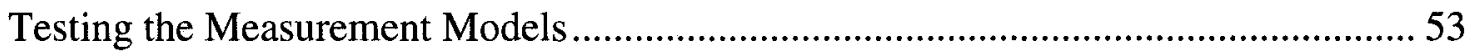

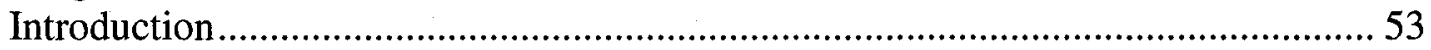

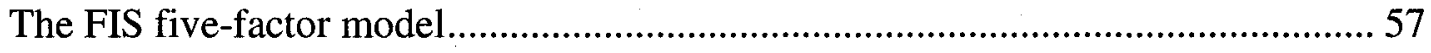

The FIS single-factor and higher order models .............................................. 71 
The OMEIS (identity status) measurement model ............................................ 74

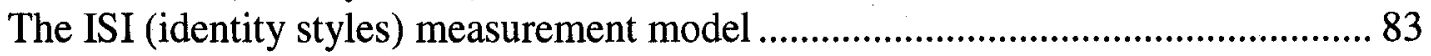

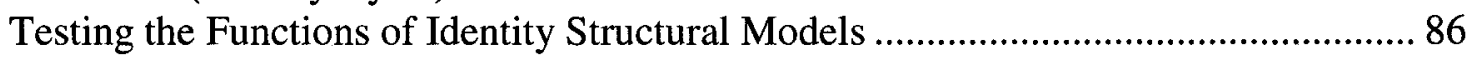

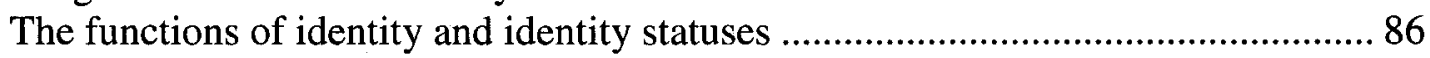

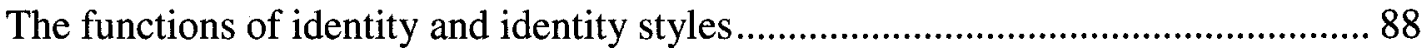

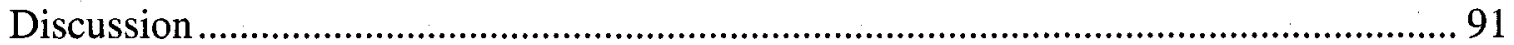

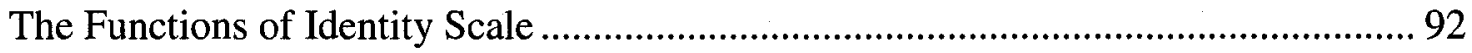

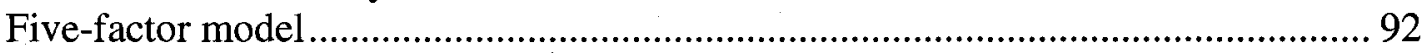

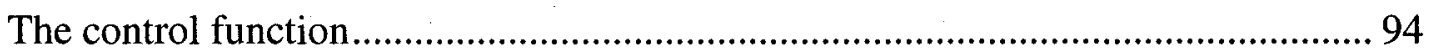

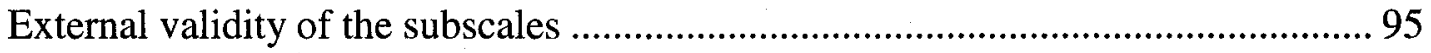

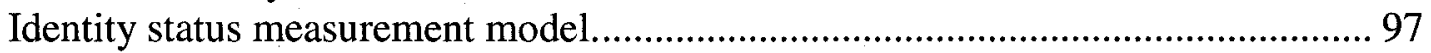

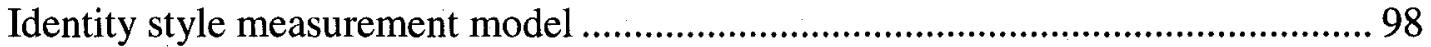

Modelling Structural Relationships Among the Functions of Identity and other Identity

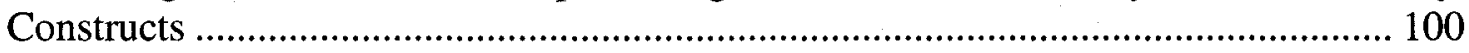

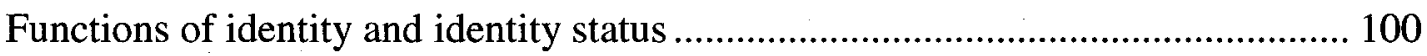

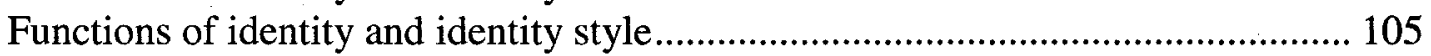

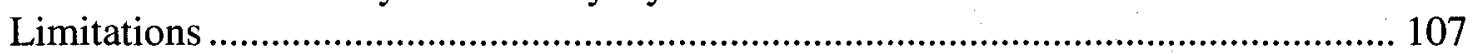

General Conclusions and Directions for Future Research ...................................... 109

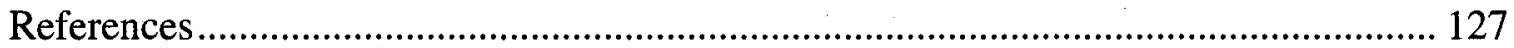

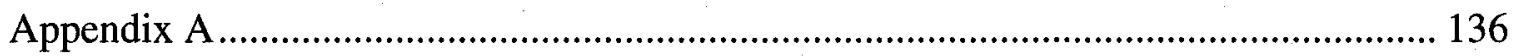

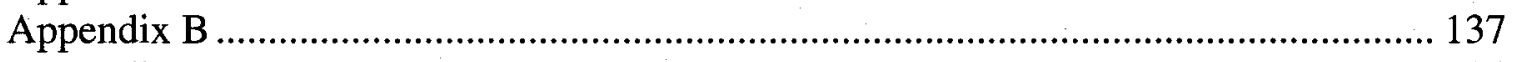

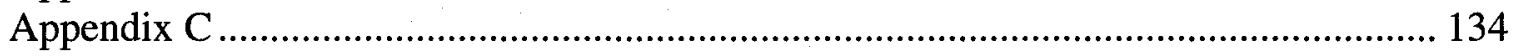

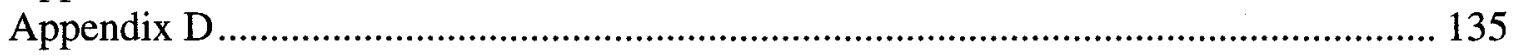

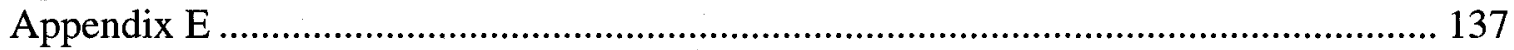

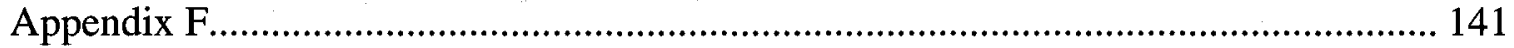

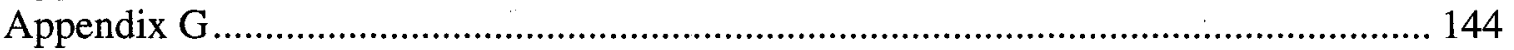

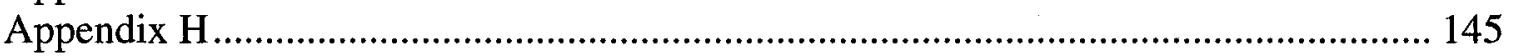

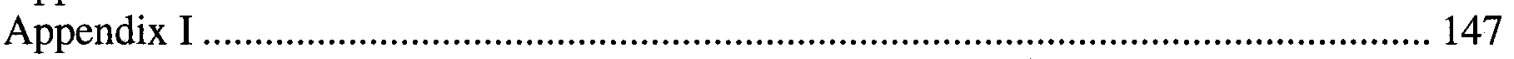

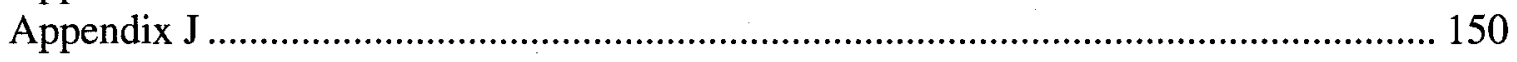




\section{List of Tables}

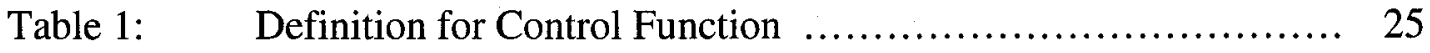

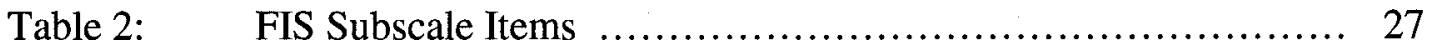

Table 3: $\quad$ Zero-Order and Partial Correlations (Controlling for Social

Desirability) for the Functions of Identity ................................. 46

Table 4: $\quad$ Zero-Order and Partial Correlations (Controlling for Social

Desirability) for the Functions of Identity Subscales and Their

Comparison Measures

Table 5: $\quad$ Zero-Order and Partial Correlations (Controlling for Social

Desirability) Between the Functions of Identity and Identity

Status Scores

Table 6: $\quad$ Zero-Order and Partial Correlations (Controlling for Social

Desirability) Between Functions of Identity and Identity Style

Scores

Table 7: $\quad$ Zero-Order and Partial Correlations (Controlling for Social

Desirability) Between Identity Status and Identity Style Scores ... 52

Table 8: $\quad$ ANOVA for the Functions of Identity Subscales by Version ..... 53

Table 9: $\quad$ Standardized Factor Loadings and SMCs for Items Comprising the Initial Five-Factor FIS Measurement Model (Model 1) ....... 59

Table 10: $\quad$ Steps in Fitting FIS Baseline Measurement Model ............. 62

Table 11: $\quad$ Standardized Factor Loadings and SMCs for Revised

Five-Factor FIS Measurement Model Items (Model 8)

Table 12: $\quad$ Continued Steps in Fitting FIS Baseline Measurement Model ... 65

Table 13: $\quad$ Standardized Factor Loadings and SMCs for the Best 4-Item

Five-Factor FIS Measurement Model (20 items)

Table 14: $\quad$ Correlations between Latent Factors for Best Four-Item

Five-Factor FIS Measurement Model (20 items)

Table 15: $\quad$ Final Steps in Fitting a Three-Item per Factor FIS Measurement Model 
Table 16: Correlations between Latent Factors for Best Three-Item, Five-Factor FIS Measurement Model (15 items)

Table 17: Indexes of Fit for Competing 15-Item Single-Factor, Five-Factor and Second-Order-Factor FIS Measurement Models .............. 73

Table 18: $\quad$ Comparison of Standardized Factor Loadings and SMCs for the Best 15-Item Single-Factor, Second-Order-Factor, and Five-Factor FIS Measurement Models

Table 19: $\quad$ Sandardized Factor Loadings for Initial Identity Status (OMEIS) Measurement Model

Table 20: $\quad$ Fit Indexes corresponding to Consecutive Steps in Fitting the Identity Status (OMEIS) Measurement Model

Table 21: $\quad$ Standardized Factor Loadings and SMCs for the Four-Item per Factor Identity Status (OMEIS) Model 79

Table 22: Fit Indexes Corresponding to Final Steps in Fitting the Identity Status (OMEIS) Measurement Model

Table 23: $\quad$ Factor Loadings and SMCs for the Four-Item per Factor Identity Styles (ISI) Model

Table 24: Indexes of Fit for ISI (Identity Status) Model Modification Process

Table 25: $\quad$ Maximum Likelihood Estimates, Standard Errors, and Structural Regression Coefficients for Identity Status and Functions Structural Model

Table 26: $\quad$ Maximum Likelihood Estimates, Standard Errors, and Structural Regression Coefficients for Identity Styles and Functions Structural Model 


\section{List of Figures}

Figure 1.

Study 3: Functions of Identity Four Factor Model

Figure 2.

Study 3: Functions of Identity and Identity Styles Predictive Model

Figure 3.

Initial Five-Factor FIS Measurement Model (32 items)

Figure 4.

Final Five-Factor FIS Measurement Model (15 items)

Figure 5.

Single-Factor General Identity Function Measurement Model (15 items)

Figure 6.

Higher-Order General Identity Factor Model (15 items)

Figure 7.

Initial OMEIS (Identity Status) Measurement Model (24 items)

Figure 8.

Final OMEIS (Identity Status) Measurement Model (12 items)

122

Figure 9.

Initial ISI (Identity Styles) Measurement Model ( 8 items)

Figure 10.

Final ISI (Identity Styles) Measurement Model

Figure 11.

Structural model 1: Functions of Identity and Identity Statuses

Figure 12.

Structural model 2: Functions of Identity and Identity Styles 126 


\section{Introduction}

\section{Eriksonian Theory of Identity Development}

Erik Erikson provided a framework for the theorizing and measuring of identity formation (e.g., Erikson, 1968). He described identity formation as the central task of adolescence and embedded it within a stage-theory of human psychosocial development, from childhood through to adulthood. While the process of identity construction as theorized by Erikson begins in adolescence, it continues through the lifecycle and is revisited at different stages of life. Erikson conceptualized identity as an active process marked by crises or turning points, choices, mastery of one's environment, differentiation, and change. While his theory was originally based on clinical interviews, much of the scholarly research that has followed has been focused on the operationalization of his identity construct (e.g., Adams, Shea, \& Fitch, 1979; Berzonsky, 1989; Grotevant \& Adams, 1984; Marcia, 1966).

James Marcia (1966) has contributed much to the operationalization of Erikson's identity stage. While Erikson's original theory of identity formation was broad and abstract, Marcia drew upon two specific dimensions of Eriksonian identity formation, crisis (exploration) and commitment, and conceptualized four types of identity formation based on these dimensions, called The Identity Status Paradigm. Marcia described the process of exploration as an examination of alternatives with the intention to make a commitment. Commitment is described as dedicating oneself to an action, goal, ideal, value, or belief.

Based on Erikson's theoretical writings, Marcia (1966) has, both on conceptual and methodological levels, delineated four types of identity based on varying levels of 
these two dimensions. Identity Diffusion refers to the least mature or advanced status, where youth have neither actively explored alternatives nor have they made ideological commitments. In fact, an avoidance of such decision-making is often characteristic of those in the Diffused identity status. Those who are Identity Foreclosed have made some commitments, typically by adopting the beliefs and values of their parents. Foreclosed youths have not, however, actively explored alternatives for themselves. Moratorium refers to the phase best characterized by active exploration of options and alternatives and an absence of firm commitments. Finally, the Identity Achieved status refers to the most advanced or mature phase of identity development where youths have experienced the exploration of the Moratorium stage and have made choices (commitments) in terms of values, beliefs, and goals that best fit who they understand themselves to be. Consistent with Eriksonian theory, the Identity Achieved status marks the most active and committed level of identity development and is most closely linked to what Erikson described as "optimal identity" (Erikson, 1968, p. 165). The Objective Measure of Ego Identity Status developed by Adams et al. (1979) is the instrument commonly used to empirically measure these identity statuses (see Schwartz, 2001 for a review).

Unlike Marcia (1966), Berzonsky (1989) considers identity statuses to be organizers of experience rather than organizations of experience. He conceptualizes identity as a process rather than a structure, and argues that people differ in the way that they process information that is relevant to the self. One style of processing such information is the Information-Oriented Style whereby people actively seek out information that might be relevant to their situation or to the issues they are considering, and they carefully evaluate this information before making a decision. This identity style 
best characterizes Marcia's Identity Achieved and Moratorium statuses. The DiffuseAvoidant Style is characterized by putting off making decisions and avoiding issues or problems by procrastinating. This identity style is most closely associated with Marcia's Diffusion. Finally, Berzonsky proposes a Normative-Oriented Style of processing identity relevant information where people rely on information such as social norms and the expectations of significant others (e.g., parents) when they are faced with issues or problems. Normative-Oriented Style is best typified by the Foreclosed identity status. Like other identity researchers who have sought to operationalize identity theory and related constructs (see Schwartz, 2001 for a review), Berzonsky has also developed a measurement instrument to measure these identity styles called the Identity Styles Inventory (ISI; Berzonsky, 1989).

\section{The Functions of Identity}

According to Eriksonian theory, identity is believed to have a self-regulatory function in the development of self. Adams and Marshall (1996) propose that identity, as a social-psychological structure, has certain properties and functions. It is a "selfregulatory system which functions to direct attention, filter or process information, manage impressions, and select appropriate behaviours" (p.433, italics in original). They discuss identity as having its own function or purpose and propose that this purpose can be surmised in what they have termed the "functions of identity" (p. 433). Based on a review of the theoretical and empirical research in the area of ego identity, Adams and Marshall propose five most commonly documented functions of identity:

a) providing the structure for understanding who one is;

b) providing meaning and direction through commitments, values and goals; 
c) providing a sense of personal control and free will;

d) providing for consistency, coherence and harmony between values, beliefs and commitments;

e) providing the ability to recognize potential in the form of future possibilities and alternative choices. (p. 433, italics in original)

Adams and Ethier (1999) followed this proposal with a review of research findings that serve as support for the existence of these five particular functions of identity. For the first function of identity, to provide the structure for understanding who one is, Adams and Ethier (1999) conceptually linked identity achievement with exhibiting low levels of anxiety about the self, whereby this anxiety could manifest itself in varying levels of self-consciousness, self-esteem and self-acceptance. For example, Adams, Abraham, and Markstrom (1987) found, in a comparison of the four identity statuses, that achieved individuals were less self-conscious than others and were the least self-focussed of all the identity statuses. The more sophisticated identity statuses have also been found to be positively related to positive body image and self-image (Bennion, 1988), higher self-esteem and self-acceptance (Owen, 1984), and lower adolescent egocentricism (O'Connor, 1995). This research suggests that understanding the self is accompanied by a lower level of anxiety about the self, and is related to the more advanced identity statuses and therefore, optimal identity development.

For the second function of identity, providing meaning and direction through commitments, values and goals, individuals who are identity achieved have been found to be more committed (Adams, Shea, \& Fitch, 1979) and more goal-directed and selfmotivated (Blustein \& Palladino, 1991) than individuals who have not formed a strong 
sense of identity (i.e., diffused individuals). Archer and Waterman (1988) also found that achieved individuals were more deliberate in their approach to romantic relationships, representing strong commitments. Commitment to religious values as manifested by weekly church attendance by Mormons has also been found to be related to a more consolidated sense of identity (i.e., identity achievement) (Markstrom-Adams, Hofstra and Dougher, 1994). Thus, some research suggests that individuals who have achieved an identity appear to be more committed and goal-oriented than those who have not.

The third function of identity is to provide a sense of personal control and free will. Adams and Ethier (1999) related the ideas of personal control and free will to the constructs of locus of control, conformity and conscientiousness. Some research offers that adolescents who are identity achieved show the least amount of external locus-ofcontrol, and those who are identity diffused show the least amount of external locus of control, suggesting that individuals with a stronger sense of identity have greater confidence in their own personal control over their lives (e.g., Abraham, 1983; Bennion, 1988; Francis, 1981). Adams, Ryan, Hoffman, Dobson, and Nielsen (1985) also showed that diffused individuals are more likely than achieved individuals to conform to peer pressure, and considering substance abuse as an indicator of personal control and possibly conformity, individuals in the less advanced identity statuses were found to be more likely than achieved individuals to show signs of substance abuse and greater beer consumption (e.g., Bishop, Macy-Lewis, Schnekloth, Puswella, \& Strussel, 1997; Jones, Hartmann, Grochowski, \& Glider, 1989).

High levels of conscientiousness have also been associated with identity achievement (Clancy \& Dollinger, 1993). A conscientious person, as described by Costa 
and McCrae (1985), is one who strives to achieve his or her goals, is motivated by tasks to be accomplished, and is organized and planful. Adams and Ethier (1999) wrote that an individual who is not conscientiousness would likely be spontaneous and self-indulgent (i.e., diffused), thus lacking the personal control associated with the highly conscientious person (i.e., identity achieved). Thus research on the relationship between identity and control, conformity, and conscientiousness suggests that an established identity functions, in part, to provide a sense of personal control.

Adams and Ethier (1999) referred to academic adjustment and defense mechanisms as support for the fourth function of identity, providing consistency, coherence and harmony between values, beliefs and commitments. When comparing overall academic adjustment, identity achieved individuals have been found to be significantly more adjusted than diffused individuals (Carlson, 1986) and tend to use defensive and adaptive narcissism (Cramer, 1995). Defense mechanisms are connected to the process of identity development in that they guard against disappointments and potential loss of self-esteem; adaptive narcissism is associated with the development of healthy self-esteem and ego-ideals. These studies suggest that individuals who have achieved an identity have higher academic adjustment and are more likely to use healthier and adaptive defense mechanisms to maintain consistency and coherence between their values, beliefs and commitments.

Harmony between values, beliefs and commitments may also manifest itself in low anxiety about the self. Adams and Ethier (1999) drew on the work of Buss (1980) and Leary (1983) in describing shyness as "a problem involving anxious selfpreoccupation and behavioural inhibition in the presence of others due to the prospect of 
the threat of being evaluated" (p. 39). As expected, shyness has not been found to be associated with the identity achieved status (Hammer \& Bruch, 1994). Low levels of anxiety about the self are thus considered reflective of the functions of identity, particularly in terms of the peace associated with harmony and consistency between one's identified values and beliefs and the commitments one makes in life.

Providing the ability to recognize potential in the form of future possibilities and alternative choices is the fifth function of identity proposed by Adams and Marshall (1996). Academic achievement, as measured by grade point average (GPA) and career planning for the future, are two of the significant areas where adolescents may find recognition of their potential (Adams \& Ethier, 1999). Individuals who are identity achieved have higher GPA scores as well as a greater desire to continue their education than do diffused individuals (Francis, 1981). Similarly, advanced identity status individuals show greater career planning and decidedness (Wallace-Broscious, Serafical, \& Osipow, 1994). Finally, adolescents who have achieved an identity are more likely to believe that facets of work represent a feasible method of fulfilling their future aspirations than identity diffused adolescents. This body of research suggests that individuals who have an established identity are more likely to be invested in endeavours that recognize their potential such as academic success and career planning for the future.

Whereas Adams and Ethier (1999) described existing research that supported the existence of the five functions of identity proposed by Adams and Marshall (1996), at that time the functions themselves had not been studied directly. More recently, Serafini and Adams (2002) sought to empirically study the functions of identity by operationalizing the constructs through the creation of a measurement instrument and 
subsequent validation research (Serafini \& Adams, 2002; Serafini, Maitland, \& Adams, 2003). This validation research on the functions of identity proposed by Adams and Marshall is detailed next.

It is important first to note the distinction between the functions of identity and the identity theories and their corresponding measures described earlier. In terms of commonalities, both Marcia's work on identity statuses and Berzonsky's work on identity styles address aspects of what Erikson originally referred to as an optimal identity in that the Identity Achieved identity status and the Information-Oriented identity style are both indicative of Erikson's notion of optimal identity development. The Functions of Identity are similar in that they depict or describe what happens when an optimal identity is attained or constructed. The instruments that measure these identity constructs are also similar in that they are self-report measures whereby respondents rate various statements on Likert-type scales. The items themselves tap into various identity domains or dimensions, such as commitment and exploration for the identity statuses and methods of processing information relevant to the self for the identity styles.

The conceptualization of identity in terms of statuses and processing styles versus functions differs in many regards. First, the functions of identity do not describe what happens when identity formation processes go awry, but Marcia's Diffusion status and Berzonsky's Diffuse Avoidant identity style do. Both Marcia and Berzonsky include in their conceptualizations ways in which identity may be poorly constructed or an avoidance of identity-related tasks. The notion of the functions of identity, however, focuses solely on the outcomes contingent on successful and mature identity developments, as per Eriksonian and related theory. Second, both the identity statuses 
and processing styles focus on how various levels or types of identity are constructed and the differences in the way people approach self-definition, whereas the functions of identity do not describe levels or types of identity formation; the functions are concerned with the outcome of self-definition. If self-definition is valued, what does it do or provide? The functions focus exclusively on what a well-established, healthy sense of identity provides an individual. In other words, the functions of identity represent the components integral to a well-functioning sense of self.

Third, both the identity status and identity styles conceptualizations are categorical approaches to understanding the processes that individuals use as they construct their sense of the self. The functions of identity, however, center not on the inner workings or "how's" of identity construction, but on what the end result provides an individual. This conceptualization focuses on the outer workings of identity - what identity functions to do rather than how identity is constructed. This approach differs from other neo-Eriksonian identity work in that it is not categorical in focus. Individuals are not placed into categories or assigned such labels as Identity Diffused, Identity Foreclosed, Information-Oriented or Diffuse-Avoidant. Rather, this theory seeks to describe how identity serves to provide individuals with: a sense of structure with which to understand self-relevant information; a sense of harmony between chosen values, beliefs and commitments; a future orientation whereby goals may be pursued in the context of achieving a sense of a possible self and fostering a congruency between one's view of oneself in the present and in the future; a goal orientation whereby individuals actively pursue goals that are congruent with an established sense of self or personal identity; and a sense of personal control, free will or agency that enables active self- 
regulation in the process of setting and achieving goals, moving toward future plans, and processing experiences in ways that are self-relevant.

The Functions of Identity Scale (FIS): Scale Construction (Study 1) and Preliminary Validation (Study2)

Study 1: Scale construction. The purpose of this study was to construct a reliable indicator of the functions of identity. Serafini and Adams (2002) followed Loevinger's (1957) method of test construction whereby the construct validity of a psychological measure has three components: substantive validity, structural validity, and external validity. Loevinger argues that these three components of validity are closely related to the process of scale construction beginning with developing a pool of items that are theoretically grounded (substantive validity), analyzing the internal structure of the item pool and selecting items to form a scoring key (structural validity), and correlating test scores with concurrent or congruent constructs (external validity).

Loevinger's substantive component of test construction is similar to what is commonly referred to as content validity. Substantive validity is "the ability of theory to account for the resultant content" (Loevinger, 1977, p. 661). This aligns with the construction or collection of a pool of items as the first step in test construction and necessary to determine whether evidence that supports the validity of the test also supports the validity of the construct. She describes the structural component of validity as "the extent to which structural relations between test items parallel the structural relations of other manifestations of the trait being measured" (p. 661). This construct includes the fidelity of the structural model and inter-item structure. The structure of the measurement model may be ascertained by first administering the original item pool to a 
normative sample, selecting the items that best fit with the chosen structural model, and then administering the test to a new sample to test the hypothesis of structural coherence. In terms of Loevinger's external validity component, she highlights the importance of making use of the validity of other test scores in relation to the new test, examining factorial patterning, and using comparison measures with which the test is expected to show a relationship. Serafini and Adams (2002) referred their readers to Loevinger's original monograph for a more detailed description of the theory and practice of test construction on which that research was based and to Clark and Watson (1995) for additional guidance for applying Loevinger's theoretical approach to scale development.

Study 1 by Serafini and Adams (2002) focused on establishing the substantive and structural validity components of Loevinger's model, which correspond to the initial process of scale construction. The first step in the process of the construction of the FIS was to determine the content area to be covered by the scale by constructing a working definition for each of the functions that was grounded in Erikson's (1968) theory of identity (see Clark \& Watson, 1995). Once a conceptually sound definition was established for each of the functions (see Appendix A), the authors moved to the operationalization of these definitions via the construction of an initial item pool (60 items in total) intended to reflect or measure each of the constructs. The initial item pool was chosen to represent a wide content area potentially relevant to the functions of identity and overall theory of identity development (Clark \& Watson, 1995; Cronbach \& Meehl, 1955; Loevinger, 1957).

The structural component of validity included both the fidelity of the structural model and the inter-item structure. The structure of the measurement instrument was 
tested by administering the original item pool to a sample of undergraduate university students $(\mathrm{N}=332)$, primarily female. Participants were asked to indicate how well each statement described them by responding on a 5-point Likert scale $(1=$ never, $2=$ seldom, $3=$ sometimes, $4=$ often, $5=$ always). Scores were summed across items for each individual function, yielding five function scores for each participant. Exploratory factor analyses (EFA) and reliability analyses were performed to select the items that best fit with the chosen structural model. Maximum likelihood EFA with varimax or oblique rotations obtained similar factors, with a five-factor solution being most salient. To be considered a factor, the items had to have a loading of .40 or higher on the primary factor and could not have loading on secondary factor. Items that did not perform well according to this cut-off were dropped from further analyses. A series of maximum likelihood oblique rotation factor analyses revealed similar results, with a five-factor solution corresponding to the five functions of identity. Of these items, those with the strongest item loadings for each factor were kept (about 3-6) in order to create an instrument that was short and easy to administer. The result was a newly constructed 22item scale containing five subscales, each measuring one of the functions of identity (see Serafini \& Adams, 2002).

As an additional test of structural validity, the internal consistency for each factor was computed using Cronbach's (1951) alpha. Each factor had a moderate to high internal consistency (Structure, $\alpha=.89$; Goals, $\alpha=.76$; Harmony, $\alpha=.80$; Control, $\alpha=$ .59 ; and Future, $\alpha=.83$ ) and inter-item correlations were low to moderate (range $=.12$ to .70) for each subscale. The internal consistency of the subscales provided initial support for the structural validity of the measure (Clark \& Watson, 1995; Loevinger, 1957). 
Correlations among the factors provided additional support for the conceptual validity of the items, indicating that the functions of identity worked together in the process of healthy identity development.

A broad group of items was constructed and included the initial item pool. This group of items was chosen based on judgment that the items were relevant to the broadly defined field of the functions of identity. Final item selection was based on empirical findings from a factor analysis, as recommended by Loevinger (1957). The remaining items were conceptually and theoretically congruent with the functions of identity as proposed by Adams and Marshall (1996). The results of Study 1 provided support for the substantive validity component of the scale. Initial support for the structural validity of the scale was established in the factorial patterning of the items; five factors that were congruent with the five functions of identity emerged. The five subscales of the instrument measuring the functions of identity were named: Structure, Future, Goals, Harmony and Control. With initial support for the substantive and structural validity of the newly constructed measure, Serafini and Adams (2002) then conducted a second study to test the scale's external and predictive validity as well as its structural coherence. The next step was to test the hypothesis of structural coherence of the FIS with a new data set, to test the scale's predictive validity, and to establish the external validity of each of the five subscales.

Study 2: External validity. The external validity component of Loevinger's (1957) approach to test construction includes what are otherwise known as concurrent, predictive and discriminant validity. Loevinger highlights the importance of making use of the validity of other test scores in relation to the new test as central to establishing the 
external validity component of the new instrument. Establishing the external validity of a psychological measure includes uncovering consistent factorial patterning, and using comparison measures with which the test is expected to show a relationship.

The main objectives of Study 2 were to establish the external validity of the scale and to test the hypothesis of the structural validity of the FIS with a new sample. The authors administered to a new sample of primarily female undergraduate students $(\mathrm{N}=$ 133) the revised FIS scale, a comparison measure for each functions subscale (see Appendix B) and an identity measure (The Objective Measure of Ego Identity Status, OMEIS, Adams et al., 1979) as a measure of predictive and discriminant validity.

The results of Study 2 provided some support for the structural validity of the scale (for three of the five functions). Maximum likelihood factor analysis revealed a four-factor solution as most appropriate, with some items corresponding to the Harmony factor loading with the Structure factor and most loading onto the Goals factors. The four factors that emerged were thus named: Structure, Future, Control and Harmonious Goals. As with the previous study, in order to be considered a factor, each item had to have a factor loading of .40 or greater. In this analysis, however, items that had secondary loadings were kept, providing that the secondary loadings were less than .40 . Two items were eliminated, resulting in a 20 -item scale consisting of two 6-item subscales and two 4-item subscales. The four subscales had good internal consistency (Structure, $\alpha=.84$; Harmonious Goals, $\alpha$ $=.80$; Future, $\alpha=.80$; and Control, $\alpha=.65$ ) as well as modest to moderate correlations between the subscales, except for Harmonious Goals and Control.

Study 2 also provided initial support for the external validity of the FIS. Each of the FIS subscales was significantly correlated with its comparison measure, except for 
Future. The authors attributed this inconsistency to methodological issues with the comparison measure (see Serafini \& Adams, 2002 for a detailed discussion).

On a conceptual level, the FIS seemed to perform well according to predictions about its relationship to the identity measure, except for the Harmonious Goals subscale. The analyses revealed that the higher the identity status (Diffusion to Achievement), the stronger the relationship between the status and the functions, except for Harmonious Goals. Analysis of variance revealed significant differences between comparison groups with significant effects of identity status for Structure, Future and Control functions. Results of discriminant function analyses also provided support for the conceptual model whereby Diffusion and Foreclosure manifested lower scores and Moratorium and Achievement higher scores on the four functions of identity subscales.

This study provided initial support for the substantive validity of the FIS as well as the external validity component of four of the five subscales. However, the structural validity of the scale was not fully established; the five-factor model found in Study 1 was not replicated.

Study 2 did not provide support for the hypothesis of structural validity suggested in Study 1. This seemed to center around the Harmony and Goals functions, whereby scale items corresponding to these functions loaded together thereby forming the Harmonious Goals factor. Neither the substantive nor structural validity components of the FIS were supported for this factor. These results suggested that on a conceptual level the Harmonious Goals factor did not represent the functions of identity as proposed by Adams and Marshall (1996). Conceptualizing the functions of identity as four, rather than five distinct functions based solely on the results of Study 2 would be premature. There may 
indeed be some conceptual issues underlying the new four-factor structure in Study 2; however, on a methodological level, the difference in sample sizes across studies could account for the differences in the factorial patterning. Clark and Watson (1995) recommend a sample size of a minimum of 300 respondents for the initial stages of test construction. The sample size in Study 2 was half the recommended size and less than half the size of the sample in the first study. It is unclear whether the different results across these two studies were due to the properties of the scale being tested or the size of the sample utilized. Given these potential conceptual and methodological issues, further research with the FIS and a new sample was warranted.

The chief limitation of validation research with the FIS thus far is that it was preliminary in nature. Because the samples were comprised almost entirely of female undergraduate students, the generalizability of the results was severely hindered. The empirical support for the functions of identity model applies only to female undergraduate students at this time. Finally, as with all self-report measures, one must consider the effects of social desirability as a threat to validity.

Future research with the FIS should address these limitations by testing the structural validity of the scale with a larger, more gender-balanced sample. An alternative comparison measure for the Future subscale should also be utilized, as well as the inclusion of a measure of social desirability. Future researchers are cautioned to be mindful of the number of non-affirmative items in the final version of the scale (see Serafini \& Adams, 2002). The Control function, for example, was comprised entirely of non-affirmative items, based on results of factor analysis. Researchers may consider creating additional affirmative items, or resurrecting some of the original items that were dropped from the 
first EFA, as they may perform differently with an alternative sample. Continued validation work with the FIS should also move beyond exploratory factor analysis to the increase the rigor of analyses via confirmatory factor analysis (CFA) and structural equation modelling (SEM).

Study 3: Validation of the Functions of Identity Scale via CFA and SEM. Adams and Marshall (1996) proposed that identity provides: (a) the structure for understanding who one is; (b) meaning and direction through commitments, values and goals; (c) a sense of personal control and free will; (d) consistency, coherence and harmony between values, beliefs and commitments; and (e) the ability to recognize potential in the form of future possibilities and alternative choices. Serafini and Adams (2002) developed the Functions of Identity Scale (FIS) to measures these five functions and examined the reliability of the five constructs for content and concurrent validity. These findings, however, could not be generalized to males because the samples were overwhelmingly female. While aspects of construct validity of the FIS have been documented, a rigorous test of construct validity remained to be completed.

Serafini et al. (2003) addressed some of the limitations of the previous validity research with the FIS. They not only took a more rigorous approach to validation by employing confirmatory factor analysis and structural equation modelling, but they also addressed two sampling issues from the previous studies: sample size and gender imbalance. Using an extant data set $(\mathrm{N}=1583)$, they assessed the construct and predictive validity of the FIS in 372 male and 1208 female undergraduate students from four universities in Southwestern Ontario. This sample was not only larger than those used in previous studies, but it also contained a greater number of male participants, thus 
enabling an examination of the fidelity of the model for both males and females.

Confirmatory factor analysis of the measurement model was conducted using structural equation modelling as a formal test of the construct validity of the model. A test of predictive validity using Berzonsky's Identity Styles Inventory (ISI) (Berzonsky, 1989), rather than the identity status measure used in Study 2, was also conducted. The rigorous statistical assessment employed was essential to determine if further scale development was necessary for measuring the functions of identity using Eriksonian and related identity theory construction.

Confirmatory factor analysis of the functions of identity measurement model was conducted using structural equation modelling to formally test the construct validity of the model. CFA was used to test both the FIS and ISI measurement models and to test the predictive validity of the FIS using the ISI as the established identity measure. For the ISI, four items each were used to measure the Information-Oriented (Info) and Diffuse-Avoidant (Diff) identity styles, as these identity styles best represent the two ends of identity development (from healthy/mature to less healthy/mature), and closely map on to the Achieved/Moratorium and Diffused identity statuses, respectively. CFA results supported a 6-item measurement model with three items measuring each latent factor, Info and Diff $\left[\chi^{2}(8)=71.75, p<.001 ; \mathrm{GFI}=.98 ; \mathrm{TLI}=.90 ; \mathrm{RMSEA}=.07\right]$. Previous exploratory analyses with the FIS (Serafini \& Adams, 2002) have provided inconsistent support for five separate subscales corresponding to the five proposed functions of identity. However, CFA revealed a 4-factor solution as the most appropriate, with the Control factor being eliminated. Modification indexes, critical ratios, and a variety of fit indexes were used to guide modification of the model. The 
resulting model consisted of 4 factors corresponding to four of the five original functions of identity (i.e., Structure, Harmony, Goals and Future), each measured by three items (see Figure 1$)\left[\chi^{2}(48)=341.44, p<.001 ; \mathrm{GFI}=.97 ; \mathrm{TLI}=.94 ; \mathrm{RMSEA}=.06\right]$. As expected, all functions of identity factors were correlated. Interestingly, contrary to Study 2, the Harmony and Goals items did not collapse together to form one factor. They remained independent factors despite a more rigorous test of structural validity. These results suggest that the Harmony and Goals factors and related items are indeed conceptually congruent with Eriksonian and related identity theory.

Results of these analyses also provided support for the predictive validity of the FIS. A test of predictive validity using Berzonsky's Identity Styles Inventory (replacing the OMEIS from Study 2 as the identity measure) was conducted. Predictions were consistent with Eriksonian identity theory: Information-Oriented and Diffuse-Avoidant Identity Styles were expected to be correlated (positively and negatively, respectively) with the functions of identity. Results of SEM suggested that these predictions were reasonable: Info was positively correlated with all four of the functions of identity and Diff was negatively correlated with two (Future and Goals) of the four functions (not Structure and Harmony) (see Figure 2). The SEM analysis allowed the researchers to go beyond correlations and to test predictive relationships. In this way, results suggested that Informational identity styles predicted all of the functions, and Diffuse-Avoidant predicted 2 of the 4 functions of identity. This study also assessed the predictive validity of the FIS by gender. Confirmatory factor analysis revealed that the final predictive model resulted in good fit for both males and females. 
Confirmatory factor analysis and structural equation modelling suggested a fourfunction FIS model as the best fitting measurement model, with three-item indicators each for Structure, Harmony, Goals and Future. This provided support for the construct validity of a four-factor FIS. Results of Study 3 also suggested that the predictive model performed best for the Information-Oriented Identity Style whereby this identity style predicted all four functions of identity. Only 2 of the 4 identity functions were predicted by Diffuse-Avoidant Identity Style. Identity style did predict the functions of identity equally well for both males and females. Given these promising results, the authors suggested that further scale development for the FIS was warranted.

This third study was not without its limitations, however. The researchers noted that the sample consisted of university students and the results, therefore, could not be generalized to other populations. Similarly, the reading level of the FIS is currently measured at a grade 7.3 reading level (Flesch-Kincaid Grade Level, Flesch, 1948). This may not impact results when studying a sample of university undergraduates whose average reading level is likely high, but may be problematic when testing a nonuniversity sample. Overall, the recommended reading level of written material is between a fifth and sixth grade reading level (e.g., Cotugna, Vickery, \& CarpenterHaefele, 2005; Paasche-Orlow, Taylor, \& Brancati, 2003; White, Wampler \& Winn, 1998). A measure of the functions of identity that is written at about a sixth grade reading level would be more inclusive of a diverse population than the current measure which is limited in its use with a university population.

Study 3 failed to address issues of external validity for one subscale and the potential impact of social desirability effects on participants' self-report responses. As 
noted in Study 2, empirical support for the external validity of the Future subscale has not yet been established. The external validity of the subscales must be clearly addressed in future research. Many social science researchers also agree that self-report methods of data collection should include controls for social desirability whenever possible.

Finally, the results of Study 3 did not provide support for the Control subscale as measuring one of the proposed functions of identity. This may be understood in two ways. First, the items comprising the Control function may not be adequately representing the construct. The final items in the control subscale are comprised solely of non-affirmative items. This suggests that the subscale may asses the absence of the construct, rather than its presence. Additionally, the Control function, as it was defined by Serafini and Adams (2002) in Study 1, privileges an emphasis on internal locus of control. The endorsement of items thus may be influenced by a conceptual association between "personal control and free will" and internal locus of control. This may not be the best representation of Eriksonian identity theory. The Control function of identity may actually be more theoretically congruent with the personal control and personal agency associated with the construct of self-regulation as a component of the executive function of the self (see Baumeister \& Vohs, 2004; Leary, 2003).

\section{The Functions of Identity: The Role of Personal Control in Self-Regulation}

The function of identity centered on personal control and free will, which was first proposed by Adams and Marshall (1996) and later empirically tested by Serafini and Adams (2002) and Serafini et al. (2003), may have been imprecisely aligned in initial test construction with the construct of internal locus of control and related active versus passive processes. Further investigation of the identity literature suggests a closer conceptual link 
between the Control function of identity and the personal control and personal agency subcomponents of the executive function of the self. The executive function of the self is discussed in terms of its self-regulatory function, which is based on the constructs of personal control and personal agency (see Baumeister \& Vohs, 2003; Schmeichel \& Baumeister, 2004; Vohs \& Ciarocco, 2004). Baumeister and Vohs describe the executive function of the self as the "active, intentional aspect of the self ... or in terms of the agentic nature of the self" (pp. 198-199). The executive functions of the self, namely selfregulation and self-control (or personal control), foster behaviour that is both intentional and self-directed (Schmeichel \& Baumeister, 2004) and can be applied to various cognitive and behavioural domains (see Leary, 2004; Vohs \& Ciarocco, 2004). Self-regulation within the context of the executive function of the self "involves the self acting on itself to alter its own responses with the (conscious or nonconscious) goal of producing a desired outcome" (Baumeister \& Vohs, 2003, p. 199). Baumeister and Vohs further underscore the importance of self-regulation in comprehending processes of self-control. The nature of selfhood is believed to include "its ability to make a better fit between the person and the environment" (p. 213) in such a way that the individual's sense of self, in terms of beliefs and values, is congruent with one's active choices regarding actions and behaviours related to achieving desired goals.

\section{Research Problem}

Validation of the Functions of Identity Scale remains a work in progress. The three studies conducted thus far provided inconsistent support for the structural validity of the scale as containing five separate subscales corresponding to the five functions of identity. Research with the FIS to date suggests that the Control function requires more 
detailed analysis from a construct validity perspective, for both the definition of the construct and the corresponding items. Additionally, external validity for only four of the five subscales has been empirically established. Further validation work with the FIS should address the limitations of the research to date, and should include continued use of rigorous statistical analyses, specifically confirmatory factor analysis and structural equation modelling, to fully explore the five-factor model of the functions of identity originally proposed by Adams and Marshall (1996).

\section{Research Objective}

Ongoing validation work with the Functions of Identity Scale addresses the methodological and conceptual limitations highlighted in previous research studies. This study revisited the scale construction process by paying close attention to the construct validity of the scale items as they represent the functions of identity, as well as the conceptual compatibility of the functions of identity (as defined by Serafini and Adams, 2002) with the identity theory on which they are based. Specifically, this current study examined the following areas: a) the structural validity of the FIS as a five-factor model;

b) the construct validity of the Control function, with movement from a conceptual emphasis on internal locus of control to self-regulation; $c$ ) the creation of new items that measure the revised Control function; d) the wording of the scale items to ensure conceptual compatibility with the functions and to lower the reading level of the items themselves; e) the external validity of the subscales, particularly for the Future subscale; f) the predictive validity of the FIS using other identity measures; and g) the potential for social desirability effects to threaten validity. 
Methods

Item Pool

The first step in the process of scale revision was to return to the definitions for the functions originally devised by Serafini and Adams (2002). In that study, the initial step in developing the item pool was to construct a working definition for each function of identity (Clark \& Watson, 1995). Therefore, in order to create new items for the Control function, a new working definition had to be established. In doing so, particular attention was paid to the original definition of Control and subscale items, and their emphasis on internal locus of control processes. The self-regulation literature (see Baumeister \& Vohs, 2003; Maddux \& Gosselin, 2003; Schmeichel \& Baumeister, 2004) acted as a theoretical base on which a new definition of the Control function was created (now called New Control). The conceptualization of the New Control function shifted to a focus on the self-regulatory nature of the executive functions of identity (as originally described by Adams and Marshall, 1996). Attention was also paid to the concepts of personal control and free will as articulated by Erikson's original theory of identity. A new definition of Control believed to more accurately reflect identity theory and to highlight the self-regulative aspects of personal control was created (see Table 1). 
Table 1

Definition for Control Function

\begin{tabular}{|c|c|}
\hline Identity Function & Definition \\
\hline Original Control & $\begin{array}{l}\text { Identity is based on the distinctions between passivity or } \\
\text { compliance and an active or willful nature. Passive forms of } \\
\text { identity are based on compliance, imitation, and identification. } \\
\text { Active forms of identity are based on self-expression, independent } \\
\text { construction, and a sense of free will and autonomy. }\end{array}$ \\
\hline $\begin{array}{l}\text { New Control } \\
\text { (Personal Control) }\end{array}$ & $\begin{array}{l}\text { Identity construction involves the active self-regulation of } \\
\text { emotions, behaviours, and choices to fit one's personal goals, } \\
\text { values, and commitments. The notion of personal control } \\
\text { underlies the distinction between active and passive identity } \\
\text { construction. Passive forms of identity are based on compliance, } \\
\text { imitation, and identification. Active forms of identity are based on } \\
\text { self-expression, independent construction, and a sense of free will } \\
\text { and autonomy. The self-regulatory nature of identity is based on } \\
\text { varying degrees of personal control that foster self-directed, } \\
\text { intentional behaviour toward the goal of producing a desired } \\
\text { outcome. This process involves actively altering emotions, } \\
\text { thoughts, and behaviours to meet such goals. Personal control and } \\
\text { a sense of free will enable self-regulatory skills to function in a } \\
\text { way that allows for a personalized, actively constructed sense of } \\
\text { self to unfold. }\end{array}$ \\
\hline
\end{tabular}

The next step involved the creation of a series of items that were believed to measure this revised construct. The process of writing these items followed a structure similar to the one used by Serafini and Adams (2002) for the initial steps of scale construction. First, approximately 22 items were written that seemed to tap into the conceptual arena identified for the New Control function. Revisions to, and deletion of, these items occurred in consultation with members of my doctoral thesis advisory committee. This process could be considered a form of "expert judgment." Two of these 
researchers were knowledgeable in the area of identity theory and research, one was new to this particular line of research, and another was a discourse analyst. The items were judged based on their conceptual compatibility with both identity theory and the selfregulation research, as well as their wording and clarity. After the items were reviewed by this team as an additional test of face validity, items were deleted and revised accordingly. The result was a New Control subscale consisting of 13 items, each tapping into some aspect of the construct of personal control in terms of the executive function of identity being the self-regulation of behaviours, thoughts, and emotions. The original and revised versions of the all FIS subscale items are presented in Table 2.

In addition to the construction of New Control items, the original FIS items were also reviewed and refined. Changes were made to the wording of some of the items to increase clarity and readability. New items were created based on the results of previous validity research with the original scale (Serafini \& Adams, 2002; Serafini et al., 2003). This procedure also underwent review by the research team, as identified above. 
Table 2

FIS Subscale Items

\begin{tabular}{|c|c|c|}
\hline $\begin{array}{l}\text { Function of } \\
\text { Identity }\end{array}$ & Original Items & Items After Revision \\
\hline \multirow{4}{*}{ Structure } & I accept who I am. & \multirow{4}{*}{ No Change } \\
\hline & $\begin{array}{l}\text { I feel I have a consistent sense of } \\
\text { self from one day to the next. }\end{array}$ & \\
\hline & $\begin{array}{l}\text { I feel a sense of peace with my self } \\
\text { and my identity. }\end{array}$ & \\
\hline & I am certain that I know myself. & \\
\hline \multirow[t]{4}{*}{ Harmony } & $\begin{array}{l}\text { My values and beliefs are } \\
\text { consistent with the commitments } \\
\text { that I make in my life at this time. }\end{array}$ & No Change \\
\hline & $\begin{array}{l}\text { My values and beliefs say a lot } \\
\text { about who I am. }\end{array}$ & No Change \\
\hline & $\begin{array}{l}\text { My values and beliefs are an } \\
\text { accurate reflection of who I am. }\end{array}$ & My values and beliefs reflect who I am. \\
\hline & $\begin{array}{l}\text { I accept that my values and beliefs } \\
\text { are coherent with the person that I } \\
\text { understand myself to be. }\end{array}$ & $\begin{array}{l}\text { My values and beliefs fit with the person } \\
\text { I am. }\end{array}$ \\
\hline \multirow{4}{*}{ Goals } & I am a goal-directed person. & No Change \\
\hline & $\begin{array}{l}\text { I tend to set goals and then work } \\
\text { towards making them happen. }\end{array}$ & No Change \\
\hline & $\begin{array}{l}\text { Self-motivation, based on my sense } \\
\text { of self, is one of my strengths. }\end{array}$ & No Change \\
\hline & $\begin{array}{l}\text { I do not have clear life goals that I } \\
\text { have constructed on my own. }\end{array}$ & $\begin{array}{l}\text { Double-barreled: create two separate } \\
\text { items: } \\
\text { - I have clear life goals. } \\
\text { - I have constructed on my own } \\
\text { personal goals for myself. }\end{array}$ \\
\hline \multirow[t]{4}{*}{ Future } & $\begin{array}{l}\text { I do not have a sense of a tangible } \\
\text { future ahead of me (e.g., career). }\end{array}$ & $\begin{array}{l}\text { Add additional items: } \\
\text { - I have a sense of an achievable } \\
\text { future ahead of me (e.g., career). } \\
\text { - My sense of an achievable future } \\
\text { ahead of me guides my current } \\
\text { choices and actions. }\end{array}$ \\
\hline & $\begin{array}{l}\text { I am undecided about where I will } \\
\text { be in the future. }\end{array}$ & $\begin{array}{l}\text { I am clear about who I will be in the } \\
\text { future. }\end{array}$ \\
\hline & $\begin{array}{l}\text { I have no idea what my future } \\
\text { holds for me. }\end{array}$ & $\begin{array}{l}\text { I have a good idea of what my future } \\
\text { holds for me. }\end{array}$ \\
\hline & & $\begin{array}{l}\text { Add additional item: } \\
\text { Thinking about my future gives me a } \\
\text { sense of direction. }\end{array}$ \\
\hline
\end{tabular}




\begin{tabular}{|c|c|c|}
\hline \multirow[t]{5}{*}{$\begin{array}{l}\text { Control } \\
\text { (original) }\end{array}$} & $\begin{array}{l}\text { Much of who I am seems to be } \\
\text { based on compliance to my } \\
\text { parent(s)' wishes. }\end{array}$ & No Change \\
\hline & $\begin{array}{l}\text { While I am influenced by others, I } \\
\text { make my own independent } \\
\text { decisions. }\end{array}$ & No Change \\
\hline & $\begin{array}{l}\text { I seem to passively accept the } \\
\text { values and beliefs of others. }\end{array}$ & No Change \\
\hline & $\begin{array}{l}\text { I prefer to comply with normal } \\
\text { standards of behaviour than to push } \\
\text { the limits of self-expression. }\end{array}$ & $\begin{array}{l}\text { Add additional items: } \\
\text { - I tend to push the limits when } \\
\text { choosing ways to express who I am. } \\
\text { - Normal or expected standards of } \\
\text { behaviour influence how I express } \\
\text { who I am. }\end{array}$ \\
\hline & $\begin{array}{l}\text { I understand my life as being } \\
\text { meaningful through identification } \\
\text { with my parent(s)' values. }\end{array}$ & $\begin{array}{l}\text { Identifying with my parent(s)' beliefs } \\
\text { and wishes gives my life a sense of } \\
\text { meaning. }\end{array}$ \\
\hline \multirow[t]{9}{*}{$\begin{array}{l}\text { New Control } \\
\text { (Personal } \\
\text { Control) }\end{array}$} & $\begin{array}{l}\text { When I'm faced with many } \\
\text { options, I can pick through them } \\
\text { and find the one that fits best for } \\
\text { me. }\end{array}$ & $\begin{array}{l}\text { When I am faced with options, I can } \\
\text { pick the one that fits best for me. }\end{array}$ \\
\hline & $\begin{array}{l}\text { I feel I can control myself when I } \\
\text { am faced with temptation. }\end{array}$ & $\begin{array}{l}\text { I can control myself when I am faced } \\
\text { with temptation. }\end{array}$ \\
\hline & $\begin{array}{l}\text { When I am working towards } \\
\text { something, I monitor my progress } \\
\text { toward that goal. }\end{array}$ & $\begin{array}{l}\text { I monitor my progress when working } \\
\text { toward a goal. } \\
\text { Add additional item: } \\
\text { When I am working toward a goal, I } \\
\text { don't really actively monitor my } \\
\text { progress. }\end{array}$ \\
\hline & $\begin{array}{l}\text { The decisions I make about how to } \\
\text { behave and act are under my } \\
\text { control }\end{array}$ & $\begin{array}{l}\text { The decisions I make about how to } \\
\text { behave and act are based on my personal } \\
\text { choices. } \\
\text { Add additional item: } \\
\text { The decisions I make about how to } \\
\text { behave and act are influenced by others }\end{array}$ \\
\hline & $\begin{array}{l}\text { I am able to control my emotions } \\
\text { when I choose/need to. }\end{array}$ & $\begin{array}{l}\text { I am able to control my emotions if I } \\
\text { choose to. }\end{array}$ \\
\hline & $\begin{array}{l}\text { I am self-directed when I set my } \\
\text { goals. }\end{array}$ & No Change \\
\hline & $\begin{array}{l}\text { I am able to change my response to } \\
\text { a situation if I want/need to. }\end{array}$ & $\begin{array}{l}\text { If I choose to, I am able to change my } \\
\text { response to a situation. }\end{array}$ \\
\hline & $\begin{array}{l}\text { I am good at making decisions that } \\
\text { involve my self. }\end{array}$ & $\begin{array}{l}\text { Making my own decisions is something } \\
\text { I am good at. }\end{array}$ \\
\hline & I am responsible for my actions. & No Change \\
\hline
\end{tabular}




\begin{tabular}{|c|c|c|}
\hline \multirow{14}{*}{$\begin{array}{l}\text { New Control } \\
\text { (Personal } \\
\text { Control) } \\
\text { Cont'd }\end{array}$} & $\begin{array}{l}\text { When what I'm doing isn't } \\
\text { working, I am able to find different } \\
\text { approaches to meeting my goal. }\end{array}$ & $\begin{array}{l}\text { When what I'm doing isn't working, I } \\
\text { am able to find different approaches to } \\
\text { meeting my goal(s). }\end{array}$ \\
\hline & & $\begin{array}{l}\text { Add additional item: } \\
\text { My sense of free will and personal } \\
\text { control guide my behaviours. }\end{array}$ \\
\hline & $\begin{array}{l}\text { I am able to adapt to new } \\
\text { situations. }\end{array}$ & Deleted \\
\hline & My behaviours are intentional. & Deleted \\
\hline & $\begin{array}{l}\text { I am aware of why I do something } \\
\text { when I do it. }\end{array}$ & Deleted \\
\hline & $\begin{array}{l}\text { I think things through before } \\
\text { acting. }\end{array}$ & Deleted \\
\hline & $\begin{array}{l}\text { I do not let my emotions influence } \\
\text { how I behave. }\end{array}$ & Deleted \\
\hline & $\begin{array}{l}\text { I am a persistent person when } \\
\text { something is important to me. }\end{array}$ & Deleted \\
\hline & $\begin{array}{l}\text { I am good at making decisions } \\
\text { about things that are important to } \\
\text { me. }\end{array}$ & Deleted \\
\hline & $\begin{array}{l}\text { I have the ability to change my } \\
\text { self. }\end{array}$ & Deleted \\
\hline & $\begin{array}{l}\text { I can change myself to fit my } \\
\text { environment. }\end{array}$ & Deleted \\
\hline & $\begin{array}{l}\text { I am able to change the way I think } \\
\text { in a given situation, if I } \\
\text { choose/need to. }\end{array}$ & Deleted \\
\hline & $\begin{array}{l}\text { I am able to change the way I feel, } \\
\text { if I want } / \text { need to. }\end{array}$ & Deleted \\
\hline & $\begin{array}{l}\text { I am able to change the way I } \\
\text { behave in a given situation, if I } \\
\text { want/need to. }\end{array}$ & Deleted \\
\hline
\end{tabular}

The new FIS items were evaluated for readability. Using the Flesch-Kincaid readability formula available from Microsoft Word (based on Flesch, 1948), a 5.5 FleschKincaid Grade Level for the FIS and associated instructions was established. Actual readability is measured using average number of syllables per word (ASW) and average sentence length (ASL). The Flesch-Kincaid Scale then assigns a score that is transformed to the minimal grade level required to read and understand the English text (range, 0 to 
12). The Flesch-Reading Ease and Flesch-Kincaid Grade Level assessments are widely used in research studies to assess the readability of measurement instruments (e.g., Ames et al., 2005; McCrae, Costa, \& Martin, 2005) as well as informed-consent forms (e.g., Paasche-Orlow et al., 2003) and written information in clinical and health settings (e.g., Ley \& Florio, 1996). A sixth grade reading level is considered reasonable for measurement instruments in order to be useful for a non-college/university sample or for persons with limited reading skills (e.g., see White et al., 1998). A fifth to sixth grade reading level is recommended for most written material (Cotugna et al., 2005; PaascheOrlow et al., 2003).

\section{Participants}

The sample consisted of 532 undergraduate students from the University of Guelph $(n=321)$ and the University of Waterloo $(n=207)$ in Southwestern Ontario. Participants ranged in age from late teens to over 26 years, with $77 \%$ of the sample $(n=$ 408) falling between the ages of 19 and 22 years $(M=2.79$, where $1=18$ years or under; $2=19$ to 20 years; $3=21$ to 22 years; $4=23$ to 25 years; and $5=26$ years or over). The sample was predominantly female $(n=422)$ and included participants from a range of ethnic/racial backgrounds: White/European $(n=363,68 \%)$, Black/AfricanCanadian/Caribbean $(\mathrm{n}=8,1.5 \%)$, East Asian/Chinese/Japanese $(\mathrm{n}=102,19.3 \%)$, and South Asian/Indian/Pakistani $(n=30,5.7 \%)$. Participants from one class received course credit for their participation in the study. Those from other classes (i.e., 60 on-campus classes and several Distance Education classes) participated on a strictly voluntary basis.

The sample was not random, but every effort was made to recruit a representative sample of undergraduate students. Students from the University of Guelph were 
recruited across all disciplines offering undergraduate courses in the summer semester. Specific courses selected for participant recruitment included those in Anthropology, Biochemistry, Biology, Botany, Chemistry, Computer Science, Economics, Engineering, English, Marketing, Microbiology, Music, Food Science, Family Relations, French, Geography, Geology, Hotel and Food Management, Applied Nutrition, History, Math, Music, Philosophy, Physics, Political Science, Psychology, Recreation and Tourism, Sociology, Soil Science, Spanish, and Statistics. Note, however, that not all instructors approached regarding recruitment from their classes supported this endeavour. Of the University of Guelph students approached, those who chose to participate in this study reported membership in the following faculties (note that percentages refer to proportion of entire sample): Arts ( $n=31,5.8 \%$; e.g., History, Languages/Literatures, Philosophy); Biological Science ( $n=45,8.4 \%$; e.g., Botany, Human Biology/Nutritional Sciences, Microbiology); Physical and Engineering Science $(n=34,6.4 \%$; e.g., Biochemistry, Chemistry, Computing, Physics); Social and Applied Human Sciences ( $n=190,35.7 \%$; e.g., Family Relations and Applied Nutrition, Consumer Studies, Economics, Psychology).

Students from the University of Waterloo were also recruited from a variety of disciplines. Courses approached for recruitment included: Accounting and Finance, Actuarial Science, Applied Math, Biology, Chemistry, Chemical Engineering, Classical Studies, Computer Engineering, Computer Science, Civil Engineering, Earth Sciences, Electrical Engineering, Mechanical Engineering, Political Science, Psychology, Religious Studies, and Sexuality Marriage and Family. Students from the University of Waterloo who chose to participate in this study reported membership in the following faculties 
(note that percentages refer to proportion of entire sample): Arts $(n=79,14.8 \%$; e.g., History, Geography, Languages, Psychology, Sociology, Sexuality, Marriage and Family); Applied Health Sciences $(n=12,2.2 \%$; e.g., Health Studies, Gerontology, Kinesiology, Recreation and Leisure); Engineering or Science ( $\mathrm{n}=62,11.6 \%$; e.g., Chemical/Civil/Electrical/Computer Engineering; Biology, Chemistry, Physics); and Mathematical, Statistical \& Computer Sciences $(n=49,9.2 \%)$.

\section{Measurement}

The Functions of Identity Scale. A revised version of the FIS was administered. This scale contained revised versions of the original 17 items representing the Structure, Harmony, Goals and Future subscales to reflect sensitivity to reading level as well as attention to clarity and construct coherence (see Table 2). In addition, the revised FIS contained several new items constructed to measure the revised Control function (13 items). Respondents were asked to indicate on a 5-point Likert scale how well each of the statements described them $(1=$ never, $2=$ seldom, $3=$ sometimes, $4=$ often, and $5=$ always). Scores were summed across items for each functions subscale yielding five functions scores for each individual.

Other identity measures. Both the Objective Measure of Ego Identity Status (OMEIS; Adams et al., 1979) and the Identity Styles Inventory (ISI; Berzonsky, 1989) served as the identity measures and thus the measures of predictive validity of the model. Because previous research has used both these measurement instruments separately, this study employed both instruments so that comparisons across studies could be made.

The 24-item version of the OMEIS was used in this study due to its shortness in length. It is composed of four, 6-item subscales measuring the four identity statuses: 
Diffusion (e.g., "I haven't really considered politics. They just don't excite me much."), Foreclosure (e.g., "My parents had it decided a long time ago what I should go into and I'm following their plans."), Moratorium (e.g., "I'm not so sure what religion means to me. I'd like to make up my mind but I'm not done looking yet."), and Achievement (e.g., "It took me a long time to decide but now I know for sure what direction to move in for a career.”). Using a 5-point Likert scale, respondents were asked to indicate the degree to which each statement reflected their own thoughts $(1=$ not like me to $5=$ exactly like me). Scoring for the OMEIS was performed following the rules detailed in Adams and Ethier (1999).

A shortened version of the original ISI served as the additional identity measure in this study. Following the protocol in Serafini et al. (2003), the same four items each were used to measure the Information-Oriented (Info) (e.g., "When making important decisions I like to have as much information as possible.") and Diffuse-Avoidant (DiffAv) (e.g., "It's best for me not to take life too seriously; I just try to enjoy it.") identity styles. The rationale for this choice was the same; these identity styles best represent healthy/mature (Info) and less healthy/mature (Diff-Av) identity development, and closely map on to the achieved/moratorium and diffused identity statuses, respectively. In this scale, respondents were asked to indicate the degree to which each item best described them using a 5 -point Likert scale $(1=$ not very much like me to $5=$ very much like me). The ISI was scored by computing the means for each subscale, producing zscores, and then assigning an identity style (Info or Diff-Av) based on the highest z-score.

Structure subscale. The Rosenberg Stability of Self Scale (1965) is a five-item scale that measures self-certainty or stability and served as the external validity measure 
for the Structure subscale in a previous study. Participants were given different instructions for different items. For the first item, "Does your opinion of yourself tend to change a good deal or does it always continue to remain the same?" respondents were asked to choose either, "changes somewhat or a great deal," or "changes very little or not at all." For the next item, "Do you ever find that on one day you have one opinion of yourself and on another day you have a different opinion?" respondents could choose either "Yes, this happens sometimes or often," or "No, this never or rarely happens." The final three items required an "agree" or "disagree" response. The items were recoded and scored so that higher scores represent a more stable sense of self. The scale was found to have a high internal consistency $(\alpha=.87)$ in previous use (Serafini \& Adams, 2002) and in the present study $(\alpha=.82)$.

Goals subscale. The Purpose in Life Test (Crumbaugh \& Maholick, 1981) is a 6item scale that measures goals, commitments, and a sense of purpose in life. It was used as the former test of external validity for this subscale. Items were scored on a 5-point Likert scale, with different anchors for each statement. For example, the first item reads, "In life I have:" and asks respondents to rate their life goals from $1=$ no goals or aims at all to $5=$ very clear goals and aims. As per Serafini and Adams (2002), the fourth item on this scale was dropped due to conceptual inappropriateness (i.e., the item measures a sense of responsibility). Scores were summed across items, with higher scores representing greater purpose in life. Previous use of the scale (Serafini \& Adams, 2002) found good internal consistency $(\alpha=.77)$ and an analysis of reliability conducted for the present study bore similar results $(\alpha=.82)$. 
Harmony subscale. Consistency, coherence and harmony between values, beliefs and commitments was found to manifest itself in a low sense of anxiety about the self or low fear of negative evaluation from others (Serafini \& Adams, 2002). The Fear of Negative Evaluation Scale (Watson \& Friend, 1969) contains 12 statements, each tapping some aspect of fear of negative evaluation or judgment by others (e.g., "I am unconcerned even if I know people are forming an unfavourable impression of me," and "I become tense and jittery if I know someone is sizing me up."). Respondents were asked to consider how well each statement describes them by rating them each as either true or false. Items were coded so that higher scores represent greater fear of negative evaluation (seven items require reverse-coding). The scale was found to have high internal consistency in both this study and the previous study (Serafini \& Adams, 2002) $(\alpha=.84$ and $\alpha=.83$, respectively) and low to moderate inter-item correlations in this study (range $=.10$ to .53 ).

Control subscale. This function of identity underwent substantial revision in this study. Its conceptual focus moved from internal locus of control to self-regulation and personal control which are understood to be the executive functions of identity. This conceptual shift was hoped to more accurately reflect the construct and honour its roots in Eriksonian identity theory. In this way, the aspect of free will that was underrepresented in the previous version of the subscale is now more visible. A short 10-item General Self-Efficacy Scale (Schwarzer \& Jerusalem, 1995) was used as a measure of external validity for this FIS subscale. This scale was chosen for its strong psychometric properties and its reliability and validity within and across countries. The scale was created to assess a general sense of perceived self-efficacy with the aim to predict coping 
with daily issues and adaptation after experiencing various types of stressful life events. The construct of perceived self-efficacy reflects an optimistic self-belief (Schwarzer, 1992); the belief that one can perform novel or difficult tasks, or cope with adversity across various domains of human functioning. Perceived self-efficacy is believed to be related to the New Control function in that it facilitates goal-setting, effort investment, persistence in face of barriers, and recovery from setbacks. The scale is designed for the general adult population, including adolescents. Responses to each statement were made on a 4-point scale, from "not at all true" to "exactly true." Responses to all 10 items were summed to yield a final composite score with a range from 10 to 40 . Each item refers to successful coping and implies an internal-stable attribution of success (e.g., "I can always manage to solve difficult problems if I try hard enough," "It is easy for me to stick to my aims and accomplish my goals," and "I can solve most problems if I invest the necessary effort"). An analysis of reliability indicated that this scale has a high internal consistency $(\alpha=.87)$ and low to moderate inter-item correlations (range $=.18$ to .58 ).

Future subscale. The essence of the fifth function is a focus on the future and one's ability to recognize one's potential in the form of future possibilities. This may be related to the notion of the ideal self which a person aspires to be. In previous validation work with this subscale, the Ideal Self Scale (Gough, Fiorvanti, \& Lazzari, 1979), an adjective checklist, was used (Serafini \& Adams, 2002). Results of that study suggested that the instructions for use of the scale may have been misread by respondents and further inspection also revealed possible problems with gendered constructions of certain adjectives within the checklist (see Serafini \& Adams, 2002 for details). A short, 
quantitative measurement instrument that taps into this real vs. future self comparison was not found. Thus, for this study, a short, 6-item Future Self Scale based on the work of Markus and Nurius (1986) and Hooker (1999) was constructed to tap into the construct of possible selves as first articulated by Markus and Nurius (1986). Previous research with this construct used primarily open-ended questionnaires in their assessment and research. Rather than exploring the possible self phenomenon, this present study sought a short, quantitative scale that would act as a comparison measure for the Future subscale of the FIS, which was one of the central goals of this study. The Future Self Scale asks respondents to think about how they see themselves in the future, including the kinds of experiences that are in store for them, and the kinds of people they might possibly become. This includes their thoughts about what they hope they will be like in the future (i.e., the self they hope to become in the future is referred to as the "hoped-for self" or “possible self”). Respondents were asked to rate, using a 5-point scale (from "not very much like me" to "very much like me"), the degree to which each statement describes how they view themselves now as compared to in the future. Items include statements such as, "When I think of the person I want to be someday, this 'possible self' is very much like the person I am today," "I am very capable of becoming the person I hope to be," and "My future self is basically the same as who I am now." Scores were summed across items, with one item reverse-coded. Higher scores represent greater consistency between the current/real self and the future/possible self. An analysis of reliability indicated that this scale has a high internal consistency $(\alpha=.82)$ and good inter-item reliability (range from .2 to .8 , with most $>.4$ ). 
Social desirability. In order to control for the effects of social desirability, the 13item short form of the Marlowe-Crowne Social Desirability Scale (Reynolds, 1982) was also administered. Reynolds (1982) found the short form to be well correlated with the standard form $(r=.85)$ and others have found it to be a viable alternative to the full scale (Zook \& Sipps, 1985). The scale items consisted of behaviours or emotions that are slightly undesirable, but common (e.g., "I sometimes try to get even rather than forgive and forget," and "There have been occasions when I took advantage of someone"). Respondents answered items on a dichotomous scale $(1=$ true, $2=$ false $)$. Higher scores on this measure represent responding that is influenced by social desirability. Although used quite extensively, this shortened version has been shown to have marginal internal consistency, with reported alphas from .62 (Brewer, Hallman, Fiedler, \& Kipen, 2004) and .63 (Reynolds, 1982) to .68 (Khoo \& Senn, 2004). The internal consistency of the scale for this study was consistent with previous usages $(\alpha=.61)$.

Demographic variables. Demographic data were collected. Respondents were asked to identify their gender, age, year of study, ethnic background, and residence status while attending school (e.g., live on-campus vs. off-campus, and alone vs. with housemates).

\section{Data Collection}

This study employed a cross-sectional design and included a sample of convenience (undergraduate university students). Because prior validation research with the FIS used a university undergraduate sample, continued validation work should be based on the same sample in order to facilitate comparisons across studies. The sample for this research project consisted of male and female undergraduate students from two 
local Universities (the University of Guelph and the University of Waterloo). These academic institutions were chosen primarily based on geographic proximity. The University of Guelph has few on-campus courses offered in the summer term, but has a large Distance Education program. Thus students were recruited from both on-campus and Distance Education classes at this university. The University of Waterloo, on the other hand, is known for its expansive co-op program, and offers a greater number of oncampus courses over the summer term than many other local universities. Because the bulk of data collection took place during the summer term, this feature influenced the decision to extend the recruitment of participants beyond Guelph to the University of Waterloo campus.

\section{Procedure}

Approximately 1200 questionnaires were distributed to students in 35 classes at the University of Guelph and 25 classes at the University of Waterloo during regular lecture periods between April 2005 and July 2005. In addition, approximately 70 Distance Education course instructors at the University of Guelph were contacted via email regarding possible recruitment from their courses. Data regarding the number of instructors who forwarded the recruitment email to their students were not available. The questionnaire package was intended to be self-administered and contained the following scales: revised Functions of Identity Scale, Stability of Self Scale, General Self-Efficacy Scale, Purpose in Life Scale, Fear of Negative Evaluation Scale, Future Self Scale, Social Desirability Scale, OMEIS, and Identity Styles Inventory. The package also included six demographic questions (i.e., age, gender, year of study, major, and living arrangements), an information/consent form that stated the purpose of the study, 
confidentiality/anonymity information, instructions for completing the study, and information regarding the availability of a summary of the findings of the study. For a copy of the questionnaire package, see Appendix C.

The research project received approval from both the Research Ethics Board at the University of Guelph and the Office of Research Ethics at the University of Waterloo. The recruitment process varied slightly across the two institutions, reflecting differing requirements for ethical approval.

In-class recruitment. The recruitment process began with a recruitment email to the course instructors, whereby the instructors were told about the study and asked whether they would consider allowing the researcher to make a short presentation to recruit participants from their classes (see Appendix D). There were 25 recruitment presentations conducted at the University of Guelph campus and 35 at the University of Waterloo. The recruitment presentation was about 3 to 4 minutes in length (see Appendix E). Here, students were told by the researcher that the study was being conducted to validate an assessment device to be used in research on the assessment of the self. They were also informed that their participation was completely voluntary, anonymous, and confidential, and were provided with a brief description of what their participation would involve and where they could find results of the study once the study was completed.

At the University of Guelph, interested participants were asked to sign and return the consent form with their completed questionnaire package, should they choose to participate. The information/consent form was filed separately from the completed packages, to ensure anonymity (see Appendix F). At the University of Waterloo, consent 
was implied via the submission of a completed package, and written consent was not required or requested (as per instructions from Office of Research Ethics). Participants from both institutions were asked to complete the package outside of class and to return it to the researcher, either by bringing it to class the following week where the researcher would be available to collect it, or by placing it in the campus mail system. Students who chose to participate in the study had their names (via University of Guelph's signed consent form) or ticket stubs (for University of Waterloo participants) entered into a draw to win one of two $\$ 200$ cash prizes.

On-line recruitment. The recruitment email to online instructors (see Appendix G) asked instructors to consider sending a recruitment letter/message (prepared and included in the email they received) and copy of the information letter (see Appendix G) as an attachment to their class list via email. This letter invited students who were interested in participating in the study to contact the researcher directly via email and to provide their mailing address so that a package of questionnaires could be sent to them by mail. All questionnaire packages sent by mail were placed in a pre-addressed, postagepaid envelope, for participants' convenience.

Approximately 70 recruitment emails were sent to instructors of Distance Education courses across disciplines at the University of Guelph. About 85 interested students contacted the researcher by email, requesting that a questionnaire package be mailed out to them. Of these, approximately 65 completed packages were returned $(76 \%$ response rate). 


\section{Order of Scales}

Two versions of the questionnaire package were distributed to potential participants during the recruitment process. The order of the scales comprising the questionnaire package was altered slightly for each version. The ordering of the scales did not follow any prescribed pattern; the only goal was to have the scales ordered differently for each version of the package (see Appendix H), with the FIS placed either first (Order 1) or near the beginning (Order 2) of the package to ensure that responses to this measure were not influenced by other identity-related items or fatigue/boredom, respectively. This procedure was employed in an effort to be sensitive to the possibility of order effects. 


\section{Results}

\section{Initial Data Screening}

All data were coded so that all the items were scored in the affirmative direction (items across scales were reverse scored accordingly). Skewness and kurtosis statistics ranged within generally acceptable limits, and in most cases the data were represented by normal curves. Missing data ranged from 0 to 8 observations per variable $(0-1.5 \%)$, which is well below the $5 \%$ rule of thumb that is considered minimal (e.g., Schafer, 1999). These data were judged to be missing at random and were handled using listwise deletion (for all SPSS analyses) and mean replacement (for AMOS analyses). As an additional check, various reliability and correlational analyses were conducted using each of three common methods to manage missing data (i.e., listwise deletion, pairwise deletion, mean replacement) and results were compared across methods. Similarity of results across methods for handling missing data provided additional support for the use of mean replacement for analyses conducted using AMOS. This method was necessary in order to obtain information about modification indexes (which was not available when the data set contained missing data). Mean substitution is not recommended for large amounts of missing data because it can greatly affect the estimated variance or standard deviation of a variable (SPSS). In this study, given the nature of the variables, the size of the sample, and the minimal number of missing observations, it was decided that mean substitution would be appropriate and would not adversely affect the accuracy of the estimates. Three cases were dropped from the analyses because the respondents completed less than $50 \%$ of the entire questionnaire package. 


\section{Reliability Coefficients}

Functions of Identity Scale. Cronbach's (1951) alpha coefficients examined the internal consistency of the revised measure. Standards regarding acceptable levels of reliability are unclear. For example, Nunnally (1978) recommends minimum alphas of .80 and .90 for basic and applied research. Clark and Watson (1995) note that researchers "commonly characterize reliabilities in the .60s and .70s as good or adequate" (p. 315). Generally speaking, a reliability coefficient of .60 or greater is considered acceptable for research with large samples (e.g., Hudson, 1982; Springer, Abell, \& Nugent, 2002). Each subscale had good internal consistency (Structure, $\alpha=.84$; Harmony, $\alpha=.83$; Goals, $\alpha=$ .84 ; Future, $\alpha=.86$; and New Control, $\alpha=.80)$, except for the Control subscale $(\alpha=$ .56). Inter-item correlations were moderate for Structure, Harmony, Goals and Future subscales (range $=.30$ to .75 ). The New Control subscale inter-items correlations ranged from low (.001 to .30$)$ to moderate (.30 to .62$)$, with most items falling between .30 and .45. The inter-item correlations for Control were very poor (range $r=-.12$ to .43 , with over half below .02).

In order to test the viability of using the FIS as a single scale measure (rather than as five subscales), the internal consistency for the full item set was also computed. When Control items were included in the analysis (39 items total), the Cronbach's alpha for the full FIS was .92. The alpha increased to .93 when the Control items were removed and the measure contained only the 32 items comprising the five strong subscales (Structure, Harmony, Goals, Future, and New Control). For all further analyses of the FIS as a single measure, the FIS total score was computed using the 32-item scale (i.e., excluding Control items). 
Identity status. The internal reliability of each of the OMEIS subscales was computed using Cronbach's alpha. Each subscale had a relatively low or marginal reliability coefficient (Diffusion, $\alpha=.56$; Foreclosure, $\alpha=.69$; Moratorium, $\alpha=.65$, Achievement, $\alpha=.55$ ), but bear in mind the small number of items comprising each subscale and Cronbach's alpha's sensitivity to number of item (e.g., Springer, Abell, \& Nugent, 2002; Tabachnick \& Fidell, 1996).

Identity style. Both the Information-Oriented and Diffuse-Avoidant subscales had low-to marginal alphas, $\alpha=.56$ and $\alpha=.61$ respectively; each of these subscales was comprised of four items.

\section{Correlations}

Correlations among the Functions of Identity subscales. Both zero-order and partial correlation coefficients, with social desirability partialled out, were computed for the functions of identity and the FIS total score (see Table 3). The zero-order correlations revealed significant positive correlations between each of the five functions subscales and the FIS total score and moderate to strong significant correlations between subscales, except for Control and Structure, $(r=.05)$, Harmony $(r=.05)$, and Future $(r=.09)$. Only Control and Goals shared a small significant relationship $(r=.10, p<.05)$. Control items were thus dropped from all further analyses.

As shown in Table 3, whereas modest significant correlations were found between social desirability and all of the functions, when social desirability was partialled out, the relationships among the functions and between the FIS total score and the functions subscales remained statistically significant. The difference between the correlation coefficients for the zero-order and partial coefficients for the relationships among the 
functions and between the functions and the FIS total score ranged from 0.003 to 0.019 $(\mathrm{M}=0.008)$

$R^{2}$ was calculated for each correlation. Overall, the percentage of explained variance between the functions ranged from $22 \%$ to $52 \%$. The $R^{2}$ for each relationship is presented above the diagonal in Table 3.

Table 3

Zero-Order and Partial Correlations (Controlling for Social Desirability) for the Functions of Identity

\begin{tabular}{|c|c|c|c|c|c|c|}
\hline & Structure & Harmony & Goals & Future & New Control & FIS Total \\
\hline Structure & $\begin{array}{l}-- \\
--\end{array}$ & .35 & .31 & .29 & .37 & .61 \\
\hline Harmony & $\begin{array}{l}.59 * * \\
(.58 * *)\end{array}$ & -- & .32 & .22 & .35 & .55 \\
\hline Goals & $\begin{array}{l}.56 * * \\
(.56 * *)\end{array}$ & $\begin{array}{c}.57 * * \\
(.56 * *)\end{array}$ & $\begin{array}{l}-- \\
--\end{array}$ & .52 & .50 & .77 \\
\hline Future & $\begin{array}{c}.54 * * \\
(.52 * *)\end{array}$ & $\begin{array}{c}.47^{* *} \\
\left(.46^{* *}\right)\end{array}$ & $\begin{array}{c}.72 * * \\
(.72 * *)\end{array}$ & -- & .24 & .64 \\
\hline New Control & $\begin{array}{c}.61 * * \\
(.59 * *)\end{array}$ & $\begin{array}{c}.59 * * \\
(.58 * *)\end{array}$ & $\begin{array}{c}.70 * * \\
(.69 * *)\end{array}$ & $\begin{array}{c}.49 * * \\
\left(.48^{* *}\right)\end{array}$ & $\begin{array}{l}-- \\
--\end{array}$ & .76 \\
\hline FIS Total & $\begin{array}{c}.78^{* *} \\
\left(.77^{* *}\right)\end{array}$ & $\begin{array}{l}.74 * * \\
\left(.74^{* *}\right)\end{array}$ & $\begin{array}{c}.88^{* *} \\
\left(.88^{* *}\right)\end{array}$ & $\begin{array}{c}.80^{* *} \\
\left(.79^{* *}\right)\end{array}$ & $\begin{array}{c}.87^{* *} \\
\left(.86^{* *}\right)\end{array}$ & -- \\
\hline
\end{tabular}

Desirability $.25 * *$

Note. Correlations are listed below the diagonal. Partial correlations for social desirability are in parentheses. $R^{2}$ are listed above the diagonal.

Significant zero-order correlations in the expected directions were found between each of the functions and its comparison measure (see Table 4). Structure was significantly related to the Stability of Self Scale $\left(r=.55, R^{2}=.30, p<.001\right)$. Goals was positively correlated with the Purpose in Life Scale $\left(r=.63, R^{2}=.40\right)$, Future with the Future Self Scale $\left(r=.49, R^{2}=.24\right)$ and New Control with the measure of self-efficacy $\left(r=.53, R^{2}=\right.$ .28 ), all at the .001 level. As expected, Harmony was negatively correlated with the Fear of 
Negative Evaluation Scale $\left(r=-.11, p<.05, R^{2}=.01\right)$. The total FIS score was also significantly related to each of the comparison measures, even after controlling for social desirability. A significant association was found between social desirability and the comparison scales and when social desirability was partialled out of the correlations, the relationships between the functions of identity and their corresponding comparison measures remained significant, except for Harmony.

Table 4

Zero-Order and Partial Correlations (Controlling for Social Desirability) for the Functions of Identity Subscales and Their Comparison Measures

\begin{tabular}{|c|c|c|c|c|c|}
\hline $\begin{array}{l}\text { Identity } \\
\text { Function }\end{array}$ & $\begin{array}{l}\text { Stability of } \\
\text { Self }\end{array}$ & $\begin{array}{l}\text { Purpose In } \\
\text { Life }\end{array}$ & $\begin{array}{c}\text { Negative } \\
\text { Evaluation }\end{array}$ & $\begin{array}{c}\text { Future } \\
\text { Self }\end{array}$ & $\begin{array}{c}\text { Self } \\
\text { Efficacy }\end{array}$ \\
\hline Structure $^{\mathbf{a}}$ & $\begin{array}{l}.55 * * \mathrm{a} \\
(.51 * *)\end{array}$ & $\begin{array}{c}.51 * * \\
(.48 * *)\end{array}$ & $\begin{array}{c}-.31 * * \\
(-.26 * *)\end{array}$ & $\begin{array}{c}.32 * * \\
(.41 * *)\end{array}$ & $\begin{array}{c}.44 * * \\
\left(.40^{* *}\right)\end{array}$ \\
\hline Harmony $^{b}$ & $\begin{array}{c}.26^{* *} \\
\left(.24^{* *}\right)\end{array}$ & $\begin{array}{c}.41 * * \\
\left(.40^{* *}\right)\end{array}$ & $\begin{array}{c}-.11 * b \\
(-.10)\end{array}$ & $\begin{array}{c}.34 * * \\
(.33 * *)\end{array}$ & $\begin{array}{c}.33 * * \\
(.32 * *)\end{array}$ \\
\hline Goals $^{c}$ & $\begin{array}{c}.29 * * \\
(.27 * *)\end{array}$ & $\begin{array}{l}.63 * * \mathrm{c} \\
(.62 * *)\end{array}$ & $\begin{array}{c}-.16 * * \\
(-.14 * *)\end{array}$ & $\begin{array}{c}.42 * * \\
(.41 * *)\end{array}$ & $\begin{array}{c}.50^{* *} \\
\left(.45^{* *}\right)\end{array}$ \\
\hline Future $^{\mathrm{d}}$ & $\begin{array}{c}.32 * * \\
(.29 * *)\end{array}$ & $\begin{array}{c}.63 * * \\
(.62 * *)\end{array}$ & $\begin{array}{l}-.18^{* *} \\
(-.14 *)\end{array}$ & $\begin{array}{l}.49 * * \mathrm{~d} \\
\left(.48^{* *}\right)\end{array}$ & $\begin{array}{l}.42 * * \\
(.40 * *)\end{array}$ \\
\hline New Control ${ }^{\mathrm{e}}$ & $\begin{array}{c}.36^{* *} \\
\left(.33^{* *}\right)\end{array}$ & $\begin{array}{c}.42 * * \\
\left(.40^{* *}\right)\end{array}$ & $\begin{array}{c}-.26 * * \\
(-.22 * *)\end{array}$ & $\begin{array}{c}.33 * * \\
(.29 * *)\end{array}$ & $\begin{array}{l}.53 * * \mathrm{e} \\
\left(.50^{* *}\right)\end{array}$ \\
\hline FIS Total & $\begin{array}{c}.43^{* *} \\
\left(.39^{* *}\right)\end{array}$ & $\begin{array}{c}.63^{* *} \\
\left(.62^{* *}\right)\end{array}$ & $\begin{array}{c}-.25 * * \\
(-.21 * *)\end{array}$ & $\begin{array}{c}.49 * * \\
(.46 * *)\end{array}$ & $\begin{array}{c}.55^{* *} \\
(.52 * *)\end{array}$ \\
\hline $\begin{array}{l}\text { Social } \\
\text { Desirability }\end{array}$ & $.26^{* *}$ & $.21 * *$ & $-.29 * *$ & $.23 * *$ & $.27 * *$ \\
\hline
\end{tabular}


Correlations between identity status and the functions of identity. Raw scores for each of the OMEIS subscales were summed to arrive at a Diffusion, Foreclosure, Moratorium, and Achieved score for each participant. Both zero-order and partial correlation coefficients, with social desirability partialled out, were computed for the functions of identity (full scale and subscales) and the identity status scores (see Table 5). The zero-order correlations revealed low to moderate significant correlations between Moratorium and Achievement and each of the functions. Diffusion was significantly and negatively correlated with three of the five functions of identity at the .001 level. Diffusion was not significantly correlated with Structure $(r=-.07)$ or New Control $(r=-$ .09). Identity Foreclosed scores were significantly negatively correlated with Harmony and New Control at the .001 level, and with Structure and Goals at the .05 level. A significant association between Foreclosure scores and Future $(r=-.04)$ was not found. Moratorium was significantly negatively correlated with each of the functions, and Identity Achievement scores were significantly positively correlated with all the functions as expected. FIS total scores were also significantly associated with each of the identity status subscores. Overall, the percentage of explained variance attributable to the statistically significant relationships between the functions and identity statuses (as computed by $R^{2}$ ) was low, ranging from $1 \%$ to $19 \%$.

The relationship between social desirability, the functions of identity and identity statuses was also examined (see Table 5). Zero-order correlations revealed a significant relationship between social desirability and two of the four identity statuses. Moratorium and Achievement scores were both significantly correlated with social desirability. Partial correlations between the identity statuses and the functions of identity, when 
controlling for the effects of socially desirability, revealed a similar pattern of significant relationships as those demonstrated by the zero-order correlations, except for Foreclosure and Goals, which were no longer significantly correlated after controlling for social desirability. Partial correlations also revealed stable significant associations between total FIS scores and identity status scores after controlling for social desirability. The differences between the correlation coefficients for the zero-order and partial coefficients for each function and identity status score were also minimal, ranging from 0.003 to $0.018(\mathrm{M}=0.01)$.

\section{Table 5}

Zero-Order and Partial Correlations (Controlling for Social Desirability) Between the Functions of Identity and Identity Status Scores

\begin{tabular}{lcccc}
\hline Identity & Diffusion & Foreclosure & Moratorium & Achieved \\
\hline Sunction & -.07 & $-.11^{*}$ & $-.25^{* *}$ & $.18^{* *}$ \\
& $(-.06)$ & $\left(-.09^{*}\right)$ & $\left(-.22^{* *}\right)$ & $\left(.16^{* *}\right)$ \\
Harmony & $-.14^{* *}$ & $-.13^{* *}$ & $-.27^{* *}$ & $.27^{* *}$ \\
& $\left(-.14^{* *}\right)$ & $\left(-.12^{* *}\right)$ & $\left(-.26^{* *}\right)$ & $\left(.26^{* *}\right)$ \\
Goals & $-.17^{* *}$ & $-.09^{*}$ & $-.30^{* *}$ & $.28^{* *}$ \\
& $\left(-.17^{* *}\right)$ & $(-.08)$ & $\left(-.28^{* *}\right)$ & $\left(.27^{* *}\right)$ \\
Future & $-.22^{* *}$ & -.04 & $-.43^{* *}$ & $.34^{* *}$ \\
& $\left(-.21^{* *}\right)$ & $(-.03)$ & $\left(-.42^{* *}\right)$ & $\left(.33^{* *}\right)$ \\
New Control & -.09 & $-.24^{* *}$ & $-.20^{* *}$ & .20 \\
& $(-.08)$ & $\left(-.23^{* *}\right)$ & $\left(-.18^{* *}\right)$ & $\left(.18^{* *}\right)$ \\
FIS Total & $-.17^{* *}$ & $-.16^{* *}$ & $-.35^{* *}$ & $.31^{* *}$ \\
& $\left(-.16^{* *}\right)$ & $\left(-.15^{* *}\right)$ & $\left(-.33^{* *}\right)$ & $\left(.29^{* *}\right)$ \\
Social & -.04 & -.07 & $-.14^{* *}$ & $.11^{*}$ \\
Desirability & & & & \\
\hline$* p<.05 . * * p<.001$. & & & \\
Note. Partial correlations for social desirability are in parentheses. &
\end{tabular}


Correlations between identity styles and the functions of identity. Participants' ISI subscale scores were computed by converting means for each subscale to a z-score and then assigning an identity style (Info or Diff-Av) based on the highest z-score. Social desirability was not significantly related to either Information-Oriented $(r=-.03)$ or Diffuse-Avoidant $(r=-.02)$ identity style scores. Zero-order and partial correlational analyses controlling for social desirability (see Table 6) revealed significant positive zero-order and partial correlations between Information-Oriented identity processing styles and Harmony, Goals, New Control and FIS total score. Structure and Future were not significantly related to the Information-based identity style. A significant negative relationship was also found between the Diffuse-Avoidant identity style and Harmony, Goals, Future, New Control and total FIS score at the .001 level, for both zero-order and partial correlations. The average difference between zero-order and partial coefficients for the functions and identity styles was 0.005 , ranging from 0.001 to 0.01 . The percentage of explained variance attributable to the statistically significant relationships between the functions and identity styles (as computed by $R^{2}$ ) ranged from $1 \%$ to $6 \%$. 
Table 6

Zero-Order and Partial Correlations (Controlling for Social Desirability) Between Functions of Identity and Identity Style Scores

\begin{tabular}{lccccccc}
\hline $\begin{array}{l}\text { Identity } \\
\text { Style }\end{array}$ & Structure & Harmony & Goals & Future & $\begin{array}{c}\text { New } \\
\text { Control }\end{array}$ & $\begin{array}{c}\text { FIS } \\
\text { Total }\end{array}$ & $\begin{array}{c}\text { Soc } \\
\text { Des }\end{array}$ \\
\hline Info & -.04 & $.12^{* *}$ & $.18^{* *}$ & .03 & $.14^{* *}$ & $.10^{*}$ & -.03 \\
& $(-.03)$ & $\left(.13^{* *}\right)$ & $\left(.18^{* *}\right)$ & $(.04)$ & $\left(.15^{* *}\right)$ & $\left(.11^{*}\right)$ & \\
Diff-Av & -.01 & $-.12^{* *}$ & $-.24^{* *}$ & $-.22^{* *}$ & $-.16^{* *}$ & $-.18^{* *}$ & -.02 \\
& $(.02)$ & $\left(-.12^{* *}\right)$ & $\left(-.24^{* *}\right)$ & $\left(-.22^{* *}\right)$ & $\left(-.16^{* *}\right)$ & $\left(-.18^{* *}\right)$ & \\
\hline
\end{tabular}

$* p<.05 . * * p<.001$.

Note. Partial correlations for social desirability in parentheses. Info = InformationOriented; Diff-Av = Diffuse-Avoidant; Soc Des = Social Desirability.

Correlations between identity statuses and identity styles. Both zero-order and partial correlation coefficients, with social desirability partialled out, were computed for identity status scores and identity style scores (see Table 7). Social desirability was significantly correlated with the Moratorium and Achieved identity statuses, but not with Diffusion, Foreclosure, or either of the identity styles. The Information-Oriented identity style was significantly positively correlated with both Moratorium and Achieved statuses, even after controlling for social desirability. Diffusion and Foreclosure scores were not significantly related to the Information-Oriented identity style. For the Diffuse-Avoidant identity style, zero-order and partial correlations both revealed a significant negative relationship with Diffusion, Foreclosure, and Moratorium, but not Achieved. Overall, the percentage of explained variance attributable to the statistically significant relationships between the identity statuses and identity styles (as computed by $R^{2}$ ) was low, ranging from $1 \%$ to $6 \%$. 
Table 7

Zero-Order and Partial Correlations (Controlling for Social Desirability) Between Identity Status and Identity Style Scores

\begin{tabular}{|c|c|c|c|c|c|}
\hline $\begin{array}{l}\text { Identity } \\
\text { Style }\end{array}$ & Diffusion & Foreclosure & Moratorium & Achieved & Soc Des \\
\hline Info & $\begin{array}{c}-.02 \\
(-.02)\end{array}$ & $\begin{array}{l}-.03 \\
(-.03)\end{array}$ & $\begin{array}{c}.17^{* *} \\
\left(.17^{* *}\right)\end{array}$ & $\begin{array}{c}.17 * * \\
(.18 * *)\end{array}$ & -.03 \\
\hline Diff-Av & $\begin{array}{c}.21^{* *} \\
\left(.21^{* *}\right)\end{array}$ & $\begin{array}{c}.20 * * \\
(-.19 * *)\end{array}$ & $\begin{array}{c}-.15^{* *} \\
(-.24 * *)\end{array}$ & $\begin{array}{c}-.04 \\
(-.03)\end{array}$ & -.02 \\
\hline SocDes & -.04 & -.07 & $-.14 * *$ & $.11 *$ & \\
\hline \multicolumn{6}{|c|}{$\begin{array}{l}* p<.05 . * * p<.001 \\
\text { Note. Info = Information-Oriented; Diff-Av = Diffuse-Avoidant; SocDes = Social } \\
\text { Desirability. }\end{array}$} \\
\hline
\end{tabular}

The order of the scales was manipulated resulting in two versions of the questionnaire package (see Appendix F). The Functions of Identity Scale was placed at the top of the order for Version 1 in order to test for potential influences due to prior responding (e.g., affective influences), fatigue, or boredom. For Version 2, the FIS was placed third in the packaging, following the OMEIS and the Social Desirability measure. One-way multivariate analysis of variance (MANOVA) was conducted with version as the independent variable and identity function as the dependent variable. A significant main effect for Version $x$ Function was found $\left(\mathrm{F}_{(6,510)}=4.33, p<.001\right)$. For each of the Functions of Identity subscales, the range of scores was as follows: Structure, $4-20, M=$ 15.21; Harmony, 4-20, $M=16.44$, Future 6-30, $M=21.67$; Goals, $5-25 ; M=18.68$ and New Control, 19-63, $M=48.10$. The difference between the means for version 1 and version 2 ranged from 0.2 to 0.75 . Subsequent univariate analysis revealed significant group differences by version for Structure, Harmony and Goals (see Table 8). However, 
as reported by eta squared, the amount of variance accounted for by these differences is no higher than 0.016 , or less than $2 \%$. Given the large sample used for these analyses, the significant differences were accounted for by statistical power as a function of sample size. Furthermore, no statistically significant Version x Identity Status interaction, or Version x Identity Style Interactions were noted.

Table 8

ANOVA for the Functions of Identity Subscales by Version

\begin{tabular}{|c|c|c|c|c|c|c|}
\hline \multirow{3}{*}{ Variable } & \multicolumn{4}{|c|}{$\begin{array}{c}\text { Mean and SD for } \\
\text { Functions of Identity }\end{array}$} & \multirow{3}{*}{$\mathrm{F}$} & \multirow{3}{*}{$\begin{array}{c}\text { Eta } \\
\text { Squared }\end{array}$} \\
\hline & \multicolumn{2}{|c|}{ Version 1} & \multicolumn{2}{|c|}{ Version 2} & & \\
\hline & Mean & $\mathrm{SD}$ & Mean & $\mathrm{SD}$ & & \\
\hline Structure & 15.53 & 2.8 & 14.78 & 3.4 & $8.50 * *$ & .016 \\
\hline Harmony & 16.65 & 2.4 & 16.13 & 3.2 & $4.98^{*}$ & .009 \\
\hline Future & 21.78 & 4.5 & 21.58 & 4.9 & 6.18 & .001 \\
\hline Goals & 18.98 & 3.5 & 18.34 & 4.3 & $4.00 *$ & .008 \\
\hline New Control & 48.25 & 5.4 & 47.89 & 6.9 & .573 & .001 \\
\hline
\end{tabular}

\section{Testing the Measurement Models}

Introduction. Confirmatory factor analysis was used to test three versions of the FIS measurement model and both the OMEIS (Identity Status) and ISI (Identity Style) measurement models. For the FIS, three competing models were examined: the fivefactor model corresponding to each of the five functions of identity and their respective indicators (see Figure 4); the single-latent-factor model using the full set of FIS items as indicators of one general latent factor, General Identity Functions (Figure 5); and a second-order-factor model with the five functions of identity and a higher order factor, called General Identity Function (see Figure 6). Only these three models were examined based on results of previous exploratory research (Serafini \& Adams, 2002; Serafini et 
al., 2003), and the importance of determining whether the FIS is best used as a singlescore measure or as a combination of five subscale scores.

All models were estimated via maximum likelihood using the Analysis of Moment Structures Program (AMOS 5.0; Arbuckle, 1999). As recommended by Browne and Cudeck (1993) and $\mathrm{Hu}$ and Bentler (1998), multiple fit indexes were used to determine how well the latent factor structure fit to the observed data. However, there is disagreement in the literature regarding how many fit indexes to report and which ones. For example, Jaccard and Wan (1996) recommend the use of at least three fit tests across various categories in order to reflect diverse criteria: chi-square; Goodness-of-Fit Index (GFI), Normative Fit Index (NFI), or Comparative Fit Index (CFI); and Nonnormed Fit Index (NNFI). Kline (1998), on the other hand, recommends the use of at least four goodness of fit tests, adding the Standardized Root Mean Square Residual (SRMR) to the previous list. Others suggest the use of chi-square, Adjusted Goodness-of-Fit Index (AGFI), Tucker-Lewis Index (TLI) and Root Mean Square Error of Approximation (RMSEA).

Four things are clear. First, although chi-square has traditionally been relied on for assessing how well a proposed model fits the observed data, its sensitivities with respect to sample size and model assumptions (e.g., normality, linearity) are well known and well documented (e.g., Bentler \& Bonett, 1980; Joreskog \& Sorbom, 1982; Marsh \& Hocevar, 1985; Muthen \& Kaplan, 1985). Second, other indicators of goodness of fit have been developed and while their use in determining the strength of a model is encouraged, overall there is a lack of consensus among researchers regarding the adequacy of various fit indexes and the cutoffs to be used for each (see Marsh, Balla, \& 
McDonald, 1988 for a review). Third, researchers are cautioned against reporting all available fit tests, as this may suggest that researchers are on a "fishing expedition." In fact, there is a high degree of redundancy among the many fit indexes and reporting them all is unnecessary. And finally, assessments of a proposed model should be made based on multiple criteria that include theoretical or substantive considerations (Joreskog, 1971; Mulaik, James, Van Alstine, Bennett, Lind, \& Stilwell, 1989; Quintana \& Maxwell, 1999).

In the analyses that follow, the fit of each model was evaluated against the following seven fit criteria (of 25 reported by AMOS): a) chi-square $\left(\chi^{2}\right)$, b) chi-square / df (z Ratio), c) Goodness-of-Fit Index (GFI), d) Adjusted Goodness-of-Fit (AGFI), e) Comparative Fit Index (CFI), f) Tucker-Lewis Index (TLI), and g) Root Mean Square Error of Approximation (RMSEA). The chi-square index assesses the degree of non-fit between the estimated and observed covariance matrices and should have a small value. This statistic is not by itself useful in assessing fit because it is strongly influenced by sample size and is sensitive to non-normality in the distribution of the data. It is therefore likely to indicate a significant probability level leading to the rejection of good-fitting models when the sample size is moderate to large (over 200) (Mulaik et al., 1989; Schumacker, 1996). Quintana and Maxwell (1999) further argue that the problem with using the chi-square statistic for evaluating the overall fit of a model is that the chi-square statistic tests for an exact fit which makes it an overly restrictive test, especially in psychological research. They suggest instead that testing for a "close fit" is more realistic and is consistent with Serlin and Lapsley's (1985) good-enough principle. The use of the $\mathrm{z}$ ratio (i.e., chi-square value divided by its degrees of freedom) is 
recommended by some researchers (Bollen, 1989). Wheaton, Muthen, Alwin, and Summers (1977) support the consideration of ratios of five or less. Carmines and McIver (1981) take a more conservative approach and recommend ratios of 2 to 1 or 3 to 1 as more representative of a good fit between the model and the data. The latter is generally considered an acceptable ratio, indicating that the model fits well to the data.

The GFI and AGFI indexes are measures of fit between the theoretical model and the data. They range from zero to one (although the AGFI is not constrained by zero), with larger values indicating a better fit (Arbuckle \& Wothke, 1999; Byrne, 2001; Hu \& Bentler, 1999). The AGFI adjusts the GFI for the degrees of freedom of a model relative to the number of variables in the model and values $>.8$ are considered strong (Browne $\&$ Cudeck, 1993). However, the generally accepted cut-off for both the GFI and AGFI is > 9 (Arbuckle \& Wothke, 1999).

The CFI and TLI are baseline comparison fit measures or tests of relative fit. They compare the absolute fit of the specified model to the absolute fit of the independence model (i.e., the most restrictive, baseline or comparison model fitted by AMOS). Larger CFI and TLI values indicate a greater discrepancy between the overall fit of the two models. Arbuckle and Wothke (1999) summarize acceptable cutoffs for the CFI and TLI as $>.9$ to indicate a good fit of the model to the data, and recommend an RMSEA value less than .05. The RMSEA does not require comparison with another model, but does take into account the degrees of freedom. Several researchers (i.e., Browne and Cudeck, 1993; MacCallum, Browne, \& Sugawara, 1996; Quintana \& Maxwell, 1999) propose the following recommendations regarding interpretation of RMSEA values: $0=$ exact fit, $<.05=\mathrm{a}$ close fit, .05 to $.08=\mathrm{a}$ fair fit, .08 to $.10=\mathrm{a}$ 
mediocre fit, and $>.10=$ a poor fit. $\mathrm{Hu}$ and Bentler (1999), however, take a different position on cutoffs and recommend Tucker-Lewis Index values of $>.95$ and RMSEA values $<.06$ as acceptable. For this study, the cut-offs for GFI, AGFI, TLI and CFI were set at .9. Models with RMSEA values of less than .08 and $z$-ratios of less than 4 were considered reasonable, providing that the latter indexes of fit were strong.

The FIS five-factor model. For identification purposes, before beginning to test the measurement model a factor may be identified using one of two common methods. The first method involves assigning one indicator per latent variable a path coefficient of 1.0 , thereby estimating the path coefficients of the other indicator variables relative to the reference item. The second method involves setting the variance of the latent variable to 1 so that factor loadings for each indicator may be obtained. Both methods were used in the analyses that follow so that the significance of all factor loadings could be calculated.

The first measurement model tested was the five-latent-factor model and included the five functions of identity as the latent variables, each measured by four to 13 indicators (items): Structure (4 items), Harmony (4 items), Goals (5 items), Future (6 items), and New Control (13 items) (see Appendix I and Figure 3). Because it was important to establish a strong measurement model prior to testing the structural models for the functions of identity and identity statuses and the functions of identity and identity styles, the following analyses were conducted to specify the best-fitting FIS measurement model. One reference item per subscale was identified and its path coefficient set to 1 (s6 for Structure, h15 for Harmony, g22 for Goals, f29 for Future, and nc32 for New Control). These were the only fixed parameters. The remaining parameters were free to 
be estimated. Therefore, the model included 73 parameters to be estimated (including error estimates), with a total of 455 degrees of freedom.

The initial five-factor measurement model (Model 1) was tested using a maximum-likelihood confirmatory factor analysis and the fit indexes suggested a poor fit to the dataset $\left[\chi^{2}(454)=2204.69, p=.001 ; z\right.$ Ratio $=4.86 ; \mathrm{GFI}=.77 ; \mathrm{AGFI}=.73 ; \mathrm{CFI}=$ $.79 ; \mathrm{TLI}=.77 ; \mathrm{RMSEA}=.085]$. Critical ratios indicated that all paths in the model were statistically significant at the .001 level, except for the path between New Control and one of its indicator variables (nc37), which was significant at the .05 level. Similarly, critical ratios for covariances revealed that all paths connecting the latent constructs were significant at the .001 level.

The standardized regression weights (or factor loadings) for the endogenous variables (scale indicators) ranged from .11 to .85 , and are presented in Table 9 . Variables with the smallest loadings were the newly constructed New Control items. The amount of variance in a particular variable that is used by the model is indicated by the squared multiple correlations (SMCs). Each of the factors, except for New Control, had at least one item for which more than $60 \%$ of the variance was accounted for by the factor. For New Control, the highest SMC was for item nc32 at .45 (45\% of the variance accounted for by the factor). Because one of the goals of these analyses was to reduce the number of scale items for each subscale and for the measurement instrument overall, particular attention was paid to the theoretical and statistical strength combined for the newest indicators. A combination of modification indexes (MIs), standardized factor loadings and squared multiple correlations was used to make changes to this model as follows. 
Table 9

Standardized Factor Loadings and SMCs for Items Comprising the Initial Five-Factor FIS Measurement Model (Model 1)

\begin{tabular}{|c|c|c|c|c|c|c|c|}
\hline $\begin{array}{c}\text { Item } \\
\text { Number }\end{array}$ & $\begin{array}{c}\text { Latent } \\
\text { Variable }\end{array}$ & $\begin{array}{c}\text { Standardized } \\
\text { Factor } \\
\text { Loading } \\
\end{array}$ & SMC & $\begin{array}{c}\text { Item } \\
\text { Number }\end{array}$ & $\begin{array}{c}\text { Latent } \\
\text { Variable }\end{array}$ & $\begin{array}{c}\text { Standardized } \\
\text { Factor } \\
\text { Loading } \\
\end{array}$ & SMC \\
\hline $\mathrm{s} 1$ & Structure & .73 & .53 & h3 & Harmony & .76 & .58 \\
\hline s6 & Structure & .78 & .61 & h15 & Harmony & .79 & .63 \\
\hline s12 & Structure & .77 & .60 & h31 & Harmony & .67 & .45 \\
\hline s14 & Structure & .73 & .53 & h39 & Harmony & .75 & .57 \\
\hline nc4 & New Control & .45 & .20 & g9 & Goals & .59 & .34 \\
\hline $\mathrm{nc5}$ & New Control & .64 & .41 & g17 & Goals & .80 & .64 \\
\hline nc8 & New Control & .56 & .31 & g21 & Goals & .72 & .52 \\
\hline nc10 & New Control & .55 & .31 & g22 & Goals & .77 & .59 \\
\hline nc16 & New Control & .58 & .34 & g35 & Goals & .70 & .49 \\
\hline nc19 & New Control & .53 & .28 & $\mathrm{f} 2$ & Future & .77 & .60 \\
\hline nc26 & New Control & .44 & .19 & f7 & Future & .64 & .40 \\
\hline nc28 & New Control & .61 & .37 & f11 & Future & .60 & .36 \\
\hline nc30 & New Control & .63 & .40 & $\mathrm{f} 24$ & Future & .61 & .37 \\
\hline $\mathrm{nc} 32$ & New Control & .67 & .45 & $\mathrm{f} 29$ & Future & .86 & .73 \\
\hline nc33 & New Control & .26 & .07 & f36 & Future & .74 & .56 \\
\hline nc37 & New Control & .11 & .01 & & & & \\
\hline nc38 & New Control & .45 & .21 & & & & \\
\hline
\end{tabular}

Note. All regression weights are significant at $p<.001$, except for nc37 $(p<.05)$. Bold items represent items considered for elimination from the model.

Analyses of the data first focused on paring down the New Control items by eliminating the weakest items, while simultaneously monitoring the performance of the other four subscales and their indicators. Comparison of standardized regression weights and SMCs for the New Control items identified six items with low factor loadings and low SMCs (see Table 9; questionable items are bolded). Modification indexes are often used to alter models to achieve a better fit, but Silvia and MacCallum (1988), among others, caution that this must be done with theoretical justification. Close inspection of the MIs for estimated regression weights revealed the highest MIs for items nc33 and 
nc19, suggesting the addition of a path between these items (nc33<-- nc19, $M I=136.42$; nc19 <-- nc33, MI = 183.71). None of the remaining MIs exceeded, or even approached, 100 (they were 44 or lower) and thus were not flagged during this round of inspections. High MIs may be indicative of redundant content of the items. Indeed, inspection of these items revealed that both items measured the process of monitoring one's progress toward a goal. Because the high MI was likely due to the redundant or overlapping content, the items were analyzed based on the strength of their standardized regression weights and SMCs and placed in the "questionable items" pile while the modification indexes for covariances were examined.

Examination of the modification indexes for covariances revealed that several pairs of error terms were highly correlated. Not surprisingly, the largest MI was associated with the error terms for nc19 and nc33 (MI = 197.98). The next largest MI occurred for the error terms for two Harmony items, h15 and h3 $(\mathrm{MI}=114.49)$. Other MIs were slightly elevated, relatively speaking (between 40 and 60) therefore, it was decided to first address the MIs for covariances that exceeded 100 and to focus on identifying the New Control items to be removed from the model. The MIs for both covariances and regression weights were reviewed again once the following changes to the model were made.

The Harmony and New Control items flagged by the MIs for covariances were inspected for theoretical justification to support allowing the error terms for these items to be correlated. Both the Harmony items identified (h3 and h15) measured how values/beliefs are indicative of personal identity ("who I am"). It made theoretical sense for these items to share some element of nonrandom measurement error, particularly 
given the redundancy of their content. Because the two New Control items flagged by the MIs (nc19 and nc33) were already considered "questionable items" based on their low regression weights and SMCs, only the correlated error terms for the Harmony items were considered at this time. According to the information provided by the modification indexes and the theoretical framework to support the statistics, the identified error terms for Harmony were allowed to correlate. Allowing these correlated errors resulted in a slight improvement in overall fit indexes (Model 2: $\chi^{2}(453)=2035.29, p<0.001 ; z$ Ratio $=4.5 ; \mathrm{GFI}=.79 ; \mathrm{AGFI}=.75 ; \mathrm{CFI}=.81 ; \mathrm{TLI}=.79 ; \mathrm{RMSEA}=.081 ; \Delta \chi_{\mathrm{M} 1-\mathrm{M} 2}^{2}(1)=$ $169.4, p<.001)$. Model fit indexes were calculated following every individual change or adjustment to the model.

Once the error terms for the two identified Harmony items were allowed to correlate, the focus returned to the New Control items. Based on low regression weights and SMCs, the six New Control items identified in Table 10 were removed from the list of indicators for that latent variable, one at a time, beginning with the weakest item. Fit indexes were calculated after each change to determine whether deletion of the item improved the overall fit of the model to the data; a chi-square difference test was conducted to determine whether these changes resulted in significant improvements to the model (see Table 10). Removing each of the identified "weaker" New Control items resulted in slight improvements in the overall indexes with each successive change; these improvements were statistically significant, as demonstrated by results of chi-square difference tests. The final model after all six items were dropped was statistically stronger than the original model $\left(\Delta \chi_{\mathrm{M1}-\mathrm{M} 8}^{2}=944.20, \Delta d f=166, p<.001\right)$. 
Table 10

Steps in Fitting FIS Baseline Measurement Model

\begin{tabular}{|c|c|c|c|c|c|c|c|c|c|}
\hline Model & $\chi^{2}$ & $d f$ & GFI & AGFI & CFI & TLI & RMSEA & $z$ Ratio & $\Delta \chi^{2}(\Delta d f)$ \\
\hline Initial Model (M1) & $2204.69 *$ & 454 & .77 & .73 & .79 & .77 & .085 & 4.86 & $\mathrm{n} / \mathrm{a}$ \\
\hline Model 2 (corr. err.) & $2035.29 *$ & 453 & .79 & .75 & .81 & .79 & .081 & 4.49 & \\
\hline $\mathrm{M} 1-\mathrm{M} 2($ diff $)$ & & & & & & & & & $169.4(1)^{*}$ \\
\hline Model 3 (NC 37) & $1945.98 *$ & 423 & .79 & .75 & .81 & .79 & .083 & 4.60 & \\
\hline M2 - M3 (diff) & & & & & & & & & $89.31(30)^{*}$ \\
\hline Model 4 (NC 33) & $1626.42 *$ & 394 & .81 & .78 & .84 & .83 & .077 & 4.13 & \\
\hline M3-M4 (diff) & & & & & & & & & $319.56(29)^{*}$ \\
\hline Model 5 (NC 38) & $1530.06^{*}$ & 366 & .82 & .78 & .85 & .83 & .078 & 4.18 & \\
\hline M4-M5 (diff) & & & & & & & & & $96.36(28)^{*}$ \\
\hline Model 6 (NC 26) & $1479.72 *$ & 339 & .82 & .78 & .85 & .83 & .080 & 4.37 & \\
\hline M5-M6(diff) & & & & & & & & & $50.34(27)^{*}$ \\
\hline Model 7 (NC 4) & $1409.03 *$ & 313 & .82 & .78 & .85 & .84 & .081 & 4.50 & \\
\hline M6-M7 (diff) & & & & & & & & & $70.69(26)^{*}$ \\
\hline Model 8 (NC 19) & $1260.49 *$ & 288 & .83 & .80 & .86 & .85 & .080 & 4.38 & \\
\hline M7-M8 (diff) & & & & & & & & & $148.54(25)^{*}$ \\
\hline
\end{tabular}

Subsequent to these changes, the FIS five-latent-factor measurement model (Model 8) contained a total of 26 items (Structure, 4 items; Harmony, 4 items; Goals, 5 items; Future, 6 items; and New Control, 7 items). Because one of the goals of this study was to specify a baseline model containing three to four indicators per latent variable (15 to 20 items total), standardized regression weights, SMCs and MIs were again reviewed to inform further trimming of the model.

The indicators for each latent factor with the lowest regression weight and SMC were flagged for potential trimming: $s 1$ for Structure, h3 for Harmony, g9 for Goals, f11 for Future and nc10 for New Control. Table 11 contains the standardized regression factor loadings and SMCs for all items (flagged items are bolded). Note that two Structure items (s1 and s14) and two Future items (f11 and f24) had comparable 
regression weights and SMCs and three New Control items had regression weights below 0.6 coupled with low SMCs (nc8, nc10, and nc16). Furthermore, modification indexes for regression weights suggested adding path coefficients between the Future item (f11) and nine other variables $(\mathrm{nc} 8, \mathrm{MI}=52.9 ; \mathrm{nc} 10, \mathrm{MI}=23.3 ; \mathrm{nc} 30, \mathrm{MI}=24.4 ; \mathrm{g} 9, \mathrm{MI}=$ 20.7; $\mathrm{g} 17, \mathrm{MI}=38.3 ; \mathrm{g} 22, \mathrm{MI}=17.4 ; \mathrm{f} 2, \mathrm{MI}=21.3 ; \mathrm{f} 24, \mathrm{MI}=28.4 ;$ and $\mathrm{h} 39, \mathrm{MI}=$ 31.4). Modification indexes also proposed the addition of error covariances between f11 and $\mathrm{f} 2(\mathrm{MI}=60.7)$, as well as between $\mathrm{f} 11$ and $\mathrm{f} 24(\mathrm{MI}=47.2)$. All these suggestions could not be theoretically justified, particularly because item f11 had the lowest factor loading for the Future subscale. Therefore, f11 was dropped from the model. This decision was also supported theoretically. Item f11 ("I am undecided about where I will be in the future") is essentially the reverse (or negative) of item f2 ("I have a good idea of what my future holds for me") and is also 1 of 4 items tapping into a similar theme, that of being able to imagine a future self or self in the future. Four items measuring a similar theme are not necessary; only the strongest indicators were considered for inclusion in the final model. After removing item $\mathrm{f} 11$, fit indexes revealed continued improvement of the model; chi-square difference test of significance indicated that the improvement was significant $\left(\right.$ Model 9: $\chi^{2}=1053.10, d f=264, p<0.001 ; \mathrm{GFI}=.86 ; \mathrm{AGFI}=.82 ; \mathrm{CFI}=$ $.88 ; \mathrm{TLI}=.87 ; \mathrm{RMSEA}=.075 ; z$ Ratio $\left.=3.99 ; \Delta \chi_{\mathrm{M} 8 \mathrm{-M} 9}^{2}(49)=207.39, p<.001\right)$. 
Table 11

Standardized Factor Loadings and SMCs for Revised Five-Factor FIS Measurement Model Items (Model 8)

\begin{tabular}{|c|c|c|c|c|c|c|c|}
\hline $\begin{array}{c}\text { Item } \\
\text { Number }\end{array}$ & $\begin{array}{c}\text { Latent } \\
\text { Variable }\end{array}$ & $\begin{array}{c}\text { Standardized } \\
\text { Factor } \\
\text { Loadings } \\
\end{array}$ & SMC & $\begin{array}{c}\text { Item } \\
\text { Number }\end{array}$ & $\begin{array}{c}\text { Latent } \\
\text { Variable }\end{array}$ & $\begin{array}{c}\text { Standardized } \\
\text { Factor } \\
\text { Loadings } \\
\end{array}$ & SMC \\
\hline s1 & Structure & .73 & .53 & h31 & Harmony & .75 & .56 \\
\hline s6 & Structure & .78 & .61 & h39 & Harmony & .80 & .64 \\
\hline $\mathrm{s} 12$ & Structure & .78 & .60 & g9 & Goals & .58 & .33 \\
\hline s14 & Structure & .73 & .53 & g17 & Goals & .81 & .66 \\
\hline nc5 & New Control & .61 & .37 & g21 & Goals & .72 & .52 \\
\hline nc8 & New Control & .56 & .31 & g22 & Goals & .76 & .57 \\
\hline nc10 & New Control & .53 & .29 & g35 & Goals & .69 & .48 \\
\hline nc16 & New Control & .58 & .34 & $\mathrm{f} 2$ & Future & .77 & .60 \\
\hline nc28 & New Control & .62 & .39 & f7 & Future & .64 & .40 \\
\hline nc30 & New Control & .67 & .44 & f11 & Future & .59 & .35 \\
\hline nc32 & New Control & .67 & .45 & $\mathrm{f} 24$ & Future & .61 & .37 \\
\hline h3 & Harmony & .61 & .37 & f29 & Future & .85 & .73 \\
\hline h15 & Harmony & .66 & .43 & $\mathrm{f} 36$ & Future & .74 & .55 \\
\hline
\end{tabular}

Note. Items in bold were eliminated. Italicized items were flagged for future consideration (elimination).

Next, the five identified items were removed from the model in a step-by-step progression and fit indexes were calculated after each step. The stronger Structure items (all $>.70)$ were exempt from elimination at this time, whereas all items with regression weights less than .60 were dropped in order to shorten the measurement instrument. One Harmony item (h3), one Future item (f24), and one New Control item (nc5) were flagged for consideration during the next round of model trimming, due to their lower regression weights compared to the remaining items $(<.70)$. In keeping with previous trends, each change to the model resulted in an improvement in fit indexes and a significant difference in chi-square values, thus indicating a significant improvement to the overall model.

Table 12 outlines the resulting fit indexes for each version of the model. 
Table 12

Continued Steps in Fitting FIS Baseline Measurement Model

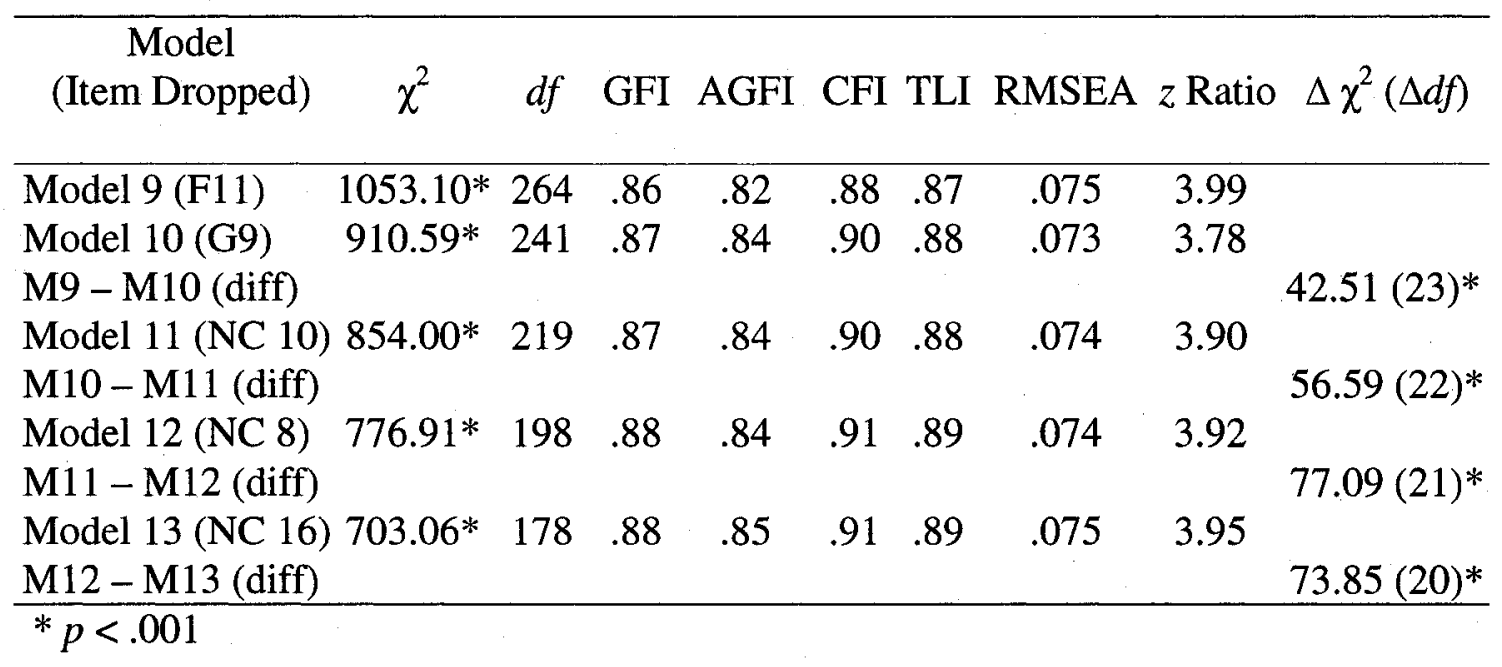

After this second set of changes to the model, the FIS five-latent-factor measurement model consisted of 21 items (Structure, 4 items; Harmony, 4 items; Goals, 4 items; Future, 5 items; and New Control, 4 items). In an effort to keep the instrument short and easy to administer, both a 4-item per factor and a 3-item per factor model were compared. Once again, the regression weights, SMCs and modification indices were used to guide the selection of the items to be eliminated and the overall modification of the model.

For the four-item per factor model, the only latent variable measured by more than four items was Future, with five indicators. The flagged item from the previous set of analyses (f24) had both the lowest regression weight (0.53) and SMC (0.33) for the group of Future indicators, and second lowest value, overall. Furthermore, modification indexes proposed that the two error terms for $\mathrm{f} 24$ and $\mathrm{f} 2$ be allowed to correlate (MI = 27.04). Because both items measure being able to imagine a tangible future, they likely share some nonrandom error (i.e., shared variance). Before proceeding with the 
elimination of this Future item, the model was tested with the 21 total indicators, but allowing for correlated error terms between $\mathrm{f} 2$ and f 24 , despite item f24's lower regression weight and SMC, as compared to the other scale items. Modification indexes reveal that this model (Model 14) was a significantly better fit to the data than the previous model tested (Model 13) (Model 14: $\chi^{2}=673.90, d f=177, p<0.001$; GFI = $.89 ; \mathrm{AGFI}=.85 ; \mathrm{CFI}=.92 ; \mathrm{TLI}=.90 ; \mathrm{RMSEA}=.073 ; z$ Ratio $=3.81 ; \Delta \chi_{\mathrm{M} 13-\mathrm{M} 14}^{2}(1)=$ $29.16, p<.001$ ). However, removal of item $\mathrm{f} 24$ to form a 4 -item per latent factor model resulted in a significantly better fit to the data (Model 15: $\chi^{2}=640.64, d f=159, p<.001$; $\mathrm{GFI}=.89 ; \mathrm{AGFI}=.85 ; \mathrm{CFI}=.92 ; \mathrm{TLI}=.90 ; \mathrm{RMSEA}=.076 ; z$ Ratio $=4.03 ; \Delta \chi^{2}{ }_{\mathrm{M} 14-\mathrm{M} 15}$ $(18)=33.26, p<.001)$; therefore, item $\mathrm{f} 24$ was eliminated to form a four-item per latent factor model. Standardized factor loadings and SMCs for all 20 FIS items are reported in Table 13.

Table 13

Standardized Factor Loadings and SMCs for the Best 4-Item Five-Factor FIS Measurement Model (20 items)

\begin{tabular}{|c|c|c|c|c|c|c|c|}
\hline $\begin{array}{c}\text { Item } \\
\text { Number }\end{array}$ & $\begin{array}{l}\text { Latent } \\
\text { Variable }\end{array}$ & $\begin{array}{c}\text { Standardized } \\
\text { Factor } \\
\text { Loadings } \\
\end{array}$ & SMC & $\begin{array}{c}\text { Item } \\
\text { Number }\end{array}$ & $\begin{array}{c}\text { Latent } \\
\text { Variable }\end{array}$ & $\begin{array}{c}\text { Standardized } \\
\text { Factor } \\
\text { Loadings } \\
\end{array}$ & SMC \\
\hline s1 & Structure & .73 & .53 & h31 & Harmony & .75 & .56 \\
\hline s6 & Structure & .78 & .61 & h39 & Harmony & .81 & .65 \\
\hline s12 & Structure & .78 & .60 & $\mathrm{~g} 17$ & Goals & .82 & .67 \\
\hline s14 & Structure & .73 & .53 & g21 & Goals & .72 & .52 \\
\hline nc5 & New Control & .56 & .31 & $\mathrm{~g} 22$ & Goals & .74 & .55 \\
\hline nc28 & New Control & .58 & .35 & g35 & Goals & .68 & .47 \\
\hline nc30 & New Control & .65 & .43 & $\mathrm{f} 2$ & Future & .72 & .52 \\
\hline nc32 & New Control & .70 & .49 & f7 & Future & .66 & .43 \\
\hline h3 & Harmony & .60 & .36 & f 29 & Future & .83 & .70 \\
\hline
\end{tabular}


The correlations (see Table 14) between the five latent factors for this four-itemper-factor model were strong, as theoretically expected. The relationship between the latent variables Future and Goals, however, was exceptionally high $(r=.96)$, thus challenging the distinctiveness of these two constructs, as measured by their indicators. The strength of the correlational relationships among the latent variables was, therefore, monitored closely as the analyses continued. Moreover, the strong correlations provided an additional rationale for testing the single-factor and second-order factor models in comparison with the proposed five-factor model. Comparing a proposed measurement model to a competing model that is theoretically grounded is recommended (e.g., Byrne, 2001; MacCallum, Wegener, Uchino, \& Fabrigar, 1993; Quintana \& Maxwell, 1999). Table 14

Correlations between Latent Factors for Best Four-Item Five-Factor FIS Measurement Model (20 items)

\begin{tabular}{lccccc}
\hline & Structure & Harmony & Goals & Future & New Control \\
\hline Structure & -- & & & & \\
Harmony & .72 & -- & & & \\
Goals & .64 & .69 & -- & & \\
Future & .72 & .66 & .96 & -- & \\
New Control & .74 & .86 & .84 & .77 & -- \\
\hline
\end{tabular}

Before moving forward with fitting a three-item per factor model, Future and Goals items were closely examined to get a clearer picture of what factors might be contributing to this exceptionally high correlation between the two subscales. Inspection of Future items suggested that items f7 and f29 were overlapping in content (i.e., current actions guided by goals for future). Item g17 clearly stood out as joining the aforementioned Future items in terms of similar content (i.e., goal-directedness). A 
review of modification indexes highlighted that Goals and Future items seemed to be strongly related, and the highest MIs for covariances suggested that the error term for g17 be allowed to correlate with the latent factor, Future $(\mathrm{MI}=42.54)$. Given these identified issues, it was not surprising that the Goals and Future latent factors shared such a strong correlational relationship. This information guided further model-trimming decisions.

A three-item per factor model was then fitted to the dataset by eliminating one item from each functions subscale. As before, this process was based on examination of standardized regression weights, SMCs, MI values, and theoretical considerations (see Table 13). First, for the Structure subscale, items s1 and s14 were equally strong statistically (based on regression weights and SMCs). From a theoretical standpoint, however, item s14 (focused on consistency of self from one day to the next) was very congruent with Eriksonian identity theory and did not share theoretical overlap with the other remaining Structure items. Item s1 ("accept" self) was similar to item s12 ("at peace" with self) and was therefore eliminated from the model (Model 16: item s1 removed). Second, for the Future items, $f 7$ was the weakest of the items and thus the obvious choice for elimination (Model 17: item $\mathrm{f7}$ removed). This decision was supported theoretically because of the content overlap between items $\mathrm{f} 7$ and $\mathrm{f} 36$; they both tapped how thinking about the future guides one's current actions/choices (see Appendix I). Third, the Harmony items $\mathrm{h} 3$ and $\mathrm{h} 15$ both tapped the same content area, so the statistically weaker of the two (h3) was dropped without any perceived sacrifice to construct validity (Model 18: item h3 removed). Fourth, the Goals items were examined carefully. While item g35 was the weakest item statistically, item g17 demonstrated theoretical overlap with the Future items and was associated with high modification indexes, particularly for its error covariance, as 
noted previously. Although g17 had the highest regression weight of the Goals items, it was eliminated from the model based on theoretical justifications (i.e., theoretical distinctiveness between the latent factors) (Model 19: item g17 removed). Finally, for the New Control factor, item nc5 was the weakest statistically, but not by much, relative to item nc28 (see Table 16). Theoretically, these items were much less similar than were pairs of items under the other functions subscales; nc5 had a strong self-regulative quality, while nc28 had a stronger decision-making quality to it. Item nc5 was thus kept for its theoretical uniqueness and as more representative of a complex construct where both self-regulation and personal control feature prominently (Model 20: item nc28 removed). Table 15 presents fit indexes corresponding to each change in the model. When models were compared across steps, chisquare difference tests indicated significant improvements to the model with each change.

Table 15

Final Steps in Fitting a Three-Item per Factor FIS Measurement Model

\begin{tabular}{|c|c|c|c|c|c|c|c|c|c|}
\hline $\begin{array}{c}\text { Model } \\
\text { (Item Dropped) }\end{array}$ & $\chi^{2}$ & $d f$ & GFI & AGFI & CFI & TLI & RMSEA & $z$ Ratio & $\Delta \chi^{2}(\Delta d f)$ \\
\hline Model 16 (S 1) & $577.80^{*}$ & 141 & .89 & .85 & .92 & .90 & .077 & 4.09 & \\
\hline M15 - N & & & & & & & & & $62.84(18) *$ \\
\hline Model 17 (F 7) & $512.50 *$ & 124 & .90 & .86 & .92 & .90 & .077 & 4.13 & \\
\hline M16-M17 (diff) & & & & & & & & & 142.51 \\
\hline Model 18 (H 3) & $492.42 *$ & 109 & .90 & .86 & .92 & .89 & .082 & 4.52 & \\
\hline $\mathrm{M} 17-\mathrm{N}$ & & & & & & & & & $56.59(22)^{*}$ \\
\hline Model 19 (G 17) & $328.00 *$ & 94 & .93 & .90 & .94 & .92 & .069 & 3.49 & \\
\hline M18-M19 (diff) & & & & & & & & & $77.09(21)^{*}$ \\
\hline Model 20 (NC28) & $277.16^{*}$ & 80 & .93 & .90 & .95 & .93 & .068 & 3.47 & \\
\hline $\mathrm{M} 19-\mathrm{M} 20$ (diff) & & & & & & & & & $73.85(20)^{*}$ \\
\hline
\end{tabular}

After making these changes, the resulting measurement model was an adequate overall fit to the dataset (see Figure 4). According to Quintana and Maxwell's (1999) interpretation of fit, based on McCallum et al.'s (1996) argument, confidence intervals 
around the RMSEA point of estimate can be useful to evaluate its level of precision. For the final FIS measurement model, the confidence interval for RMSEA (.060-.077) revealed support for the rejection of the null hypothesis of not a fair fit (because the confidence interval did not exceed .08). In fact, because the range of the entire confidence interval was below .08 , the model would be considered a fair fit for the data by these standards. That being said, a "fair" fit should not be confused with a "strong" fit (which would be evidenced by RMSEA values of $<.05$ ).

Other model considerations also need to be discussed. For example, correlations between the latent variables remained strong, whereas the problematic correlation between Goals and Future revealed in earlier models was reduced after specification (see Table 16). The highest correlation was between the Harmony and New Control factors. Inspection of the remaining indicators for each latent variable suggested that item nc30 may have been tapping into the sense of congruency between values/goals and actions/behaviours that characterizes the Harmony factor. When nc30 was removed from the model instead of nc28, the correlation between these two factors decreased from .92 to .72 and fit indexes were comparable to the final five-factor model. Despite this difference in strength of association between the Harmony and New Control latent constructs with the removal of item nc30, the item was kept in the model. This decision was based on a combination of considerations: its strong regression weight and SMC, and its theoretical focus on active, personal choice, which was believed to be better representative of the construct than was item nc28 (i.e., being good at making own decisions). 
Table 16

Correlations between Latent Factors for Best Three-Item, Five-Factor FIS Measurement Model (15 items)

\begin{tabular}{|c|c|c|c|c|c|}
\hline & Structure & Harmony & Goals & Future & New Control \\
\hline Structure & - & & & & \\
\hline Harmony & .75 & -- & & & \\
\hline Goals & .61 & .68 & -- & & \\
\hline Future & .75 & .64 & .81 & -- & \\
\hline New Control & .77 & .92 & .88 & .75 & -- \\
\hline
\end{tabular}

Cronbach alpha coefficients were obtained to test the internal consistency of the revised measurement. Each subscale had a moderate to high internal consistency (Structure, $\alpha=.80$; Harmony, $\alpha=.77$; Goals, $\alpha=.80$; Future, $\alpha=.82$; and New Control, $\alpha=.65$ ). Inter-item correlations were low to moderate (range $=.33$ to .44 ).

The FIS single-factor and higher order models. In order to endorse the five-factor FIS measurement model previously determined, it was necessary to compare it to a competing one-factor model and a second-order factor model, given the prior statistical support for using the FIS Total Score. Recall that the Cronbach's alpha for the full FIS was .93 (including the 32 items corresponding to the five functions); the FIS total score was also significantly positively correlated with each of the functions subscales, and it was significantly related to each of the comparison measures, even after controlling for social desirability. Therefore, both single-factor and second-order factor FIS models containing the same 15 scale indicators as the final five-factor FIS model were tested using maximum likelihood confirmatory factor analysis.

The single-factor measurement model contained 15 indicators and one latent factor, General Identity Function (see Figure 5). Critical ratios indicated that all paths in the model (i.e., paths from each of the indicators to the General Identity Function latent 
factor) reached statistical significance at the .001 level. Fit indexes for this single-factor model, however, were poor $\left(\chi^{2}=745.43, d f=90, p<.001 ; z\right.$ Ratio $=8.28 ; \mathrm{GFI}=.81$; $\mathrm{AGFI}=.75 ; \mathrm{CFI}=.82 ; \mathrm{TLI}=.79 ; \mathrm{RMSEA}=.12$ ). Comparison of fit indexes for the competing models are reported in Table 17.

A second-order analysis was also specified with the same 15 indicators, five latent factors corresponding to each of the functions of identity, and one higher-order General Identity factor (see Figure 6). Comparison of fit indexes for the competing models are reported in Table 17 and comparison of standardized factor loadings and SMCs are reported in Table 18. Although the factor loadings were significant, there was a clear decrement in fit indexes compared to the proposed five-factor model, as evidenced by a decrease in GFI, AGFI, CFI and TLI, and an increase in both RMSEA and $z$ Ratio, thus indicating that the fit of the model was worsening (see Table 18). Whereas this can be interpreted as further evidence that the five-factor solution is the best solution for these data, the differences in fit indexes for the two models may be considered marginal, despite a significant difference in chi-square values. The factor loadings for both models were quite comparable, with differences of .01 for seven of the 15 indicators (three were higher and four lower for the five-factor model compared to the second-order model). Note that the GFI, AGFI, CFI and TLI for the five-factor model were greater than those for the second-order model by .02 each. However, whereas the RMSEA difference for the two models was .011, the confidence interval for RMSEA for the second-order factor model was .071 to .088 . Because the range of the entire confidence interval was below .08 , the model would not be considered a fair fit for the data by Quintana and Maxwell's 
(1999) standards for interpretation of fit. Note also that the z-Ratio for the second-order factor model exceeds 4 , the cutoff previously established for these analyses.

Table 17

Indexes of Fit for Competing 15-Item Single-Factor, Five-Factor and Second-OrderFactor FIS Measurement Models

\begin{tabular}{|c|c|c|c|c|c|c|c|c|c|}
\hline Model & $\chi^{2}$ & $d f$ & GFI & AGFI & CFI & TLI & RMSEA & $z$ Ratio & $\Delta \chi^{2}(\Delta d f)$ \\
\hline Single-Factor & $745.43^{*}$ & 90 & .81 & .75 & .82 & .80 & .117 & 8.28 & \\
\hline Five-Factor & $277.16^{*}$ & 80 & .93 & .90 & .95 & .93 & .068 & 3.47 & \\
\hline Difference & & & & & & & & & $468.27(10) *$ \\
\hline $\begin{array}{l}\text { Second-Order- } \\
\text { Factor }\end{array}$ & $367.77^{*}$ & 85 & .91 & .88 & .92 & .91 & .079 & 4.33 & \\
\hline Difference & & & & & & & & & $90.6(5)^{*}$ \\
\hline
\end{tabular}


Table 18

Comparison of Standardized Factor Loadings and SMCs for the Best 15-Item SingleFactor, Second-Order-Factor, and Five-Factor FIS Measurement Models

\begin{tabular}{lcccccc}
\hline & \multicolumn{2}{c}{$\begin{array}{c}\text { Single-Factor } \\
\text { Model }\end{array}$} & \multicolumn{2}{c}{$\begin{array}{c}\text { Second-Order- } \\
\text { Factor Model }\end{array}$} & \multicolumn{2}{c}{$\begin{array}{c}\text { Five-Factor } \\
\text { Model }\end{array}$} \\
\cline { 2 - 7 } $\begin{array}{c}\text { Item } \\
\text { Number }\end{array}$ & $\begin{array}{c}\text { Standardized } \\
\text { Factor } \\
\text { Loading }\end{array}$ & SMC & $\begin{array}{c}\text { Standardized } \\
\text { Factor } \\
\text { Loading }\end{array}$ & SMC & $\begin{array}{c}\text { Standardized } \\
\text { Factor } \\
\text { Loading }\end{array}$ & SMC \\
\hline s6 & .68 & .46 & .77 & .60 & .78 & .61 \\
s12 & .60 & .36 & .75 & .57 & .75 & .56 \\
s14 & .63 & .39 & .74 & .54 & .73 & .54 \\
nc5 & .54 & .29 & .56 & .31 & .55 & .30 \\
nc30 & .59 & .35 & .62 & .38 & .63 & .40 \\
nc32 & .65 & .43 & .68 & .47 & .68 & .46 \\
h15 & .58 & .33 & .65 & .42 & .64 & .41 \\
h31 & .67 & .45 & .76 & .58 & .76 & .58 \\
h39 & .65 & .43 & .79 & .62 & .79 & .63 \\
g21 & .71 & .50 & .73 & .53 & .73 & .53 \\
g22 & .70 & .50 & .82 & .68 & .82 & .67 \\
g35 & .64 & .40 & .74 & .55 & .75 & .55 \\
f2 & .62 & .38 & .73 & .54 & .74 & .54 \\
f29 & .77 & .59 & .87 & .75 & .87 & .75 \\
f36 & .69 & .48 & .72 & .52 & .72 & .52 \\
\hline
\end{tabular}

Overall, the five-factor Functions of Identity model demonstrated significantly better fit to the data than the single-factor General Identity Function model or the secondorder model, as indicated by chi-square difference test and comparison of fit indexes, and was thus used to test the structural relationships between the functions of identity and the identity statuses, and then the functions and identity styles in later analyses.

The OMEIS (identity status) measurement model. The OMEIS measurement model was tested using maximum likelihood confirmatory factor analysis, following the same model-fitting procedures and methods of evaluating the fit of the model as 
employed for the FIS measurement model, including similar identification procedures (i.e., items d53, f54, m57, and a61 were chosen as reference items). Because the OMEIS measurement model would be used in the structural equation modelling of the relationship between identity functions and identity statuses, the best identity status measurement model was sought.

The initial OMEIS measurement model contained 24 indicators, six per latent factor (Identity Achievement, Moratorium, Diffusion, and Foreclosure). The items comprising each factor are presented in Appendix $\mathrm{J}$ (see also Figure 7). Fit indexes for this initial model were poor $\left(\chi^{2}=2069.42, d f=246, p<.001 ; z\right.$ Ratio $=8.41 ;$ GFI $=.74 ;$ AGFI = .68; $\mathrm{CFI}=.51 ; \mathrm{TLI}=.45 ; \mathrm{RMSEA}=.118)$. Critical ratios revealed that only three of the six paths between the latent variables were significant. Moratorium was significantly negatively related to Achievement $($ C.R. $=-2.79, p<.01)$ and positively related to Diffusion $($ C.R. $=2.62 p<.01)$, and Diffusion and Foreclosure were positively related $($ C.R. $=4.18, p<.001)$. The relationship between Diffusion and Achievement was not significant and Foreclosure was not significantly related to either Achievement or Moratorium. With respect to the relationships between the latent variables and their scale indicators, critical ratios revealed that all but four paths in the model reached statistical significance, four at the $p<.05$ level and the rest at the $p<.001$ level (see Table 20). The paths between Achievement and two of its indicator variables (a65 and a76) as well as those between Diffusion and two of its indicator variables (d55 and d68) were not significant. The standardized factor loadings for the scale indicators ranged from .05 to .91 , and are presented in Table 19 . The amount of variance in a particular variable that is used by the model is indicated by the SMC. Each of the factors accounted for more than 
$60 \%$ of the variance of at least one of the indicators, but for most of the items, this was less than $20 \%$ (see Table 19). A combination of modification indexes, standardized factor loadings, SMCs, and theoretical considerations was used to strengthen the model and to shorten the measurement instrument.

Table 19

Standardized Factor Loadings for Initial Identity Status (OMEIS) Measurement Model

\begin{tabular}{|c|c|c|c|c|c|c|c|}
\hline \multirow[b]{2}{*}{$\begin{array}{c}\text { Item } \\
\text { Number }\end{array}$} & \multicolumn{3}{|c|}{ Standardized } & \multirow[b]{2}{*}{$\begin{array}{c}\text { Item } \\
\text { Number }\end{array}$} & \multicolumn{3}{|c|}{ Standardized } \\
\hline & $\begin{array}{c}\text { Latent } \\
\text { Variable }\end{array}$ & $\begin{array}{c}\text { Factor } \\
\text { Loading. }\end{array}$ & SMC & & $\begin{array}{c}\text { Latent } \\
\text { Variable }\end{array}$ & $\begin{array}{l}\text { Factor } \\
\text { Loading }\end{array}$ & $\mathrm{SMC}$ \\
\hline Ach61 & Achievement & $.18^{\mathrm{R}}$ & .03 & For54 & Foreclosure & $.36^{\mathrm{R}}$ & .13 \\
\hline Ach62 & Achievement & $.88 * *$ & .77 & For56 & Foreclosure & $.30 * *$ & .09 \\
\hline Ach65 & Achievement & .05 & .01 & For59 & Foreclosure & $.39 * *$ & .15 \\
\hline Ach66 & Achievement & $.93 * *$ & .86 & For69 & Foreclosure & $.51 * *$ & .26 \\
\hline Ach70 & Achievement & $.15^{*}$ & .02 & For73 & Foreclosure & $.70 * *$ & .49 \\
\hline Ach76 & Achievement & .06 & .01 & For75 & Foreclosure & $.78 * *$ & .61 \\
\hline Mor57 & Moratorium & $.20^{\mathrm{R}}$ & .04 & Diff53 & Diffusion & $.75^{\mathrm{R}}$ & .57 \\
\hline Mor64 & Moratorium & $.34 * *$ & .12 & Diff55 & Diffusion & .05 & .01 \\
\hline Mor67 & Moratorium & $.27 * *$ & .07 & Diff58 & Diffusion & $.14^{*}$ & .02 \\
\hline Mor71 & Moratorium & $.19 *$ & .04 & Diff60 & Diffusion & $.10 *$ & .01 \\
\hline Mor72 & Moratorium & $.72 * *$ & .51 & Diff63 & Diffusion & $.91 * *$ & .83 \\
\hline Mor74 & Moratorium & $.80 * *$ & .64 & Diff68 & Diffusion & .08 & .01 \\
\hline
\end{tabular}

Model-trimming procedures began with close examination of the statistical power of the indicators. Two items per each latent variable were chosen for elimination from the model at this time. Items with nonsignificant path coefficients were considered first. For the Achievement factor, items a65 and a76 had nonsignificant paths leading to the latent variable. The corresponding standardized regression weights for these items were extremely low (.05 and .06, respectively), as were their SMCs (.01 for both). These items were thus eliminated from the model. Modification indexes supported the removal of 
these items. The Diffusion variable contained two items with nonsignificant paths, d55 $($ factor loading $=.05 ; \mathrm{SMC}=.01)$ and $\mathrm{d} 68($ factor loading $=.08 ; \mathrm{SMC}=.01) ;$ therefore, these items were eliminated from the model. This decision was also supported by modification indexes.

The next set of lowest regression weights corresponded to three Moratorium variables, $\mathrm{m} 71(.187), \mathrm{m} 57(.201)$ and $\mathrm{m} 67$ (.273). All three indicators were represented by very low SMCs, with the Moratorium factor accounting for only 3 to $7 \%$ of the variance of the items (see Table 19). The first two items were focused on political views and the last item was concerned with religion. Item $\mathrm{m} 71$ (re: politics) was eliminated because it was the weakest statistically of the three items. Items $\mathrm{m} 57$ and $\mathrm{m} 67$ were both also statistically weak and also had some elevated MIs. For m67, MIs suggested the addition of a path between this Moratorium item and m64. Both items focused on confusion around religion and making choices in this domain. More disturbing theoretically, however, were the high MIs between $\mathrm{m} 57$ and a Diffusion item (d63, MI = 89.11), as well as $\mathrm{m} 57$ and the Diffusion latent variable overall $(\mathrm{MI}=90.98)$. The item m57 was thus removed from the model at this time.

The Diffusion indicators were examined next. Items f56, f54, and f59 were the weakest items according to regression weights and SMCs (see Table 19). Examination of MIs for regression weights revealed high MIs (over 100) for both f56 and f54, suggesting the addition of two new paths to the model (f56 <-- f54, MI $=104.41$; f54 <-- f56, MI = 112.95). Both these items addressed vocational domains of identity development and reflected parental influences in personal decision-making. Item f59 dealt with politics, and also contained an element of parental influence. MIs did not reveal any issues with 
f59; thus items f54 and f56 were chosen for elimination from the model at this time. Fit indexes corresponding to each modification in the model revealed slight overall improvements in the model with each change. They are reported in Table 20. Results of chi-square difference tests indicate that each change in the model contributed to a significant improvement in the model. The indexes of fit, however, suggest that the OMEIS measurement model containing four indicators per latent factor is not a strong model. The four-item per latent variable model showed some initial promise; therefore a shorter, three-item per variable model was tested.

Table 20

Fit Indexes Corresponding to Consecutive Steps in Fitting the Identity Status (OMEIS) Measurement Model

\begin{tabular}{|c|c|c|c|c|c|c|c|c|c|}
\hline $\begin{array}{c}\text { Model } \\
\text { (Item Dropped) }\end{array}$ & $\chi^{2}$ & $d f$ & GFI & AGFI & CFI & TLI & RMSEA & $z$ Ratio & $\Delta \chi^{2}(\Delta d f)$ \\
\hline Model 1 (A 65) & $1902.50^{*}$ & 224 & .74 & .68 & .53 & .47 & .119 & 8.49 & \\
\hline Model 2 (A 76) & $1792.08 *$ & 203 & .75 & .69 & .54 & .48 & .122 & 8.28 & \\
\hline M1- M2 (diff) & & & & & & & & & $110.42(21)^{*}$ \\
\hline Model 3 (D 55) & $1348.69 *$ & 183 & .79 & .73 & .62 & .56 & .110 & 7.37 & \\
\hline $\mathrm{M} 2-\mathrm{M} 3(\mathrm{diff})$ & & & & & & & & & $443.39(20)^{*}$ \\
\hline Model 4 (D 68) & $1233.65^{*}$ & 164 & .80 & .74 & .64 & .58 & .111 & 7.52 & \\
\hline M3 - M4 (diff) & & & & & & & & & $115.04(19)$ \\
\hline Model 5 (M 71) & $1078.37 *$ & 146 & .82 & .76 & .67 & .61 & .110 & 7.39 & \\
\hline M4 - M5 (diff) & & & & & & & & & $155.28(18)^{*}$ \\
\hline Model 6 (M 57) & $945.20^{*}$ & 129 & .83 & .77 & .69 & .64 & .109 & 7.33 & \\
\hline M5 - M6 (diff) & & & & & & & & & $133.17(17)^{*}$ \\
\hline Model 7 (F 56) & $758.86^{*}$ & 113 & .85 & .80 & .74 & .68 & .104 & 6.72 & \\
\hline M6 - M7 (diff) & & & & & & & & & $186.34(16)^{*}$ \\
\hline Model 8 (F 54) & $697.15^{*}$ & 98 & .86 & .80 & .75 & .69 & .108 & 7.11 & \\
\hline M7 - M8(diff) & & & & & & & & & $61.71(15)^{*}$ \\
\hline
\end{tabular}

In order to fit a 12-item identity status model (three items per latent variable), one additional indicator for each identity status latent variable was eliminated. Again, critical ratios, regression weights, SMCs, MIs and theoretical considerations informed the 
modifications to the model. Examination of critical ratios for regression weights indicated that all but one path between the indicator variables and their latent constructs was significant $(\mathrm{d} 60, \mathrm{C} . \mathrm{R} .=1.87, \mathrm{~ns})$. Critical ratios for two indicators were significant at $p<.01$ (i.e., a70 and $\mathrm{d} 58$ ) and the remaining critical ratios for regression coefficients were significant at $p<.001$. Table 21 presents regression weights and SMCs for all the items.

Table 21

Standardized Factor Loadings and SMCs for the Four-Item per Factor Identity Status (OMEIS) Model

\begin{tabular}{|c|c|c|c|c|c|c|c|}
\hline $\begin{array}{c}\text { Item } \\
\text { Number }\end{array}$ & $\begin{array}{c}\text { Latent } \\
\text { Variable }\end{array}$ & $\begin{array}{c}\text { Standardized } \\
\text { Factor } \\
\text { Loading }\end{array}$ & SMC & $\begin{array}{c}\text { Item } \\
\text { Number }\end{array}$ & $\begin{array}{c}\text { Latent } \\
\text { Variable }\end{array}$ & $\begin{array}{l}\text { tandardized } \\
\text { Factor } \\
\text { Loading }\end{array}$ & SMC \\
\hline Ach61 & Achievement & .18 & .03 & For59 & Foreclosure & .38 & .14 \\
\hline Ach62 & Achievement & .87 & .76 & For69 & Foreclosure & .49 & .24 \\
\hline Ach66 & Achievement & .93 & .87 & For73 & Foreclosure & .72 & .52 \\
\hline Ach70 & Achievement & .14 & .02 & For75 & Foreclosure & .81 & .66 \\
\hline Mor64 & Moratorium & .30 & .09 & Diff53 & Diffusion & .75 & .56 \\
\hline Mor67 & Moratorium & .24 & .06 & Diff58 & Diffusion & .14 & .02 \\
\hline Mor72 & Moratorium & .69 & .47 & Diff60 & Diffusion & .09 & .01 \\
\hline Mor74 & Moratorium & .85 & .72 & Diff63 & Diffusion & .92 & .84 \\
\hline
\end{tabular}

Note. Bolded items were eliminated from final model

For each of the OMEIS latent variables, items a70, m67, f59 and d60 had the weakest statistical support among their group of indicators. Modification indexes for regression weights were also examined prior to deciding which items to drop from the model. MI results provided support for considering the elimination of items a70, m67, and $\mathrm{d} 60$. 
Elevated MIs for item a70 ranged from 44.06 to 73.04 and suggested the addition of paths from a70 to both a61 and d58. Achievement items a70 and a61 are similar in content. They both focus on faith and the process of individual questioning before reaching conclusions about one's individual and personal religious beliefs. Items a70 and d58 also share a focus on religious ideals, the difference being that d58 centers on the absence of questioning and indicates a lack of interest in religiosity as important to one's sense of self. These modifications would not be necessary if item a70 with its repetitive theoretical focus was removed from the model.

MIs also suggested the addition of two paths between items m67 and m64 (m67 <-$\mathrm{m} 64, \mathrm{MI}=84.71 ; \mathrm{m} 64<--\mathrm{m} 67, \mathrm{MI}=88.72$ ). Both Moratorium items focused on the confusing nature of religious considerations and respondents' decision to continue searching or considering alternatives. Given the redundancy of content across these items, the statistically weaker of the two (i.e., m67) was dropped from the model.

MIs also suggested the addition of paths between d60 and two Achievement items, two Moratorium items, and both respective latent factors. These changes could not be endorsed theoretically, and were therefore not employed. More importantly, however, these suggestions for changes to the model were not justified given that the path coefficient from the indicator $\mathrm{d} 60$ and its latent variable, Diffusion, was not significant. This item was therefore dropped from the final version of the model. Rather than make statistically driven changes to the model (as suggested by MIs) that were not theoretically justified, these problematic items were eliminated from the model.

The final item removed during this last round of modifications was item f59, primarily due to its low regression weight and SMC. The content of item f59 was 
represented in the stronger item $\mathrm{f} 69$ (i.e., aligning with parental political ideals), thus providing some theoretical support for this decision. Fit indexes and chi-square differences for each modified model are presented in Table 22. Chi-square difference tests indicate that each change resulted in a significant improvement to the OMEIS measurement model. The internal reliability of each of the new OMEIS subscales was computed using Cronbach's alpha. Each subscale had a low to adequate alpha (Hudson, 1982; Springer, Abell, \& Nugent, 2002) given the large sample size and the few number of items comprising each subscale (Diffusion, $\alpha=.56$; Foreclosure, $\alpha=.69$; Moratorium, $\alpha=.62$, Achievement, $\alpha=.66$ ). Note that the internal consistency of the Achievement subscale increased by .11 from the initial version, alphas for Diffusion and Foreclosure did not change, and the Cronbach's alpha for Moratorium decreased by .03 .

Table 22

Fit Indexes Corresponding to Final Steps in Fitting the Identity Status (OMEIS) Measurement Model

\begin{tabular}{lllllllllll}
\hline $\begin{array}{c}\text { Model } \\
\text { (Item Dropped) }\end{array}$ & $\chi^{2}$ & $d f$ & GFI & AGFI CFI TLI RMSEA & $z$ Ratio & $\Delta \chi^{2}(\Delta d f)$ \\
\hline Model 9 (A 70) & $553.08 *$ & 84 & .89 & .84 & .79 & .74 & .103 & 6.58 & \\
M8- M9 (diff) & & & & & & & & $144.07(14)^{*}$ \\
Model 10 (M 67) & $425.07 *$ & 71 & .91 & .86 & .83 & .78 & .097 & 5.99 & \\
M9-M10(diff) & & & & & & & & & $128.01(13)^{*}$ \\
Model 11 (D 60) & $220.46 *$ & 59 & .94 & .91 & .91 & .89 & .072 & 3.74 & \\
M10- M11 (diff) & & & & & & & & $204.61(12)^{*}$ \\
Model 12 (F 59) & $175.50 *$ & 48 & .95 & .92 & .93 & .90 & .071 & 3.66 & \\
M11-M12 (diff) & & & & & & & & $44.96(11)^{*}$ \\
\hline$p<.001$.
\end{tabular}

Fit indexes provide support for the proposed measurement model representing a mediocre fit to the data. Examination of the confidence interval for RMSEA $(.060-.082)$ in particular revealed support for the rejection of the null hypothesis of not a mediocre fit. 
This confidence interval was very close to the range of support (i.e., below .08) for considering the alternative hypothesis of the model as a fair fit for the data (see Quintana \& Maxwell, 1999). The three-item per factor identity status measurement model (Figure 8) garnered stronger statistical support than the other versions of the model, and was therefore used to test the structural relationships between the functions of identity and identity statuses in later analyses. Note, however, that indexes of overall fit of the model to the data do not necessarily provide information about poorly specified or weaker parts of the model.

While fit indexes provided some overall support for the OMEIS measurement model, alternative sources of information about the model should also be considered. Critical ratios for regression weights indicated that each exogenous variable (scale indicator) significantly predicted its corresponding latent variable; however, critical ratios for covariance identified several nonsignificant relationships between the latent factors (i.e., Achievement and Diffusion, Achievement and Foreclosure, and Foreclosure and Moratorium). Furthermore, not all the significant correlations between latent variables were in the expected directions. Contrary to expectations, Moratorium and Foreclosure were significantly positively associated with Diffusion and the relationship between Achievement and Moratorium was negative, rather than positive. Furthermore, of the 12 exogenous variables comprising the final model, three had regression weights less than .04 , and although each latent variable had at least one indicator with a SMC value greater than 0.6 , some were extremely low (i.e., less than 0.2 ). The average SMC for each latent variable ranged from 0.4 to 0.6 (Achievement $=0.55$, Diffusion $=0.48$, Foreclosure $=$ 0.47 and Moratorium $=0.43$ ) 
The ISI (identity styles) measurement model. The ISI measurement model was also tested in a manner consistent with previous model testing procedures, using maximum likelihood confirmatory factor analysis. The ISI model was comprised of two latent factors (Information-Oriented and Diffuse-Avoidant) each measured by four indicators. Both the initial four-item per factor and then a three-item per factor model were tested for fit to the data. The best model would be used to test the structural relationships between the functions of identity and identity styles.

The version of the original ISI measurement that was used in this study contained eight indicators, four per latent factor or identity style (i.e., Information-Oriented $=$ Info and Diffuse-Avoidant = DAv; see Serafini et al., 2003). The items comprising each factor are presented in Appendix K. The reference items were selected arbitrarily for identification (i.e., the first indicator for each latent variable in the instrument was chosen, i93 and dav95). A CFA was conducted to determine how well the model fit the data. Critical ratios for regression weights and covariances indicated that all paths in the model were significant at the .001 level. Standardized factor loadings and SMCs are presented in Table 23. Fit indexes, however, provided mixed support for the model as an adequate fit to the data $\left(\chi^{2}=137.79, d f=19, p<.001 ; z\right.$ Ratio $=7.25 ;$ GFI $=.94 ;$ AGFI $=$ $.89 ; \mathrm{CFI}=.78 ; \mathrm{TLI}=.67 ; \mathrm{RMSEA}=.109)$. The model is presented graphically in Figure 9. 
Table 23

Factor Loadings and SMCs for the Four-Item per Factor Identity Styles (ISI) Model

\begin{tabular}{cccc}
\hline $\begin{array}{c}\text { Item } \\
\text { Number }\end{array}$ & Latent Factor & $\begin{array}{c}\text { Standardized } \\
\text { Factor Loading }\end{array}$ & SMC \\
\hline I 93 & Information-Oriented & .33 & .11 \\
I 99 & Information-Oriented & .47 & .22 \\
I 103 & Information-Oriented & .65 & .42 \\
I 104 & Information-Oriented & .58 & .34 \\
DAv 95 & Diffuse-Avoidant & .59 & .35 \\
DAv 97 & Diffuse-Avoidant & .59 & .33 \\
DAv 100 & Diffuse-Avoidant & .48 & .23 \\
DAv 102 & Diffuse-Avoidant & .50 & .25 \\
\hline
\end{tabular}

Next, a three-item per factor ISI measurement model was tested. One indicator for each latent variable was dropped from the model, based on comparison of regression weights, SMCs, MIs and theoretical considerations. For the Information-Oriented identity style, items i93 and i99 were the weakest statistically (see Table 23), but were comparable theoretically; therefore, the weaker item (i93) was dropped. This decision was supported by the modification indexes for regression weights, which suggested adding paths from 193 to dav97 $(\mathrm{MI}=40.10)$ and from dav97 to i93 $(\mathrm{MI}=43.31)$. These suggestions could be understood from a theoretical position, because these items seem to be the reverse or negative of one another (i.e., thinking about the future vs. not thinking about the future). Removing item $\mathrm{i} 93$ from the model thus reduced the redundancy of content among items.

For the Diffuse-Avoidant identity style, items dav 100 and dav102 were the weakest indicators (see Table 24). MIs also suggested adding a path from dav102 to i103 $(M I=21.13) ;$ these items also seem to be the reverse of one another (see Appendix $\mathrm{K}$ ). 
Given that theoretically both these items were tapping a similar construct, item dav102 was dropped from the model so as to decrease repetition among the items. Fit indexes for each step in the model-fitting procedures are reported in Table 24. The confidence interval for RMSEA (.057 - .110) suggested, however, that the null hypothesis of not a mediocre fit could not be rejected because the entire confidence interval was not less than .10 (see Quintana \& Maxwell, 1999). Other fit indexes did seem to provide statistical support for the adequacy of the ISI measurement model as a fit to the data, as did other sources of information. For example, critical ratios for regression weights indicated that each exogenous variable significantly predicted its corresponding latent variable, and critical ratios for covariance identified a significant negative relationship between the latent factors Information-Oriented and Diffuse-Avoidant, as theoretically expected. Cronbach alpha coefficients for the subscales were calculated revealing low to marginal internal consistency (Info, $\alpha=.58$, DiffAv, $\alpha=.56$ ), with the internal consistency of the Info subscale decreasing by .02 from its initial version and the DiffAv subscale increasing by .05 . Despite the inconsistent support for the ISI measurement model, it was used to model the structural relationships between the functions of identity and identity styles (see Figure 10). 
Table 24

Indexes of Fit for ISI (Identity Status) Model Modification Process

\begin{tabular}{|c|c|c|c|c|c|c|c|c|c|}
\hline $\begin{array}{c}\text { Model } \\
\text { (Item Dropped) }\end{array}$ & $\chi^{2}$ & $d f$ & GFI & AGFI & CFI & TLI & RMSEA & $z$ Ratio & $\Delta \chi^{2}(\Delta d f)$ \\
\hline $\begin{array}{l}\text { Model } 1 \\
\text { (all eight items) }\end{array}$ & $137.79^{*}$ & 19 & .94 & .89 & .78 & .67 & .109 & 7.25 & \\
\hline Model 2 (I 93) & $78.41 *$ & 13 & .96 & .91 & .85 & .76 & .098 & 6.03 & \\
\hline$M 1-M 2$ (diff) & & & & & & & & & $59.38(6)^{*}$ \\
\hline Model 3 (Dav 102) & $36.80^{*}$ & 8 & .98 & .94 & .91 & .84 & .083 & 4.60 & \\
\hline $\mathrm{M} 2-\mathrm{M} 3$ (diff) & & & & & & & & & $41.61(5)^{*}$ \\
\hline
\end{tabular}

Testing the Functions of Identity Structural Models

The functions of identity and identity statuses. The structural relationships between identity statuses and the functions of identity were tested using the final OMEIS measurement model (i.e., Model 12) and the five-factor FIS measurement model (see Figure 11). Results of SEM provided mixed support for the predictive validity of the functions of identity using the identity status measure. Consistent with Eriksonian identity theory, Achievement and Moratorium were expected to be positively correlated with the functions of identity, and Foreclosure and Diffusion were expected to be negatively correlated with the functions. Results indicated that 12 of the $20(60 \%)$ structural paths estimated were significant (six paths significant at $p<.001$, three paths significant at $p<.01$, and three paths significant at $p<.05$ ), but not all relationships were in the expected directions (see Table 26). Some of these predictions were reasonable, whereas others were not supported empirically: Moratorium was significantly correlated with all functions, but in the negative direction. Foreclosure was significantly negatively correlated (as expected) with 3 of the 5 functions (Structure, Harmony and New Control). The relationship between Foreclosure and Goals was not significant. Achievement was 
expected to be positively correlated with all of the functions of identity but only the relationship between Achievement and Future was significant in the expected direction. Achievement was significantly negatively associated with New Control, and not significantly correlated with the remaining three functions (Structure, Harmony, and Goals). Also contrary to expectation, Diffusion was significantly positively correlated with 2 of the 5 functions (Structure and Future), and not significantly correlated with Harmony, Goals, or New Control. Only the nonsignificant relationship between Diffusion and Goals was negative. Fit indexes suggested that the structural model is a mediocre-to-fair fit to the data (chi-square $=1190.16, d f=304, p<0.001 ; z$ Ratio $=3.92$; $\mathrm{GFI}=.85 ; \mathrm{AGFI}=.81 ; \mathrm{CFI}=.85 ; \mathrm{TLI}=.83, \mathrm{RMSEA}=.074, \mathrm{RMSEA}$ confidence interval $=.070-.079)$. Parameter estimates and structural regression coefficients corresponding to this structural model are presented in Table 25. The final Functions of Identity as predicted by Identity Statuses structural model is presented in Figure 11. 
Table 25

Maximum Likelihood Estimates, Standard Errors, and Structural Regression Coefficients for Identity Status and Functions Structural Model

\begin{tabular}{llcccc}
\hline $\begin{array}{l}\text { Identity } \\
\text { Statuses }\end{array}$ & $\begin{array}{l}\text { Functions of } \\
\text { Identity }\end{array}$ & Estimate & SE & CR & $\begin{array}{c}\text { Structural } \\
\text { Regression } \\
\text { Coefficients }\end{array}$ \\
\hline ACH & Structure & -.01 & .03 & -.06 & .00 \\
ACH & Harmony & -.04 & .02 & -1.74 & -.08 \\
ACH & Goals & .05 & .03 & 1.66 & .07 \\
ACH & Future & $.21 * *$ & .03 & 6.97 & .30 \\
ACH & New Control & $-.05^{*}$ & .02 & -2.18 & -.11 \\
DIFF & Structure & $.07 *$ & .03 & 2.24 & .11 \\
DIFF & Harmony & .02 & .02 & .78 & .04 \\
DIFF & Goals & -.02 & .03 & -.54 & -.03 \\
DIFF & Future & $.06 *$ & .03 & 1.98 & .09 \\
DIFF & New Control & .01 & .03 & .23 & .01 \\
FOR & Structure & $-.14^{* *}$ & .05 & -3.10 & -.15 \\
FOR & Harmony & $-.10^{*}$ & .03 & -2.84 & -.14 \\
FOR & Goals & -.04 & .04 & -.88 & -.04 \\
FOR & Future & .01 & .04 & .30 & .01 \\
FOR & New Control & $-.10^{*}$ & .04 & -2.70 & -.14 \\
MOR & Structure & $-1.02^{* *}$ & .11 & -9.13 & -.80 \\
MOR & Harmony & $-.79 * *$ & .09 & -8.62 & -.81 \\
MOR & Goals & $-1.07^{* *}$ & .11 & -9.44 & -.85 \\
MOR & Future & $-1.23 * *$ & .13 & -9.78 & -.88 \\
MOR & New Control & $-.93^{* *}$ & .10 & -9.24 & -.94 \\
\hline$* p<.05 . * *$ & $<.001$. & & & & \\
& & & & & \\
\hline
\end{tabular}

The functions of identity and identity styles. The structural relationships between identity styles and the functions of identity were modeled using the final six-item ISI measurement model and the five-factor FIS measurement model (see Figure 12). The model was specified and estimated in AMOS and the program claimed to reach a solution. However, upon examination of estimates, it was clear that there was an error in the estimation procedure. Another program, LISREL 8.3, was used to estimate the 
model. Upon examination of LISREL estimates, the parameters appeared to be within acceptable ranges; therefore, the LISREL solution was reported.

For the Identity Styles structural model, Information-Oriented and DiffuseAvoidant identity styles were expected to be positively and negatively associated with the functions of identity, respectively. Results provide mixed support for these predictions: Info was positively correlated with 3 of the 5 functions (Harmony, Goals, and New Control), but only one of these relationships was significant (Goals). Diffuse-Avoidant identity style was negatively related to 4 of the 5 functions (excluding Structure), with three of these relationships being significant (Goals, Future and New Control). Fit indexes suggested that the structural model is a fair fit to the data $\left(\chi^{2}=483.52, d f=168\right.$, $p<.001 ; z$ Ratio $=2.90 ; \mathrm{GFI}=.92 ; \mathrm{AGFI}=.89 ; \mathrm{CFI}=.93 ; \mathrm{TLI}=.91 ; \mathrm{RMSEA}=.060$ RMSEA confidence interval $=.054-.067)$. Table 26 presents the parameter estimates and regression coefficients corresponding to this structural model. The final Functions of Identity as predicted by Identity Styles structural model is presented in Figure 12. 
Table 26

Maximum Likelihood Estimates, Standard Errors, and Structural Regression Coefficients for Identity Styles and Functions Structural Model

\begin{tabular}{clcccc}
\hline $\begin{array}{c}\text { Identity } \\
\text { Style }\end{array}$ & $\begin{array}{c}\text { Functions of } \\
\text { Identity }\end{array}$ & Estimate & SE & CR & $\begin{array}{c}\text { Structural } \\
\text { Regression } \\
\text { Coefficients }\end{array}$ \\
\hline Dav & Structure & .07 & .10 & .70 & .05 \\
Dav & Harmony & -.11 & .08 & -1.43 & -.10 \\
Dav & Goals & $-.38 * *$ & .11 & -3.49 & -.26 \\
Dav & Future & $-.51 * *$ & .13 & -3.9 & -.30 \\
Dav & Ncontrol & $-.21 *$ & .09 & -2.42 & .19 \\
Info & Structure & -.02 & .07 & -.027 & -.02 \\
Info & Harmony & .11 & .06 & 1.91 & .13 \\
Info & Goals & $.17 *$ & .07 & 2.27 & .15 \\
Info & Future & -.12 & .09 & -1.45 & -.10 \\
Info & Ncontrol & .11 & .06 & 1.86 & .14 \\
\hline
\end{tabular}

$* p<.05$. ** $p<.01$. 


\section{Discussion}

Erik Erikson provided a framework for the theorizing and measuring of identity formation. He identified identity formation as the central task of adolescence. According to Eriksonian theory, identity is believed to have a self-regulatory function in the development of self. Adams and Marshall (1996) have proposed that there are five basic functions of identity. These include: (a) providing the structure for understanding who one is; (b) providing meaning and direction through commitments, values and goals; (c) providing a sense of personal control and free will; (d) providing consistency, coherence and harmony between values, beliefs and commitments; and (e) providing the ability to recognize potential in the form of future possibilities and alternative choices.

Several studies have examined the validity of these constructs, each with its own strengths and limitations. Serafini and Adams (2002) first sought to empirically study the functions of identity by operationalizing the constructs through the creation of a measurement instrument, the Functions of Identity Scale (FIS). This exploratory work supported the existence of these constructs for undergraduate females. A subsequent study (Serafini et al., 2003) assessed the construct and predictive validity of the FIS in a sample of male and female undergraduate students. CFA of the measurement model was conducted using SEM as a formal test of its construct and predictive validity. Results revealed support for four functions of identity (Structure, Harmony, Goals and Future; the Control factor was eliminated). Results also provided support for elements of the predictive model tested, and suggested that it was a reasonable fit for both males and females. 
The present study addressed the gaps in previous works within the framework of continued revision and validation of the FIS measure. In order to address these concerns, the study had four main goals: to assess the structural validity of a five-factor model, to revise the Control subscale and establish its construct validity, to establish the external validity of each of the subscales, and to test the structural relationships between the functions of identity and other identity constructs (i.e., identity statuses and identity styles).

The gaps identified in previous works were addressed in this study in a movement towards continued validation of the FIS. The original FIS scale items have been revised to increase readability and clarity. Conceptual revisions have also been carried out for the Control function and its corresponding items, with a shift in conceptual emphasis from internal locus of control to personal control and self-regulation. A revised five factor model with the new Personal Control subscale was tested using CFA and SEM. Results support the construct validity of this measurement model. The external validity of each of the subscales was established and predictive relationships between the functions of identity and two related constructs (identity statuses and identity styles) were tested; several of these relationships were supported. A detailed discussion of the specific results of the current study follows.

\section{The Functions of Identity Scale}

Five-factor model. Examining the structural validity of the FIS as a five-factor model was the main goal of this study. Previous research had provided mixed support for both four and five factor models (Serafini \& Adams, 2002; Serafini et al., 2003). CFA supported a five factor model in the current study. Five distinct yet related factors 
corresponding to the five functions of identity were clearly established. The results also emphasized the need to use the instrument as containing five subscales rather than a Total Functions of Identity score or a General Identity Functions score. CFA results did not support a unidimensional model (i.e., single-latent-factor model) but provided some support for a second-order model. Whereas the viability of a second-order-factor model was suggested, the empirical evidence favoured a five-factor model over a second-order model; therefore, the FIS should be used as five subscale scores rather than a single General Identity Function score. Future replication is needed to establish the secondorder factor.

While the functions of identity work in combination and are closely related, they are distinct and the utility of a second-order factor model has not been fully theoretically or empirically supported. The higher order General Identity Function may be understood in light of Erikson's optimal identity, which shapes the existence of the five functions. As has been argued throughout this work, the functions of identity are the outerworkings of identity consolidation or synthesis - what Erikson called an optimal identity. It is thus reasonable for the functions to be caused by this optimal identity, but what does this conceptualization provide in terms of a measurement model? The functions of identity act as part of a coherent system delineating what a consolidated sense of identity provides an individual. They have been shown to be closely related, yet distinct enough to highlight the nuances of identity synthesis and the different functions that such synthesis or consolidation provides. Considering identity functions as a general overarching factor, while theoretically reasonable, may obscure the richness and multidimensionality of the construct in terms of the information that each function provides about identity synthesis. 
Advocating a higher-order model over a first-order five-factor model may also mislead researchers into using the FIS as a single-score measure, which serves to limit its utility, particularly in clinical settings. It is difficult to denote what the benefits of a secondorder General Identity Model would be; the potential risks and losses are more apparent.

The control function. One key change in the FIS that needed to be addressed was the Control function. The main focus was a close examination of the construct validity of the Control function. In doing so, two hypotheses were tested. Previous research had provided inconsistent support for the Control function as it was originally theorized and measured (Serafini \& Adams, 2002; Serafini et al., 2003). Problems with the Control subscale could be understood either as reflecting the nature of the items written to measure the construct, or in terms of conceptual incongruities between the way the construct was defined and the foundational theory on which it was based. In the present study, the original Control function as defined by Serafini and Adams was tested with a new sample, with the original test items having undergone some minor revisions. Wording was altered slightly to increase clarity and a couple of new items were added that were believed to measure the Control function as it was originally proposed. If the inconsistencies in previous research were related to the scale items themselves, it was expected that the new and revised items would remedy this. The competing hypothesis explored the theoretical foundation of the Control function, with movement from a conceptual emphasis on internal locus of control to self-regulation and personal agency. New items were written accordingly and the hypothesis that this version of personal control would more closely align with Erikson's notions of personal control and free will was tested. 
The data provide support for a five-factor model of the Functions of Identity, with the New Control construct clearly surpassing the revised Original Control construct. The evidence supports a conceptual shift from locus of control as delineating the personal control aspect of the functions of identity to personal control grounded in a sense of personal agency and self-regulation. The results evoke confidence that the new Personal Control factor meets the needs of the model.

External validity of the subscales. As per Serafini and Adams (2002), the external validity of the subscales was tested following Loevinger's (1957) method of validation. Each functions subscale was significantly correlated with its comparison measure. Once social desirability of responding was controlled for, however, the relationship between Harmony and its comparison measure (Fear of Negative Evaluation Scale) was reduced to nonsignificance. The Fear of Negative Evaluation Scale (Watson \& Friend, 1969) is an older instrument than the other scales used in the present study, and may be too emotion-based when compared to the functions' psycho-social foundations. It may also be that social desirability and fear of negative evaluation measures tap similar constructs When the variance of social desirability is controlled for, shared variance with Fear of Negative Evaluation is removed and thus, reduced to nonsignificance.

The Fear of Negative Evaluation Scale has been used as a comparison measure for a FIS subscale in past research. Recall that when this instrument was used as the comparison measure in Serafini and Adams' 2002 study, it was paired with the "Harmonious Goals function" rather than the pure Harmony function. The relationship was statistically significant, but social desirability was not accounted for in this model. In this current study, the relationship between the Harmony function and the Fear of 
Negative Evaluation scale was also significant, but this relationship became nonsignificant once social desirability was controlled. It may be that the Fear of Negative Evaluation is not the best comparison measure for the Harmony function due to its emotion-based items, content overlap with social desirability items, or vulnerability to socially desirable responding.

The external validity of the Future subscale had not been established in previous research due to problems with the comparison measure used (see Serafini \& Adams, 2002 for details). The present study tested the external validity of the Future subscale with an alternative comparison measure and found that Future was significantly positively correlated with its comparison measure, even after controlling for social desirability. The comparison measure used, the Future Self Scale, was created for this study, based on the prior work by Markus and Nurius (1986) and Hooker (1999) on the possible selves construct. The Future subscale of the FIS considers the role of future orientation in determining one's current sense of identity. In this way, identity is, in part, based on a sense of purpose that offers the promise of fulfilling one's range of capacities towards the realization of a tangible future. Comparing oneself in the present to how one sees oneself in the future, and the congruency between these selves, was thus believed to reflect or measure the degree to which planning for the future and striving toward future goals operate in terms of identity consolidation. The significant relationship between the Future subscale and the Future Self Scale indicates that this conceptual link is reasonable and that those who have a strong future orientation (in terms of the functions of identity) also have a higher congruence between their sense of self in the present and their possible 
or future self. That is to say, those who score high on the Future subscale have a strong sense of who they will be in the future and are likely on their way to achieving that goal.

\section{Other Identity Measures}

Identity status measurement model. The instrument used to measure identity statuses for this study was the OMEIS, a widely used but dated scale not without its complexities. Although the internal reliabilities of the four subscales measuring the four identity statuses could be considered low to moderate for six items per subscale, they were much lower than the reliabilities for the final FIS subscales containing three items each. Reliabilities for the final OMEIS model, which was trimmed to three items per subscale, remained exactly the same for two factors (Diffusion and Foreclosure), increased for Achievement (from .55 to .66) and decreased slightly for Moratorium (from .65 to .62). Although fit indexes for the final identity status measurement model were adequate, many of the factor loadings for the final items were low.

Additionally, whereas each scale item significantly predicted its latent factor (identity status), several relationships among the identity statuses were not statistically significant. According to theoretical expectations, the most significant differences between identity status groups were expected for Diffusion and Achievement because they represent the least developed and most developed identity statuses, respectively. However, results indicated that the Achievement and Diffused identity statuses did not share a significant negative relationship. Similarly, Achievement and Moratorium were not significantly negatively related to Foreclosure. In sum, only half of the expected relationships among the identity status latent factors were significant. Several explanations are offered. 
Central to understanding these results is the nature of the scale itself and the items comprising the measure. The scale is dated and has not undergone any recent revisions. The items themselves, therefore, may not be current enough to accurately examine or represent the identity questions and concerns salient for present-day youths and adults. For example, some participants reported, both verbally and in writing, that they did not "like" the OMEIS questions. Some referred to them as "biased," "repetitive," and "not inclusive." In fact, the largest portion of missing responses occurred for the OMEIS questions. Some respondents identified that they purposely did not answer the questions, especially those related to religion. One can only speculate as to how many other participants felt the same way, but did not communicate their feelings. These issues may, in part, account for the atypical functioning of the OMEIS measure in this study. The current research has highlighted the need for revisions to the OMEIS. This issue has also been identified by other researchers in the identity field, and such a project is currently underway (Schwartz, 2005, personal communication).

Identity style measurement model. The identity style measurement model with the ISI measure was also examined using CFA. Fit indexes provided poor support for the eight-item model and only minimal support for the six-item model after adjustments were made to improve fit. Despite varied strength of fit indexes for the six-item ISI model, all exogenous variables significantly predicted their identity style factor and the InformationOriented and Diffuse-Avoidant factors were significantly negatively related, as expected. Information-Oriented and Diffuse-Avoidant represent the polar ends of identity processing styles whereby the former is characterized by actively seeking out and engaging in thinking and processing self-relevant information, and the latter is 
characterized by avoidance of decision-making and procrastination. Results of this study provide support for the conceptualization of identity processing as having these two polar ends in terms of one's ability to actively search for and analyze information that is relevant to self-related issues or problems.

Note, however, that the version of the ISI used for this study was a shortened version of the original. Any conclusions drawn about the six-item short version do not necessarily apply to the full version. The same short version was used by Serafini et al. (2003) with mixed support. The final six-item version in that study differed from the final model used in the present study by one item (i.e., an alternative Diffuse-Avoidant item was dropped from the model in the current study; Information-oriented items were the same for both studies). This difference may be understood by considering the nature of the different samples across studies, the size of the samples (almost 1600 in 2003 as compared to 533 in the present study), and the length and content of the questionnaire packages for both studies.

For the current study, the negative affect that may possibly have been evoked by the OMEIS items may also have transferred to the completion of the ISI items later in the questionnaire package for some participants. The ISI followed the OMEIS in both versions of the questionnaire package where order was manipulated. This may account for some respondents' comments that the items in the questionnaire package were repetitious. Perhaps three identity measures in one questionnaire package are too many, considering the possible overlap of thematic content across items. 
Modelling Structural Relationships Among the Functions of Identity and other Identity

\section{Constructs}

Functions of identity and identity status. SEM was used to test the structural relationships between the identity status and the functions of identity latent factors. A significant structural path between identified factors indicates that the function of identity is predicted by the identity status designated by the structural path. Results revealed that for the Identity Status structural model, 12 of the 20 structural paths identified were significant $(60 \%)$. Consistent with the results of correlational analyses where Moratorium was significantly negatively correlated with each of the functions, results of SEM confirmed that Moratorium significantly predicted all the functions; the relationships were negative and theoretically coherent. Recall that the identity statuses are based on varying levels of exploration and commitment. The Achieved status is characterized by having made commitments (to values, beliefs, actions, etc.) after careful consideration and a period of exploration. This process of exploration is the main characteristic of the Moratorium stage. Because individuals in the Moratorium status are on their way to making identity commitments, they may also be experiencing various levels of anxiety during this exploration stage. As Marcia (1994) noted, "to explore requires patience, a moderate level of anxiety, and some cognitive flexibility. To make commitments requires courage" (p. 37). It is therefore understandable that Moratorium and the functions of identity would be negatively related because the identity commitments on which the functions are in part based are missing from the Moratorium stage. Those in Moratorium are immersed in the process of figuring things out and have not yet achieved Erikson's notion of an optimal identity. Given these contextual issues, 
the prediction that Moratorium and the Functions of Identity would be positively related for the currents sample was unreasonable. In fact, Serafini and Adams (2002) also found that for undergraduate students, Moratorium was negatively related to the functions of identity, although only two of those relationships were significant. It would be interesting to explore whether the same relationships hold across other non-academic samples, or whether the anxiety associated with the Moratorium status is more pronounced for university undergraduates because of the academic context.

Because the Functions of Identity describe what having a well-formulated identity provides an individual, Achievement, the most sophisticated and mature of the identity statuses, was expected to predict each of the functions of identity. Although correlational analyses identified a significant positive relationship between Achievement and each of the functions of identity, results of SEM did not substantiate these results. Here, Achievement predicted only Future significantly. Contrary to theoretical expectations, Achievement was significantly negatively associated with New Control, indicating that higher Achievement scores on the OMEIS predicted lower personal control scores for this sample. This does not fit with theoretical understandings of identity construction and the functions of identity. A well-consolidated sense of identity should be associated with greater personal agency and personal control than a sense of self that lacks consolidation and synthesis. Equally puzzling were the nonsignificant relationships between Achievement and the remaining three Functions of Identity (Structure, Harmony, and Goals). These results may be understood in terms of the characteristics of the sample used for this study. All participants were enrolled in undergraduate programs at two local universities. The middle to end of the academic term is typically a stressful time for 
students because most academic assessment occurs during this period; this coincided with the bulk of data collection. Perhaps the anxiety or stress associated with academic and personal demands impacted participants' responses to the measures used in this study. Higher life stress could be associated with a lowered sense of personal control over one's environment and could impede self-regulative processes.

Foreclosure is characterized by having made commitments to beliefs, values, ideals and actions without having actively explored options for oneself. Commitments are typically based on the values of significant others, such as parents and mentors. Without the personal agency and personal control associated with the process of exploration, Foreclosure was expected to negatively predict each of the functions of identity. Correlational analyses showed that Foreclosure was significantly negatively associated with Structure, Harmony and Personal Control (after controlling for social desirability). SEM results indicated that these predictions were reasonable for Structure, Harmony and Personal Control. Participants who scored high on the Foreclosure subscale could be interpreted to have a relatively weaker structure by which to organize elements of self understanding, less consistency and harmony between their values and beliefs and actions, and a lower sense of personal control and agency than participants low on Foreclosure. Because the relationship between Foreclosure and Goals was not significant, conclusions about goal-orientation for Foreclosed individuals cannot be drawn. One may hypothesize that because Goals within the context of the Functions of Identity are predicated on the notion that they are self-chosen goals, rather than goals or expectations put forth by someone in a position of social or relational authority, as would more likely be the case for someone who is identity foreclosed, Foreclosure may not 
significantly predict Goals in this context. Similarly, Foreclosure did not significantly negatively predict Future. Note that the theoretical constructs of Future and Goals are closely related. Goals typically have a future orientation, even when the future is only hours, days, or months away. The difference between the two in terms of the Functions of Identity lies in the focus on personal agency. Goals in this context are understood to be primarily self-chosen and self-driven. The future, on the other hand, may not be so closely aligned with personal agency for Foreclosed individuals. A Foreclosed individual may have clearly defined goals that are not personally constructed (e.g., expectations of parents or significant others), while still having a clearly mapped out future that aligns quite closely with the self in the present.

The Diffusion status is best characterized by avoidance of any identity-related questioning or exploration and lack of commitments to values, beliefs and the like. For this study, high Identity Diffusion subscale scores significantly predicted Structure and Future, but the relationships were positive, thus suggesting that higher Diffusion scores predict having greater Structure for understanding who one is and a strong sense of Future possibilities. This finding does not align with Eriksonian or neo-Eriksonian theory. Diffusion, however, did not significantly predict Harmony, Goals, or New Control. These results were foreshadowed by results of previous correlational analyses that demonstrated nonsignificant relationships between Diffusion and the Functions of Identity. Diffusion and Achievement represent the two most extreme types of identity construction characterized by commitments after exploration (Achievement) and lack of exploration (or desire to explore) and few to no commitments (Diffusion). One would expect that these identity statuses would be the most likely of the statuses to clearly 
predict the functions of identity, given that the functions are theoretically congruent with Achievement and not theoretically aligned with Diffusion, where an optimal identity has not been established.

Two key factors are important to consider when interpreting these results. First, one must consider the characteristics of the social-historical context of the sample. Undergraduate students are emerging adults and the context of post-secondary education may fuel exploration of the self in terms of values, ideals, career options and intimate relationships. Although specific data regarding family structure and other contextual information was not gathered, one can speculate that youths at this stage and place in life are also facing the challenges associated with changes in living environment, often moving from the family home to residence or to living with peers, as well as challenges associating with the restructuring family relationships (particularly parent-child relationships as adulthood approaches). Participants in this study may also have been experiencing additional anxiety associated with academic responsibilities, such as tests, assignments and exams, particularly given that the data collection process occurred primarily during the second half of the academic semester, a time when assessments figure prominently. Given these contextual issues, this sample may have been experiencing some heightened anxiety or stress, as compared to other times in the respondents' lives. This could account, in part, for the clearly established relationships between the Moratorium status and the Functions of Identity whereby Moratorium was negatively associated with each of the functions. This situational or contextual anxiety, particularly in terms of academic time-lines and responsibilities, may also have impacted respondents' scoring on other identity status items. 
Second, the properties of the instrument used to measure the identity statuses need to be examined closely. It is imperative to consider the construct validity of the OMEIS instrument. While the FIS measurement model had strong support for its construct and external validity, the OMEIS measure was not without its limitations. Every effort was made to modify the OMEIS measurement model based on sound empirical and theoretical considerations. Still, fit indexes for the final OMEIS measurement indicated that the model was a fair fit to the data, but the identity status factors did not perform in line with theoretical expectations and some of the scale indicators had very low factor loadings and SMCs. Respondents' reported frustration and negativity towards the items could also have impacted their interpretation of the items, and participants' affective response to some of the items may have influenced the validity of the data gathered using the OMEIS, thus impacting the viability of the proposed identity status and functions structural model. Results using the OMEIS must therefore be interpreted with caution.

Functions of identity and identity style. SEM was also used to test the structural relationships between two identity style factors and the functions of identity. The functions of identity portray what successful identity questioning and resulting identity synthesis provide an individual; therefore, Information-Oriented identity style was expected to positively predict each of the five functions, while Diffuse-Avoidant identity was expected to negatively predict the functions. Results of this study support some of these predictions. Information-Oriented identity style significantly predicted only one of the five functions, Goals. This suggests that participants in this study who use an Information-Oriented processing style for identity construction also have clear goals that they have constructed on their own. 
Whereas direct comparisons with previous research examining the Identity Style and Functions structural model cannot be made due to differences in the items comprising the two measures, it is noteworthy that the identity styles did not cleanly predict the functions of identity in a sample of almost 1600 university students in a previous study (Serafini et al., 2003). In that study, the Information-Oriented identity style was a better predictor of the functions of identity than was the Diffuse-Avoidant identity style (Info predicted all functions except Future and Diff-Av predicted only Future and Goals). The fit indexes for that structural model, however, were weaker than those for the model tested with this current sample. In the present study, the DiffuseAvoidant identity style was a better predictor of the functions of identity than was the Information-Oriented identity style, predicting Goals, Future and Personal control, but not Harmony or Structure. Results of this study suggest that individuals who deal with identity-related issues or problems by avoidance and putting off making decisions do not have clearly established, self-directed goals, a sense of future self and future possibilities, or the personal control and agency associated with strong self-regulative skills. As noted earlier, the instrument used to measure the identity styles has not undergone validity testing. A shortened version of the original Identity Styles Inventory (Berzonsky, 1989) was used for this present study. The final six-item measure used may suffer from lack of empirical evidence attesting to its validity and reliability. This version of the ISI, while having reasonable statistical support (via CFA), may not be the ideal representation of Berzonsky's identity styles construct. Similarly, theoretically incongruent results of the structural equation modelling may lie in the differences in theoretical foundations of the Identity Functions and Identity Styles models. Whereas the Identity Styles construct 
shares some overlap with Marcia's Identity Status Paradigm, the Identity Styles espouses a more cognitive orientation towards understanding identity development (see Berzonsky, $1986,1990,2002)$. This social-cognitive emphasis of the Identity Styles may not be a strong fit with the Functions of Identity construct, as originally believed. Because the Identity Styles move away from Erikson's psychosocial emphasis towards a more cognitive emphasis, the Identity Styles factors may not be the best predictor variable for the functions of identity, which are grounded quite strongly in Eriksonian identity theory.

\section{Limitations}

There are a number of limitations to be considered with respect to this research. In terms of the generalizability of results, the sample consists of university students and the results, therefore, may not be generalized to other populations. All previous validation work with the FIS has used university student samples, and this same sample was sought for the present study to facilitate comparisons across studies. Now that the validity of the FIS has been more clearly established and important revisions to the scale have been made, it can be tested with other populations. Because this study was devoted to validation work using CFA and SEM, it did not explore any specific psychological, social, or cultural factors that may impact the pattern of identity development in youth and emerging adults. This study looked only at particular identity statuses and identity styles, rather than identity trends or patterns in a certain sample (e.g., numbers of individuals who are Diffused, Foreclosed, etc.). Given the aim of validation and modelling structural relationships, this study was concerned only with testing the FIS measurement model and the relationships between identity statuses and styles and the Functions of Identity. 
Another limitation of this study concerns the identity measures used to model the structural relationships between the Functions of Identity and other identity constructs. Both the OMEIS and the ISI used in this study suffered from issues that question their validity. The instruments used to measure the Identity Status and Identity Style theoretical constructs may not have been accurately measuring those constructs; therefore, drawing theoretical conclusions about the relationships between Identity Styles, Identity Statuses and the Functions of Identity based on this data should be done with caution. Despite the identified issues with each of the identity measures used in the present study, the OMEIS and short version of the ISI used in validation work to date have provided consistently promising results. It is believed that the exceptions to the hypothesized relationships between the Functions and other identity constructs are more likely to be a function of problems with the measures, than with the Functions construct itself.

A possible limitation of this study may be its use of CFA over EFA for item deletion. There is controversy in the literature concerning the best approach for item deletion. Stanton, Sinar, Balzer and Smith (2002) review various approaches to item deletion strategies for reducing the length of self-report measure and the issues surrounding each method. Among these methods, they note that internal consistency maximization is the most widely used method, and factor analysis (often leading to increased internal consistency) is also common. Overall, the use of EFA is recommended when "there is a weak literature base, when one wishes to determine the number of factors, when one wishes to determine whether the factors are correlated or uncorrelated, and when the variable (items) are free to load on all factors" (Springer, Abell, \& Hudson, 
2002, p. 428). Byrne (2005) discusses the distinctions between EFA and CFA and highlights the appropriate use of CFA when the researcher has a priori knowledge about the structure of the latent variables (based on theory and/or prior empirical research) and statistically tests hypotheses about the relationships between underlying factor structure and the observed measures. This current study was more confirmatory than exploratory in nature; an apriori factor structure was proposed and tested. Byrne also highlights that CFA is a more rigorous approach than EFA and is often used in post hoc model fitting when a proposed model has been rejected. Here, CFA is used in an exploratory fashion to determine which parameters in the model are misspecified. This may involve both the addition and removal of parameters. Removal of parameters is equivalent to item deletion. Byrne underscores the importance of making substantively-driven decisions in model-fitting. In this current study, items were deleted (or parameters removed) in a controlled, thoughtful, stepwise fashion, based both theoretical and empirical justifications. In this current study, CFA was deemed an appropriate method to confirm a model based on a strong literature base, with a predetermined correlated number of factors (supported theoretically and to some degree empirically), and with constraints placed on the variable (items).

General Conclusions and Directions for Future Research

This study provides empirical support for the revised Functions of Identity Scale as a measure of the ego functions of identity, as proposed by Adams and Marshall (1996). CFA revealed strong support for the five-factor model as superior to a single-factor or second-order-factor model. The five factors were both conceptually and theoretically congruent with the functions of identity and Erikson's (1968) optimal identity. 
Eriksonian ego identity theory incorporates a variety of processes that are presumed to act together to establish healthy or optimal identity development. Adams and Marshall also conceptualized the functions of identity as working together, rather than as mutually exclusive processes, to illustrate what a mature or healthy identity provides an individual. Therefore, the functions were expected to be empirically related to one another, indicating that they work together in the process of healthy identity development. Results of correlational analyses, CFA and SEM showed that, as expected, the functions are distinct, but not mutually exclusive. They are connected in that they function together in the creation of strong, well-integrated, self-regulative sense of identity.

The readability of the FIS scale items underwent revision in this study and the entire measure, including instructions, now stands at a 5.5 grade reading level. This allows for comparisons across groups whereby the FIS can be used with more diverse individuals who have different reading abilities, including adolescents and persons with learning disabilities. The FIS is ready to be tested with adolescent and other nonuniversity samples in order to assess whether the Functions of Identity factors fit for persons outside the academic realm.

Future research should also include invariance testing. Factorial invariance is determined by the consistency of results across variations in participants and reflected in either identical factor loadings or replication of the pattern of the simple structure of the model (e.g., Byrne, 2001; Schumacker, 1996). The structural relationships among the factors of the FIS should thus be examined for patterns. It will be important to first establish the invariance of the factor structure across samples of undergraduate students before testing the factorial structure with other groups, such as youths, non-student 
groups, adults, older adults and diverse ethnic groups. Previous work with the FIS has provided some evidence for gender comparisons whereby the model was found to work similarly for males and females (see Serafini et al., 2003). Invariance of the factorial structure across genders must also be examined.

The structural paths among the factors and between the factors and other identity constructs should also be examined. In doing so, alternative identity measures should be sought that are both psychometrically sound and constructually compatible with the Functions of Identity. While the structural validity of the five-factor measurement model proposed by the FIS has been supported empirically in the present study, the predictive validity of the model using other established identity measures has not been fully established at this time.

Future research with the FIS should also expand to include larger models. The relationships between the functions of identity and their comparison measures were established via correlational analyses, but the predictive relationships between the functions and other such constructs have yet to be explored. This course of action should begin with an examination of the predictive relationships between the functions of identity and other identity measures. Central to this endeavour will be to locate valid and reliable identity measures and to use them in their entirety, as intended by their designers.

The utility of the FIS is applicable to both research and clinical settings. In terms of its potential to further research in the area of identity, the FIS is a psychometrically strong instrument. Scale construction and validation have been mindful and structured processes, guided by both statistical and theoretical considerations. Since their creation in 2002 , the FIS scale items have undergone revisions in order to increase their clarity 
and readability, and the Control construct has been revamped significantly in light of empirical evidence accumulated across validation studies. Validation work thus far has spanned four studies in an effort to create the most theoretically and psychometrically sound instrument as possible. Because both theoretical and empirical justifications have guided model adjustments, researchers who use the FIS in their work can feel confident that the scale is measuring what it proposes to measure.

The value of the FIS is not limited to its construction and validation methods, but also includes its orientation to the identity construct. Whereas other measures are categorical, such as the OMEIS where people are grouped by identity status, or the ISI where people are assigned a primary identity processing style, the FIS does not categorize participants into any group. The FIS provides a window into the way in which various theorized functions of identity are present in a person's life, and avoids the artificial nature of fitting individuals into general categories or groups, which may minimize individual differences and the role of parallel processes in identity construction.

Another strength of the FIS is that is moves beyond viewing identity construction as based solely on exploration and commitment, such as with Marcia's Identity Status work. These are only two dimensions of Erikson's complex construct, and identity consolidation is not limited solely to having explored and then made commitments. The FIS reflects the outcomes of successful identity synthesis across various dimensions, not limited solely to those of exploration and commitments. It is a more inclusive construct than the Identity Status Paradigm (Marcia, 1966) and believed to better reflect the complexity and self-regulative nature of identity as theorized by Erikson. 
The FIS can be used with SEM to model hypothesized relationships between the functions of identity and other related constructs in larger models. For example, the FIS may predict or be predicted by variables encompassing psychological well-being. Note that psychological well-being may be measured not only by absence of pathological manifestations, such as depression, anxiety, and high-risk or deviant behaviour (e.g., drug or alcohol abuse, gambling, theft, assault, or social isolation) but also by the presence of various capacities and qualities, such as: self-esteem, coping, resiliency, self-efficacy, assertiveness, positive body image, self-confidence, academic or job success, and various domains of life satisfaction (e.g., relationship satisfaction, job satisfaction). Larger models may examine the predictive relationships between the functions of identity and a range of constructs and behaviours believed to be related to healthy and adaptive identity functioning in order to further our understanding of how having a synthesized and consolidated sense of identity predicts or is predicted by other processes or variables.

The utility of the FIS is not limited to research contexts alone. Serafini and Adams (2002) noted the importance of considering the FIS as a useful tool for clinical settings as well. The non-categorical approach of the FIS may be particularly advantageous or appropriate for clinical settings by avoiding the stigma associated with labels and the possible impact that the labelling process may have on a person's developing sense of self. With the FIS, however, individuals are not grouped into categories based on the presence or absence of some valued skill or quality. Rather, individuals are assessed equally on five dimensions of identity functioning, where strength and competence in one area may be met by edges for growth in other areas, as evidenced by Functions subscale scores. Someone may thus score high on Structure and 
Harmony, but lower on Goals, Future and Personal Control. This may be helpful information for clinicians in terms of highlighting the usefulness of making space for therapeutic conversations regarding goal-setting, future possibilities (and present-future self congruence) and personal control and agency in terms of self-regulative processes. Although the FIS is a relatively new measure in the identity field, it has undergone consistent and rigorous validity testing. The five-factor measure is short, consisting of only 15 items, and thus, it is easy to administer and score. The measure is based on a unique facet of identity theory that moves beyond existing work whereby the process of identity construction is the unit of analysis, to the outerworkings of identity consolidation or synthesis - the functions of identity. Two common approaches to studying the process of identity construction are based either on the presence or absence of exploration and commitment (i.e., identity statuses) or rooted in the way that identityrelated information is processed (i.e., identity styles). The FIS focuses instead on the outerworkings of identity synthesis and moves away from a categorical emphasis of identity type or style. This alternative lens may open up space for identity research to move in a direction that could be more directly applicable to clinical contexts. A clinical milieu, particularly one that is informed by constructionist therapies, may already be sensitized to issues associated with the use of labels. Consequently, a tool that does not employ a label or categorical focus may lend itself more easily to use in some clinical domains, thereby facilitating the integration of research and practice. Future work using the FIS may, in fact, strengthen the bridge connecting identity theory, research and application. 
Figure 1

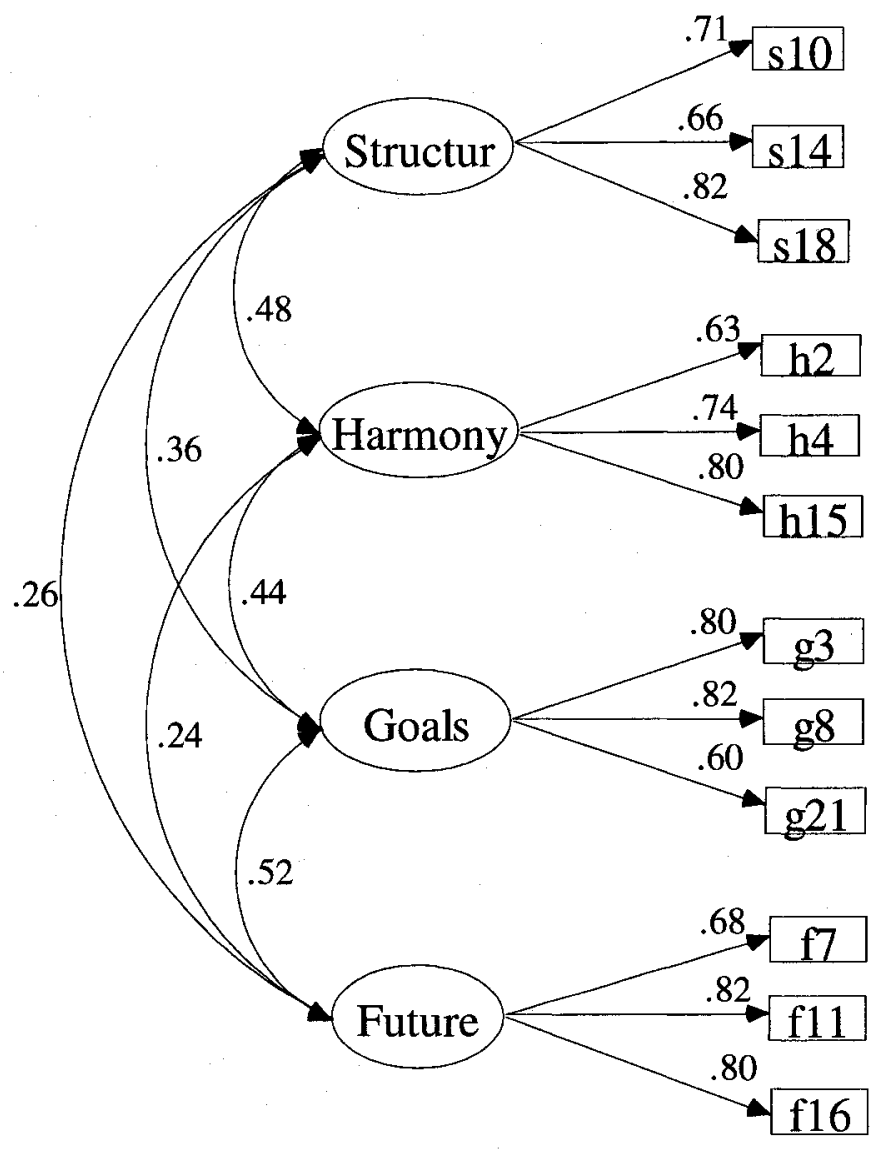

Chi-square $=341.44, d f=48, p<.001 ; \mathrm{GFI}=.97 ; \mathrm{TLI}=.94 ;$ and $\mathrm{RMSEA}=.062$ 
Figure 2

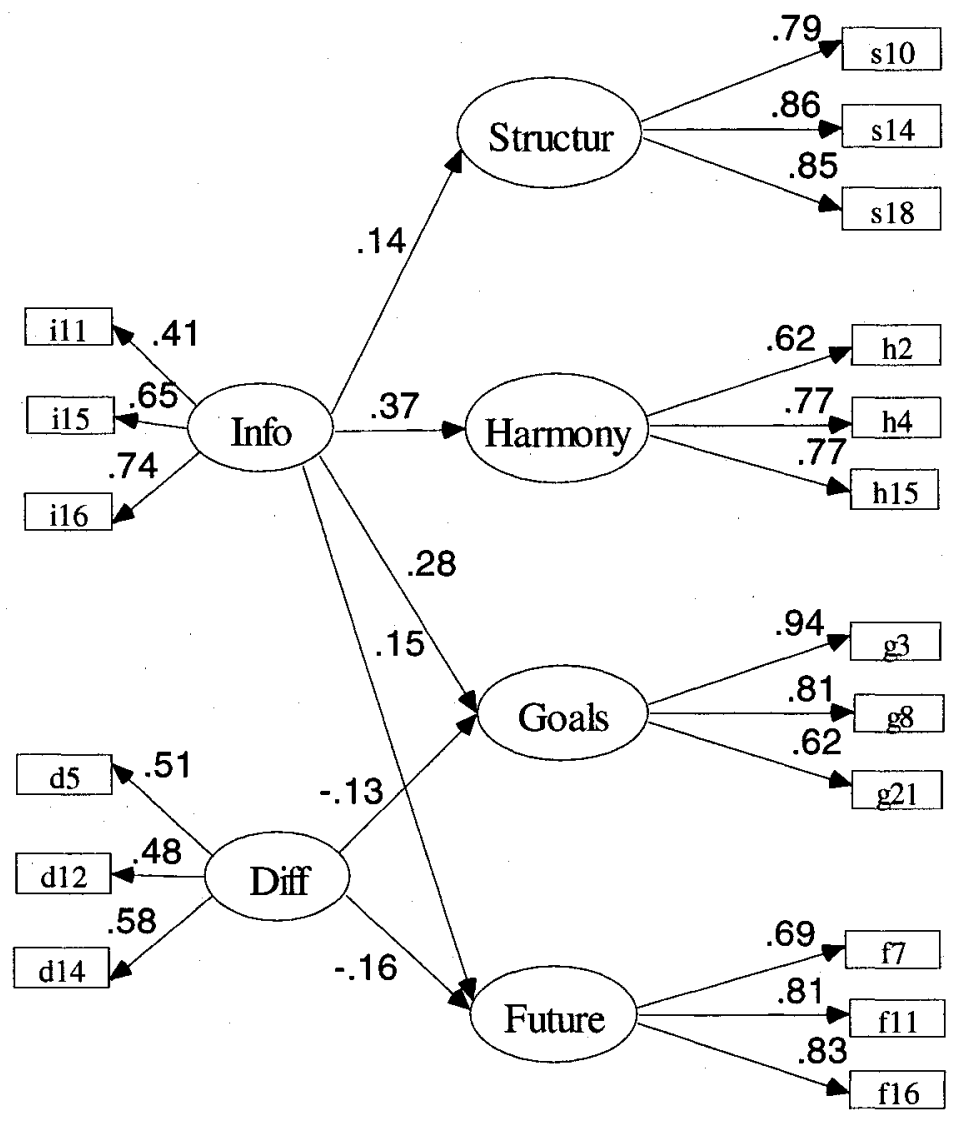

Chi-square $=2110.87, d f=132, p<.001 ; \mathrm{GFI}=.89 ; \mathrm{AGFI}=.85 ; \mathrm{TLI}=.72$;

RMSEA $=.098$ 
Figure 3 .

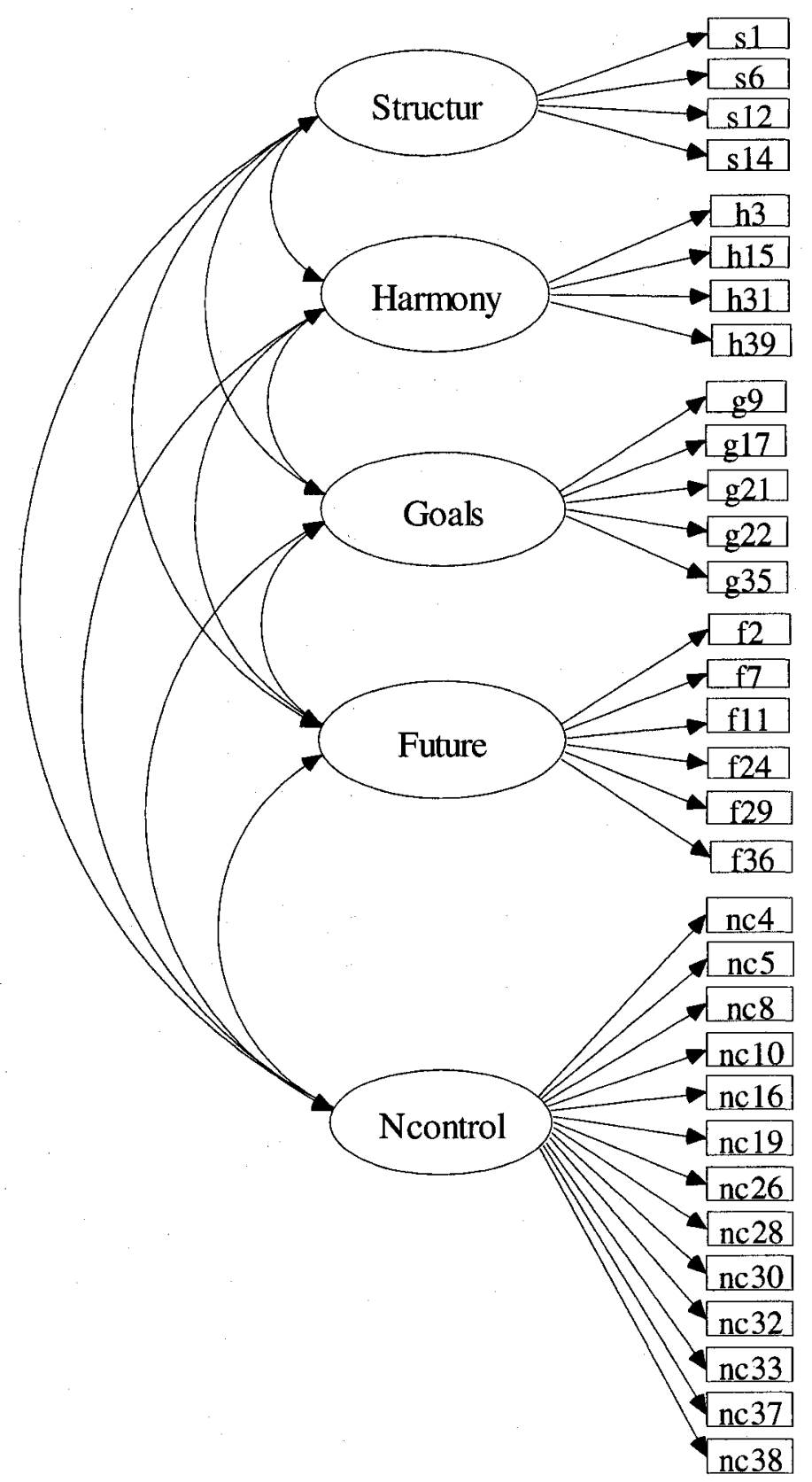

Chi-square $=2204.69, d f=454, p<.001 ; \mathrm{GFI}=.77 ; \mathrm{AGFI}=.73 ; \mathrm{TLI}=.77$; RMSEA $=.085$ 
Figure 4

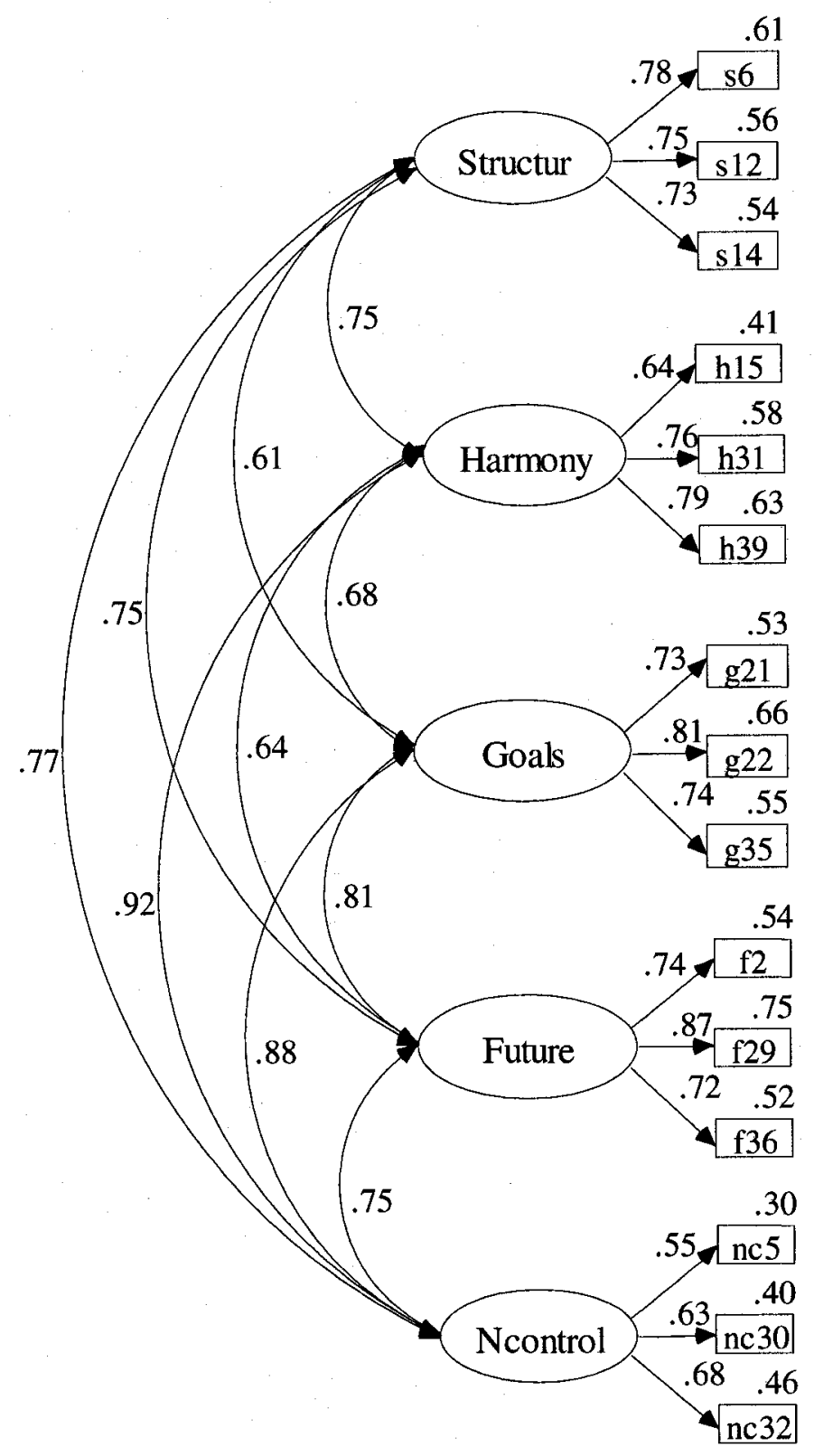

Chi-square $=277.16, d f=80, p<.001 ; \mathrm{GFI}=.93 ; \mathrm{AGFI}=.90 ; \mathrm{TLI}=.93$; $\mathrm{RMSEA}=.068$ 
Figure 5

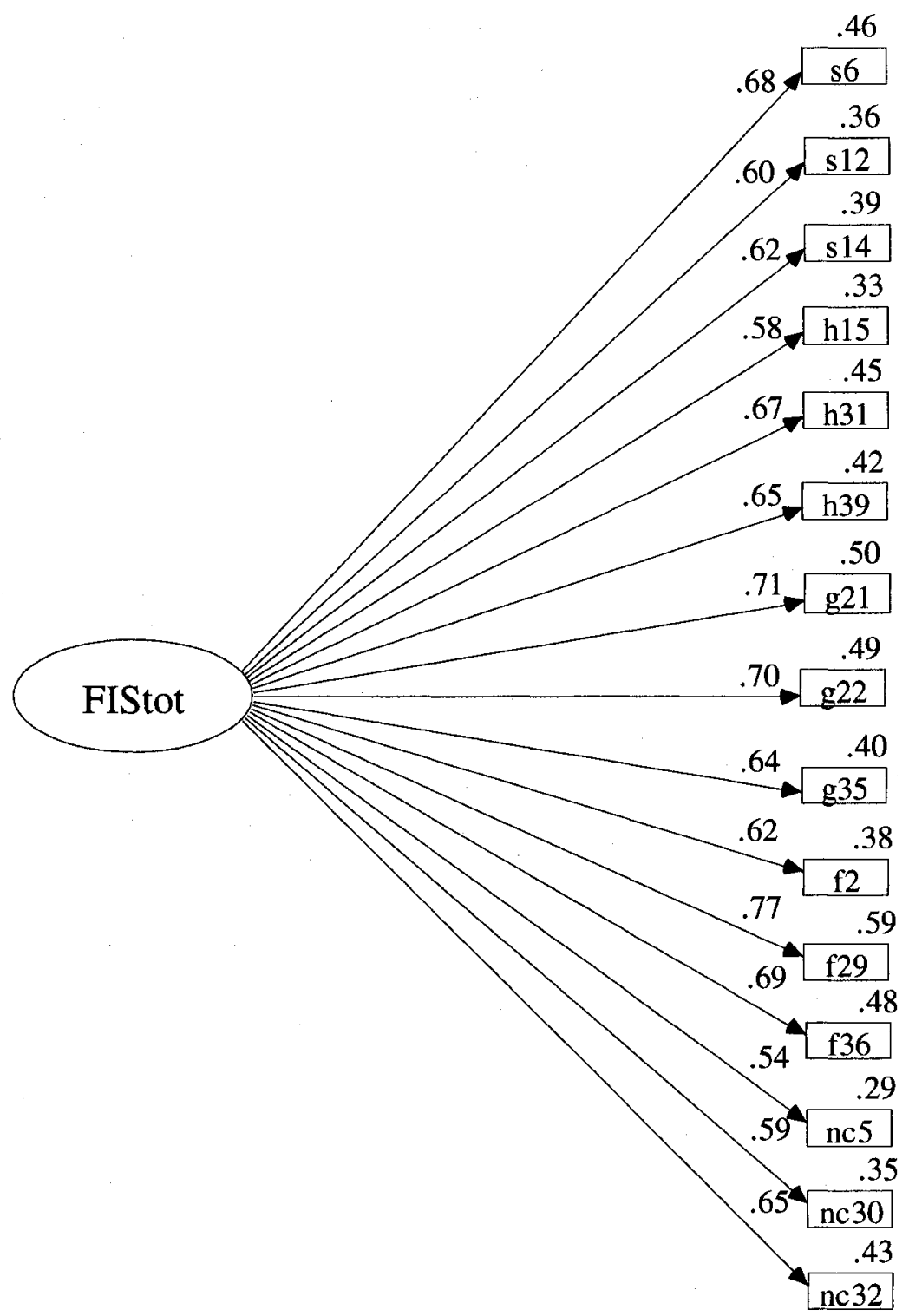

Chi-square $=745.43, d f=90, p<.001 ; \mathrm{GFI}=.81 ; \mathrm{AGFI}=.75 ;$ TLI $=.80 ;$ RMSEA $=.117$ 
Figure 6

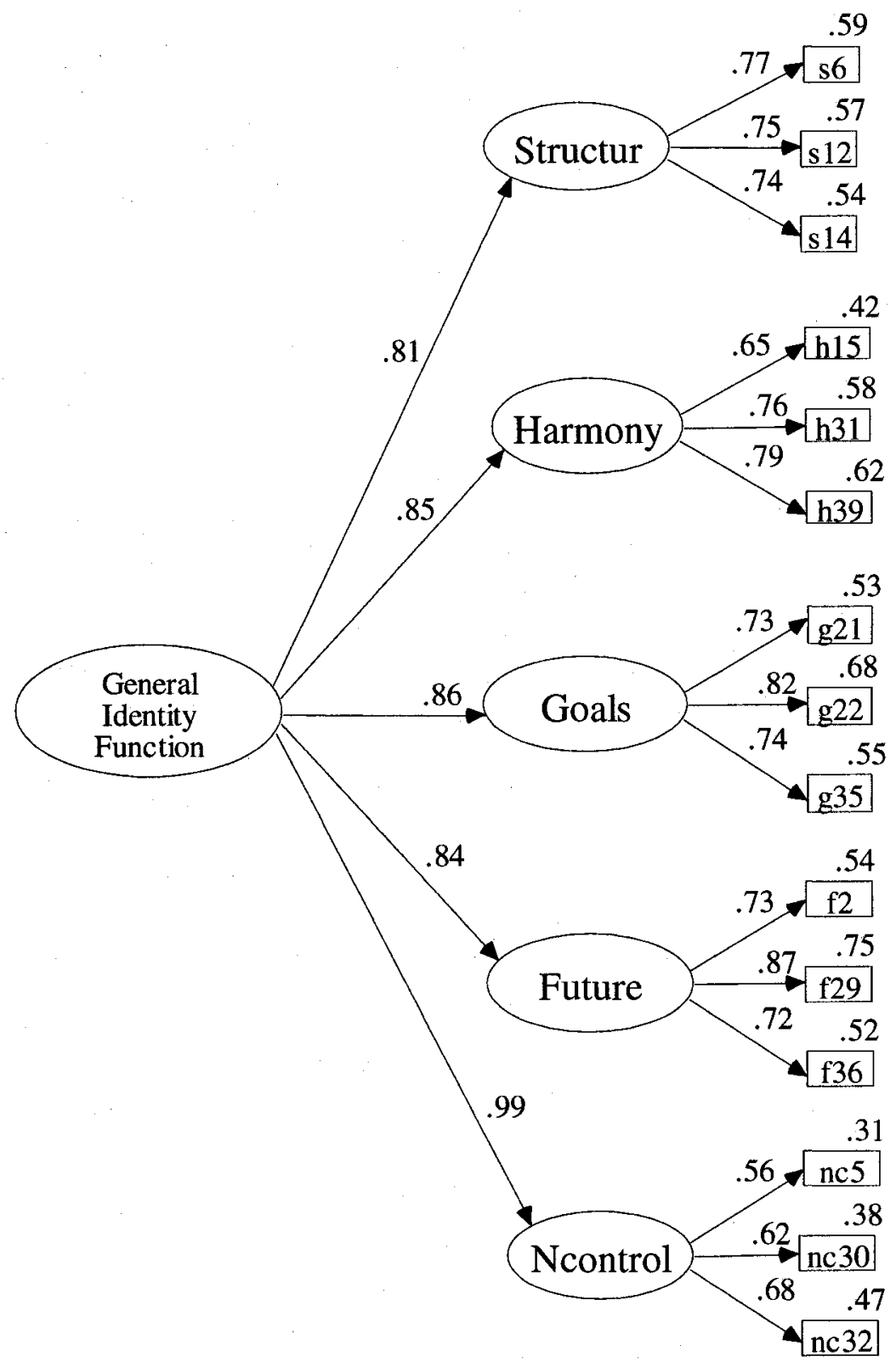

Chi-square $=367.77, d f=85, p<.001 ; \mathrm{GFI}=.91 ; \mathrm{AGFI}=.88 ; \mathrm{TLI}=.91$; RMSEA $=.079$ 
Figure 7

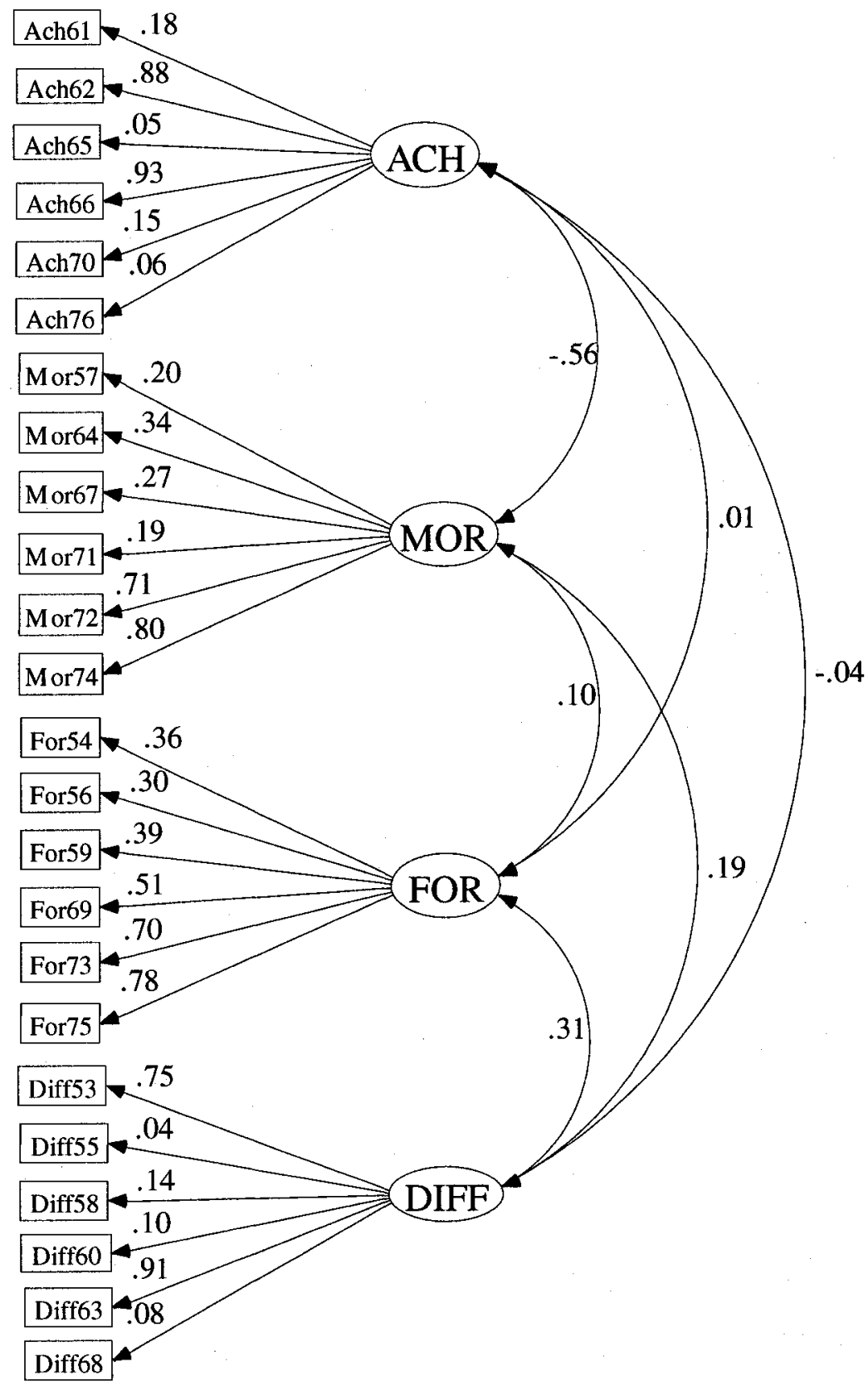

Chi-square $=2069.42, d f=246, p<.001 ; \mathrm{GFI}=.735 ; \mathrm{AGFI}=.667 ; \mathrm{TLI}=.446$; RMSEA $=.118$

Note: Paths connecting these latent variables are not significant:

ACH $<-->$ DIFF, ACH $<-->$ FOR, and MOR $<->$ FOR 
Figure 8.

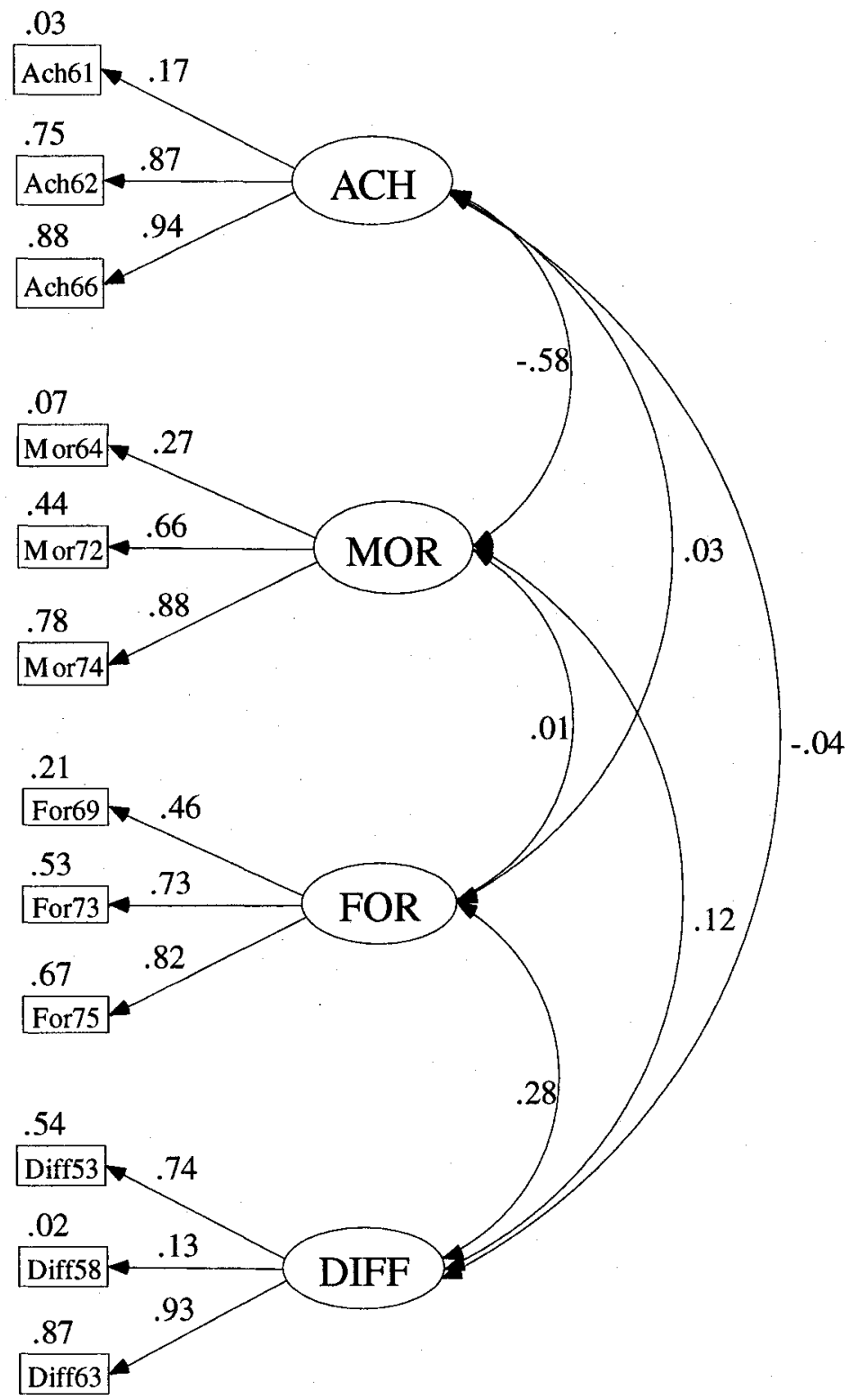

Chi-square $=175.50, d f=48, p<.001 ; \mathrm{GFI}=.95 ; \mathrm{AGFI}=.92 ; \mathrm{TLI}=.90 ;$ $\mathrm{RMSEA}=.071$

Note: Paths connecting these latent variables are not significant: ACH $<-->$ DIFF, ACH $<->$ FOR, and MOR $<-->$ FOR 
Figure 9.

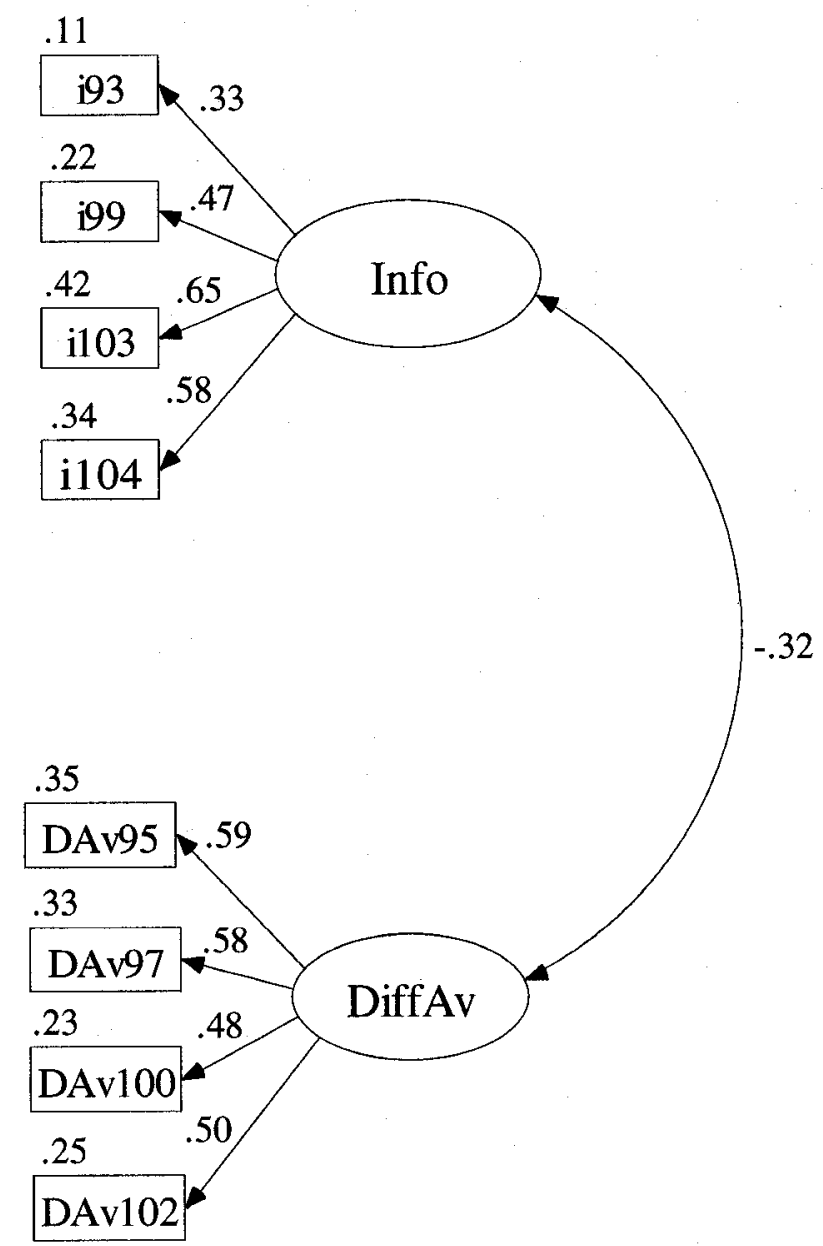

Chi-square $=137.79, d f=19, p<.001 ; \mathrm{GFI}=.94 ; \mathrm{AGFI}=.89 ; \mathrm{TLI}=.672$;

RMSEA $=.109$ 
Figure 10

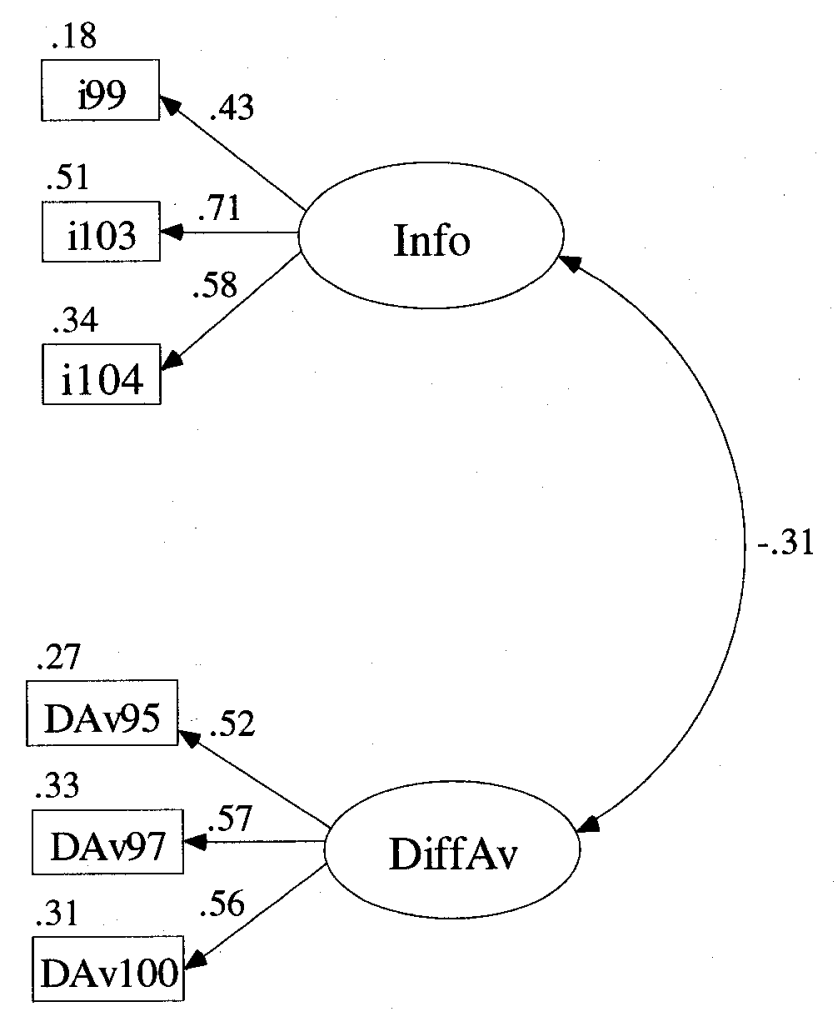

Chi-square $=36.80, d f=8, p<.001 ; \mathrm{GFI}=.98 ; \mathrm{AGFI}=.94 ; \mathrm{TLI}=.84 ; \mathrm{RMSEA}=.083$ 
Figure 11

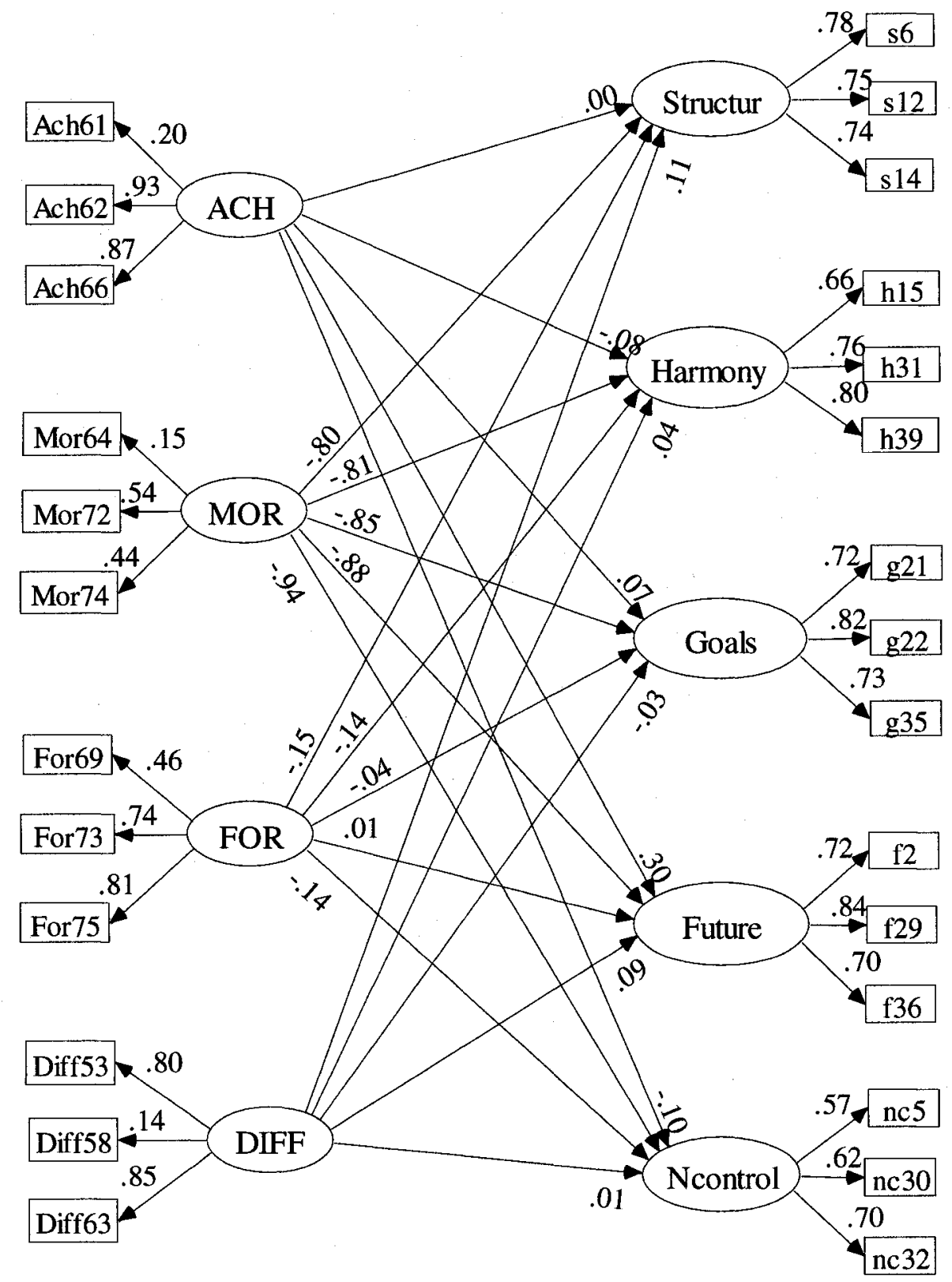

Chi-square $=1190.16, d f=304, p<.001 ; \mathrm{GFI}=.85 ; \mathrm{AGFI}=.84 ; \mathrm{TLI}=.81 ;$

RMSEA $=.074$ 
Figure 12

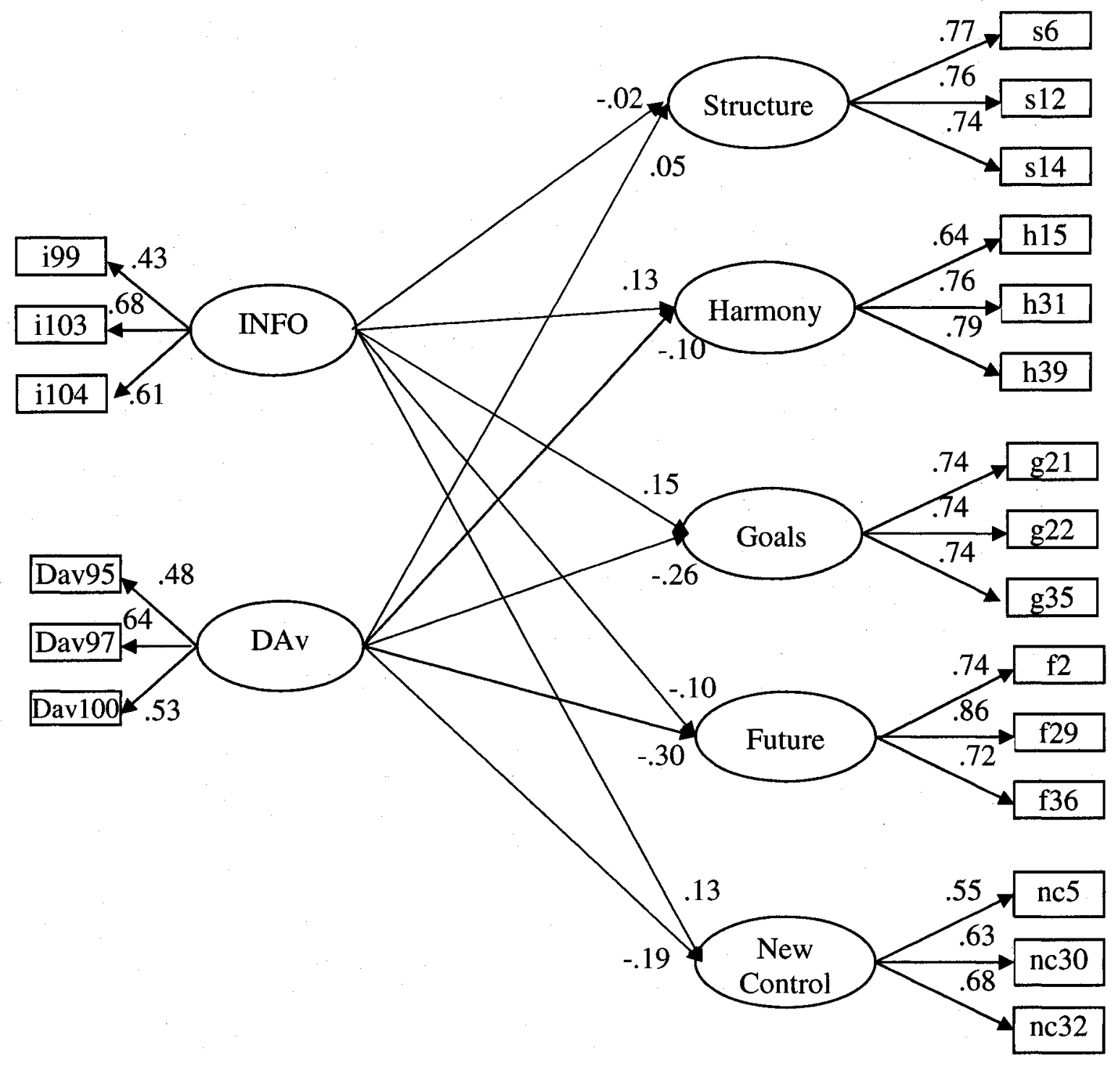

Chi-square $=483.52, d f=168, p<.001 ; \mathrm{GFI}=.92 ; \mathrm{AGFI}=.89 ; \mathrm{TLI}=.91 ;$

RMSEA $=.06$ 


\section{References}

Abraham, K. G. (1983). The relation between identity status and locus of control among high school students. Journal of Early Adolescence, 3, 257-264.

Adams, G. R., Abraham, K. G.,\& Markstrom, C. A. (1987). The relationships between identity development and self-consciousness during middle and late adolescence. Developmental Psychology, 19, 292-297.

Adams, G. R. \& Ethier, J. L. (1999). The Objective Measure of Ego Identity Status: A Manual on theory and test construction. Unpublished manual, Department of Family Relations and Applied Nutrition. University of Guelph, Guelph, Ontario, Canada.

Adams, G. R. \& Marshall, S. (1996). A developmental social psychology of identity: Understanding the person in context. Journal of Adolescence, 19, 1-14.

Adams, G. R., Shea, J., \& Fitch, S. A. (1979). Toward the development of an objective assessment of ego-identity status. Journal of Youth and Adolescence, 8, 223-237.

Ames, S. C., Offord, K. P., Nirelli, L. M., Patten, C. A., Friedrich, W. N., \& Decker, P. A., et al. (2005). Initial development of a new measure of minor stress for adolescents: The adolescent minor stress inventory. Journal of Youth \& Adolescence, 34, 207-219.

Arbuckle, J. (1999). Amos 4.0 user's guide. Chicago: SmallWaters Corporation.

Archer, S. L. \& Waterman, A. L. (1988, March). Identity status and the quality of romantic relationships. Paper presented at the biennial meeting of the Society for Research on Adolescence, Alexandria, VA.

Baumeister, R. F., \& Vohs, K. D. (Eds.). (2004). Handbook of self-regulation: Research, theory, and applications. New York: Guilford Press.

Baumeister, R. F., \& Vohs, K. D. (2003). Self-regulation and the executive function of the self. In M. R. Leary \& J. Price Tangney (Eds.), Handbook of self and identity (pp. 197-217). New York: Guilford Press.

Bennion, L. D. (1988). Measuring adolescent ego-identity status: A comparison of the semistructured interview and the objective measure of ego identity status. Unpublished master's thesis, Utah State University, Logan.

Bennion, L., \& Adams, G. R. (1986). A revision of the extended version of the objective measure of ego identity status: An identity instrument for use with late adolescents. Journal of Adolescent Research, 1, 183-198. 
Bentler, P. M., \& Bonett, D.G. (1980). Significance tests and goodness of fit in the analysis of covariance structures. Psychological Bulletin, 88, 588-606.

Berzonsky, M. D. (1986). Discovery versus constructivist interpretations of identity formation: Consideration of additional implications. Journal of Early Adolescence, 6, 111-117.

Berzonsky, M. D. (1989). Identity style: Conceptualization and measurement. Journal of Adolescent Research, 4, 267-281.

Berzonsky, M. D. (1990). Self-construction over the life-span: A process perspective on identity formation. Advances in Personal Construct Psychology, 1, 155-186.

Bishop, D. I., Macy-Lewis, J. A., Schenekloth, C. A., Puswella, S.,\& Struessel, G. L. (1997). Ego identity status and reported alcohol consumption: A study of firstyear college students. Journal of Adolescence, 20, 209-218.

Blustein, D. L., \& Palladino, D. E. (1991). Self and identity in late adolescence: Atheoretical and empirical integration. Journal of Adolescent Research, 6, 437453.

Bollen, K. A. (1989). Structural equations with latent variables. New York: Wiley.

Brewer, N. T., Hallman, W. K., Fiedler, N., \& Kipen, H. M., (2004). Why do people report better health by phone than by mail? Medical Care, $42,875-883$.

Browne, M. W., \& Cudeck, R. (1993). Alternative ways of assessing model fit. In K. A. Bollen \& J. S. Long (Eds.), Testing structural equation models (pp. 136-162). Newbury Park, CA:Sage.

Byrne, B. M. (2005). Factor analytic models: Viewing the structure of an assessment instrument from three perspectives. Journal of Personality Assessment 85, 17-32.

Byrne, B. M. (2001). Structural equation modeling with AMOS: Basic concepts, applications, and programming. London: Lawrence Erlbaum Associates.

Clark, L. A., \& Watson, D. (1995). Constructing validity: Basic issues in objective scale development. Psychological Assessment, 7, 309-319.

Cooper, C. R., \& Carlson, C. I. (1991). Continuity and change in family communication during adolescence: Developmental, gender, and ethnic perspectives. Paper presented at the Society for Research in Child Development, Seattle, WA. 
Cotugna, N., Vickery, C. E., \& Carpenter-Haefele, K. M. (2005). Evaluation of literacy level of patient education pages in health-related journals. Journal of Community Health: The Publication for Health Promotion \& Disease Prevention, 30, 213219.

Cronbach, L. J. (1951). Coefficient alpha and the internal structure of tests. Psychometrika, 16, 297-334.

Crumbaugh, J. C., \& Maholick, L. T. (1981). Manual of instructions for the Purpose in Life Test. Murfeesboro, TN: Psychometric Affiliates.

Erikson, E. H. (1968). Identity: Youth and crisis. New York: Norton

Flesch, R. (1948). A new readability yardstick. Journal of Applied Psychology, 32, 221233.

Francis, S. J. (1981). Dropout decisions perceived as a function of the relationship between identity status, locus of control and ego development: A developmental approach to retention and attrition (Doctoral dissertation, Boston College, 1981). Dissertation Abstracts International, 42, 4319A.

Fulton, A. S. (1997). Identity status, religious orientation, and prejudice. Journal of Youth and Adolescence, 26, 1-11.

Gough, H G., Fioravanti, M., \& Lazzari, B. (1979). A cross-cultural unisex ideal self scale for the adjective checklist. Journal of Clinical Psychology, 35, 314-319.

Grotevant, H. D., \& Adams, G. R. (1984). Development of an objective measure to assess ego identity in adolescence: Validation and replication. Journal of Youth and Adolescence, 13, 419-438.

Hammer, R. J., \& Bruch, M. A. (1994). The role of shyness and private selfconsciousness in identity development. Journal of Research in Personality, 28, $436-452$.

Hooker, K. (1999). Possible selves in adulthood: Incorporating telenomic relevance into studies of the self. In T.M. Hess \& F. Blanchard-Fields (Eds.), Social cognition and aging (pp. 99-117). San Diego: Academic Press.

Hu, L., \& Bentler, P. M. (1998). Fit indices in covariance structure modeling: Sensitivity to underparameterized model misspecification. Psychological Methods, 3, 424-453.

Hu, L., \& Bentler, P. M. (1999). Cutoff criteria for fit indexes in covariance structure analysis: Conventional criteria versus new alternatives. Structural Equation Modeling, 6, 1-55. 
Jaccard, J. \& Wan, C. K. (1996). Quantitative applications in the social sciences. Thousand Oaks, CA: Sage

Jackson, D. L. (2001). Sample size and number of parameter estimates in maximum likelihood confirmatory factor analysis: A Monte Carlo investigation. Structural Equation Modeling, 8, 205-223.

Jackson, D. L. (2003). Revisiting sample size and number of parameter estimates: Some support for the N:Q hypothesis. Structural Equation Modeling, 10, 128-141.

Jones, R. M., Hartmann, B. R., Grochowski, C. O., \& Gilder, P. (1989). Ego identity and substance abuse: A comparison of adolescents in residential treatment with adolescents in school. Personality and Individual Differences, 10, 625-631.

Joreskog, K. G., (1971). Simultaneous factor analysis in several populations. Psychometrika, 36, 409-426.

Joreskog, K. G., \& Sorbom, D. (1982). Recent developments in structural equation modeling. Journal of Marketing Research, 19, 404-416.

Khoo, P. N., \& Senn, C. Y., (2004). Not wanted in the inbox!: Evaluations of unsolicited and harassing e-mail. Psychology of Women Quarterly, 28, 204-214.

Kline, R. B. (1998). Principles and practice of structural equation modeling. New York: Guilford Press.

Leary, M. R., \& Price Tangney, J. (Eds.) (2003). Handbook of self and identity. New York: Guilford Press.

Ley, P., \& Florio, T. (1996). The use of readability formulas in health care. Psychology, Health \& Medicine, 1, 7-28.

Loevinger, J. (1957). Objective tests as instruments of psychological theory. Psychological Reports, 3, 635-694.

MacCallum, R. C., Wegener, D. T., Uchino, B. N., \& Fabrigar, L. R. (1993). The problem of equivalent models in applications of covariance structure analysis. Psychological Bulletin, 114, 185-199.

Maddux, J. E., \& Gosselin, J. T. (2003). Self-efficacy. In M. R Leary \& J, Price Tangney (Eds.). Handbook of Self and Identity (pp. 218-238). New York: Guilford Press.

Marcia, J. (1966). Development and validation of ego-identity status. Journal of Personality and Social Psychology, 3, 551-558. 
Marcia, J. (1994). Identity and psychotherapy. In S. L. Archer (Ed.), Interventions for adolescent identity development (pp. 29-46). London: Sage.

Markstrom-Adams, C., Hofstra, G., \& Dougher, K. (1994). The ego-virtue of fidelity: A case for the study of religion and identity formation in adolescence. Journal of Youth and Adolescence, 23, 453-469.

Markus, H. \& Nurius, P. (1986). Possible selves. American Psychologist, 41, 954-969

Marsh, H. W., Balla, J. R., \& MacDonald, R. P. (1988). Goodness-of-fit indexes in confirmatory factor analysis: The effect of sample size. Psychological Bulletin, 103. 391-410.

Marsh, H. W., \& Hocevar, D. (1985). Application of confirmatory factor analysis to the study of self-concept: First- and higher order factor models and their invariance across groups. Psychological Bulletin, 97, 562-582.

McCrae, R. R., Costa, P. T. J., \& Martin, T. A. (2005). The NEO-PI-3: A more readable revised NEO personality inventory. Journal of Personality Assessment, 84, 261270.

Mulaik, S., James, L. R., Van Alstine, J., Bennett, N., Lind, S., \& Stilwell, C. D. (1989). Evaluation of goodness-of-fit indices for structural equation models.

Psychological Bulletin, 105, 430-455.

Muthen, B., \& Kaplan, D. (1985). A comparison of some methodologies for the factor analysis of nonnormal Likert variables. British Journal of Mathematical and Statistical Psychology, 38, 171-189.

Nunnally, J. C. (1978). Psychometric theory (2 ${ }^{\text {nd }}$ ed.). New York: McGraw-Hill.

O'Connor, B. P. (1995). Identity development and perceived parental behavior as sources of adolescent egocentrism. Journal of Youth and Adolescence, 24, 205227.

Owen, R. G. (1984). Ego identity status distribution of Anglo and Cuban-American college males and tests of status-by-culture interaction on measures of psychological development and self-esteem. Unpublished doctoral dissertation, University of Miami, Coral Gables, FL.

Paasche-Orlow, M. K., Taylor, H. A., \& Brancati, F. L. (2003). Readability standards for informed-consent forms as compared with actual readability. New England Journal of Medicine, 348, 721-726. 
Quintana, S. M., \& Maxwell, S. E., 1999. Implications of recent developments in structural equation modeling for counseling psychology. Counseling Psychologist, 27, 485-427.

Reynolds, W. M. (1982). Development of the reliable and valid short forms of the Marlowe-Crowne social desirability scale. Journal of Clinical Psychology, 38, 119-129.

Rosenberg, M. (1965). Society and the adolescent self-image. Princeton, NJ: Princeton University Press.

Schafer, J. L. (1999). Multiple imputation: A primer. Statistical Methods in Medical Research, 8, 3-15.

Schmeichel, B. J. \& Baumeister, R. F. (2004). Self-regulatory strength. In R. F Baumeister \& K. D. Vohs, (Eds.), Handbook of self-regulation: Research, theory, and applications (pp. 84-98). New York: Guilford Press.

Schumacker, R. E. (1996). Beginner's guide to structural equation modeling. Mahwah, NJ: Erlbaum.

Schwartz, S. J. (2001). The evolution of Eriksonian and neo-Eriksonian identity theory and research: A review and integration. Identity: An International Journal of Theory and Research, 1(1) 7-58.

Schwarzer, R. (Ed.) (1992). Self-efficacy: Thought control of action. Washington, DC: Hemisphere.

Schwarzer, R., \& Jerusalem, M. (1995). Generalized Self-Efficacy scale. In J. Weinman, S. Wright, \& M. Johnston, Measures in health psychology: A user's portfolio. Causal and control beliefs (pp. 35-37). Windsor, UK: NFER-NELSON.

Serafini, T. E. \& Adams, G. R. (2002). Functions of identity: Scale construction and validation. Identity, 2, 361-389.

Serafini, T. E., Maitland, S. B., \& Adams, G. R. (2003, May). Toward validation of the Functions of Identity Scale. Poster presented at the tenth annual meeting of the Society for Research on Identity Formation, Vancouver, BC, Canada.

Serafini, T. E., Maitland, S. B., \& Adams, G. R. (2006, March). The Functions of Identity Scale: Revisions, validation and model testing. Poster presented at the Biennial Meeting of the Society for Research on Adolescence, San Francisco, California. 
Springer, D. W., Abell, N., \& Hudson, W. W. (2002). Creating and validating rapid assessment instruments for practice and research: Part 1. Research on Social Work Practice, 12, 408-439.

Springer, D. W., Abell, N., \& Nugent, W. R. (2002). Creating and validating rapid assessment instruments for practice and research: Part 2. Research on Social Work Practice, 12, 768-795.

Stanton, J. M., Sinar, E. F., Balzer, W. K., \& Smith, P. C. (2002). Issues and strategies for reducing the length of self-report scales. Personnel Psychology, 55, 167-194.

Tabachnick, B. G. \& Fidell, L. S. (1996). Using multivariate statistics (Third Edition). New York: HarperCollins.

Vohs, K. D. \& Ciarocco, N. J. (2004). Interpersonal functioning requires self-regulation. In R. F Baumeister \& K. D. Vohs, (Eds.), Handbook of self-regulation: Research, theory, and applications (pp. 84-98). New York: Guilford Press.

Vondracek, F. W., Schulenberg, J., Skorikov, V., Gillespie, L. K., \& Wahlheim, C. (1995). The relationship of identity status to career indecision during adolescence. Journal of Adolescence, 18, 17-29.

Wallace-Broscious, A., Serafica, F. C., \& Osipow, S. H. (1994). Adolescent career development: Relationships to self-concept and identity status. Journal of Research on Adolescence, 4, 127-149.

Watson \& Friend (1967). Measure of social evaluative anxiety. Journal of Consulting \& Clinical Psychology, 33, 448-457.

White, J. M., Wampler, R. S., \& Winn, K. I. (1998). The identity style inventory: A revision with a sixth grade reading level (ISI-6G). Journal of Adolescent Research, 13, 223-245.

Zook, A., \& Sipps, G. J. (1985). Cross-validation of a short form of the MarloweCrowne Social Desirability Scale. Journal of Clinical Psychology, 41, 236-238. 
Appendix A

Functions of Identity Definitions

\begin{tabular}{|c|c|}
\hline Functions of Identity & $\begin{array}{c}\text { Original Definition } \\
\text { (Serafini \& Adams, 2002) }\end{array}$ \\
\hline $\begin{array}{l}\text { To provide the structure for understanding } \\
\text { who one is (Structure) }\end{array}$ & $\begin{array}{l}\text { Identity provides an awareness of the self } \\
\text { as an independent and unique individual. It } \\
\text { is most apparent when it is about to } \\
\text { transform or change, where change is } \\
\text { accompanied by extreme identity } \\
\text { consciousness. A sense of understanding } \\
\text { who one is provides the structure for a) } \\
\text { self-certainty and self-esteem and b) a } \\
\text { foundation for an emerging and unfolding } \\
\text { self. }\end{array}$ \\
\hline $\begin{array}{l}\text { To provide meaning and direction through } \\
\text { commitments, values and goals (Goals) }\end{array}$ & $\begin{array}{l}\text { Identity is based on the capacity for faith } \\
\text { that commitments or chosen values or } \\
\text { goals will receive institutional } \\
\text { confirmation. The commitments or goals } \\
\text { of identity direct or channel behaviours and } \\
\text { actions. }\end{array}$ \\
\hline
\end{tabular}




\begin{tabular}{|c|c|}
\hline $\begin{array}{l}\text { To provide a sense of personal control and } \\
\text { free will (Control) }\end{array}$ & $\begin{array}{l}\text { Identity is based on the distinctions } \\
\text { between passivity or compliance and an } \\
\text { active or willful nature. Passive forms of } \\
\text { identity are based on compliance, imitation } \\
\text { and identification. Active forms of identity } \\
\text { are based on self-expression, independent } \\
\text { construction, and a sense of free will and } \\
\text { autonomy }\end{array}$ \\
\hline $\begin{array}{l}\text { To provide consistency, coherence and } \\
\text { harmony between values, beliefs and } \\
\text { commitments (Harmony) }\end{array}$ & $\begin{array}{l}\text { Identity formation is based on the } \\
\text { organizing agency of synthesis or } \\
\text { integration at one point and across time. } \\
\text { Identity in its best state offers a sense of } \\
\text { coherence between values, beliefs and } \\
\text { commitments. This sense of coherence is } \\
\text { accompanied with harmony or low anxiety } \\
\text { and a sense of peace with one's self }\end{array}$ \\
\hline $\begin{array}{l}\text { To provide the ability to recognize } \\
\text { potential in the form of future possibilities } \\
\text { and alternative choices (Future) }\end{array}$ & $\begin{array}{l}\text { A sense of identity is, in part, based on } \\
\text { self-initiative and on a sense of purpose } \\
\text { that offers the promise of fulfilling one's } \\
\text { range of capacities. Thus, self-initiative, } \\
\text { purpose, and capacities offer the promise of } \\
\text { a tangible future. }\end{array}$ \\
\hline
\end{tabular}


Appendix B

Functions of Identity and Comparison Measures (Study 2)

\begin{tabular}{|c|c|}
\hline $\begin{array}{l}\text { FUNCTIONS OF } \\
\text { IDENTITY }\end{array}$ & COMPARISON MEASURES \\
\hline $\begin{array}{l}\text { Structure } \\
\text { (self-understanding, self- } \\
\text { certainty) }\end{array}$ & $\begin{array}{l}\text { Stability of Self Scale (Rosenberg, 1965) } \\
\text { Structure would manifest itself in stable sense of self }\end{array}$ \\
\hline $\begin{array}{l}\text { Goals } \\
\text { (goals, commitments, } \\
\text { purpose) }\end{array}$ & $\begin{array}{l}\text { The Purpose In Life Test (Crumbaugh \& Maholick, 1981) } \\
\text { Measures goals, commitments and sense of purpose in life }\end{array}$ \\
\hline $\begin{array}{l}\text { Control } \\
\text { (free will, internal locus of } \\
\text { control) }\end{array}$ & $\begin{array}{l}\text { Internal Locus of Control Scale (based on Rotter, 1966) } \\
\text { Personal control and free will conceptually match up with } \\
\text { internal locus of control }\end{array}$ \\
\hline $\begin{array}{l}\text { Harmony } \\
\text { (low anxiety) }\end{array}$ & $\begin{array}{l}\text { Fear of Negative Evaluation Scale (Watson \& Friend, 1969) } \\
\text { Harmony among values, beliefs and commitments expected } \\
\text { to manifest itself in low sense of anxiety about the self or } \\
\text { low fear of negative evaluation }\end{array}$ \\
\hline $\begin{array}{l}\text { Future } \\
\text { (recognize potential, future } \\
\text { possibilities) }\end{array}$ & $\begin{array}{l}\text { The Ideal Self Scale (Gough, Fiorvanti \& Lazzari, 1979) } \\
\text { Future focus depicted in construct of "ideal self" } \\
\text { High scores on ISS believed to suggest ability to pursue and } \\
\text { attain goals, socially effective }\end{array}$ \\
\hline
\end{tabular}


Thank you for your participation. Please answer each item as honestly as possible and rate the items based on your first response (i.e., do not think about each item long; we are interested in your initial responses).

INSTRUCTIONS: Using the following scale, please circle the numbered response that best represents how well each of the following statements describes you. Please be sure to transfer your responses to the computer card provided.

$\begin{array}{ccccc}1 & 2 & 3 & 4 & 5 \\ \text { never } & \text { seldom } & \text { sometimes } & \text { often } & \text { always }\end{array}$

1. I accept who I am.

2. I have a good idea of what my future holds for me.

3. My values and beliefs say a lot about who I am.

4. I am able to control my emotions if I choose to.

5. When what I'm doing isn't working, I am able to find different approaches to meeting my goal(s).

6. I am certain that I know myself.

7. My sense of an achievable future ahead of me guides my current choices and actions.

8. I am responsible for my actions.

9. Self-motivation, based on my sense of self, is one of my strengths.

10. My sense of free will and personal control guide my behaviours.

11. I am undecided about where I will be in the future.

12. I feel a sense of peace with my self and my identity.

13. I seem to passively accept the values and beliefs of others.

14. I feel I have a consistent sense of self from one day to the next.

15. My values and beliefs reflect who I am.

16. When I am faced with options, I can pick the one that fits best for me.

17. I have clear life goals.

18. I tend to push the limits when choosing ways to express who I am.

19. I monitor my progress when working toward a goal. 
20. Much of who I am seems to be based on compliance to my parent(s)' wishes.

21. I have constructed my own personal goals for myself.

22. I tend to set goals and then work towards making them happen.

23. Identifying with my parent(s)' beliefs and wishes gives my life a sense of meaning.

24. I do not have a sense of a tangible future ahead of me (e.g., career).

25. While I am influenced by others, I make my own independent decisions.

26. I can control myself when I am faced with temptation.

27. I prefer to comply with normal standards of behaviour than to push the limits of selfexpression.

28. Making my own decisions is something I am good at.

29. I am clear about who I will be in the future.

30. The decisions I make about how to behave and act are based on my personal choices.

31. My values and beliefs are consistent with the commitments that I make in my life at this time.

32. I am self-directed when I set my goals.

33. When I am working toward a goal, I don't really actively monitor my progress.

34. Normal or expected standards of behaviour influence how I express who I am.

35. I am a goal-directed person.

36. Thinking about my future gives me a sense of direction.

37. The decisions I make about how to behave and act are influenced by others.

38. If I choose to, I am able to change my response to a situation.

39. My values and beliefs fit with the person I am. 
INSTRUCTIONS: Listed below are a number of statements concerning personal attitudes and traits. Read each item and decide whether the statement is true or false as it pertains to you personally.

Please be sure to transfer your responses to the computer card provided.

$$
1=\text { TRUE = FALSE }
$$

40. It is sometimes hard for me to go on with my work if I am not encouraged.

41. I sometimes feel resentful when I don't get my way.

42. On a few occasions, I have given up doing something because I thought too little of my ability.

43. There have been times when I felt like rebelling against people in authority even though I knew they were right.

44. No matter who I'm talking to, I'm always a good listener.

45. There have been occasions when I took advantage of someone.

46. I'm always willing to admit it when I make a mistake.

47. I sometimes try to get even rather than forgive and forget.

48. I am always courteous, even to people who are disagreeable.

49. I have never been irked when people expressed ideas very different from my own.

50. There have been times when I was quite jealous of the good fortune of others.

51. I am sometimes irritated by people who ask favours of me.

52. I have never deliberately said something that hurt someone's feelings. 
INSTRUCTIONS: In past interviews, people have given us personal descriptions of themselves. Sometimes these descriptions have a single thought, and sometimes double thoughts go together. Please read each of the following statements, which come from those interviews, and indicate on a continuum from NOT LIKE ME to EXACTLY LIKE ME, how you see each statement reflecting your own thoughts. There are no right or wrong answers, people simply differ in how the statements fit their own state of mind.

Please use the following scale to record your answers and shade the appropriate number on the computer card provided.
1
2
3
4
not like me slightly like me somewhat like me more like me

53. I haven't really considered politics. They just don't excite me much.

54. I might have thought about a lot of different things, but there has never really been a decision since my parents said what they wanted.

55. When it comes to religion I just haven't found any that I'm really into myself.

56. My parents had it decided a long time ago what I should go into and I'm following their plans.

57. There are so many different political parties and ideals. I can't decide which to go with until I figure it all out.

58. I don't give religion much thought and it doesn't bother me one way or the other.

59. I guess I'm pretty much like my folks when it comes to politics. I follow what they do in terms of voting and such.

60. I haven't chosen the occupation I really want to get into, but I'm working toward becoming a until something better comes along.

61. A person's faith is unique to each individual. I've considered and reconsidered it myself and know what I can believe.

62. It took me a long time to decide but now I know for sure what direction to move in for career.

63. I really never was involved in politics enough to have to make a firm stand one way or the other.

64. I'm not so sure what religion means to me. I'd like to make up my mind but I'm not done looking yet. 
65. I've thought my political beliefs through and realize I may or may not agree with many of my parent's beliefs.

66. It took me a while to figure it out, but now I really know what I want for a career.

67. Religion is confusing to me right now. I keep changing my views on what is right and wrong to me.

68. I'm sure it will be pretty easy for me to change my occupational goals when something better comes along.

69. My folks have always had their own political and moral beliefs about issues like abortion and mercy killing and I've always gone along accepting what they have.

70. I've gone through a period of serious questioning about faith and can now say I understand what $\mathrm{I}$ believe in as an individual.

71. I'm not sure about my political beliefs, but I'm trying to figure out what I can truly believe in.

72. I just can't decide how capable I am as a person and what jobs I'll be right for.

73. I attend the same church as my family has always attended. I've never really questioned why.

74. I just can't decide what to do for an occupation. There are so many possibilities.

75. I've never really questioned my religion. If it's right for my parents it must be right for me.

76. Politics are something that I can never be too sure about because things change so fast. But I do think it's important to know what I believe in.

INSTRUCTIONS: Below you will find a number of statements about beliefs, attitudes, or ways of dealing with issues. Read each carefully and indicate to what degree that item describes you using the scale below.

Please be sure to transfer your responses to the computer card provided.

\section{1}

Not at all true
2

Hardly true
3

Moderately true

\section{4} Exactly true

1. I can always manage to solve difficult problems if I try hard enough.

2. If someone opposes me, I can find the means and ways to get what I want.

3. It is easy for me to stick to my aims and accomplish my goals. 
3. It is easy for me to stick to my aims and accomplish my goals.

4. I am confident that I could deal efficiently with unexpected events.

5. Thanks to my resourcefulness, I know how to handle unforeseen situations.

6. I can solve most problems if I invest the necessary effort.

7. I can remain calm when facing difficulties because I can rely on my coping abilities.

8. When I am confronted with a problem, I can usually find several solutions.

9. If I am in trouble, I can usually think of a solution.

10. I can usually handle whatever comes my way.

This questionnaire addresses how you see yourself in the future. We all think about our future to some extent. When we do so, we might think about the kinds of experiences that are in store for us, and the kinds of people we might possibly become. Sometimes we think about what we HOPE we will be like (selves we hope to become in the future -- "hoped-for self" or "possible self").

INSTRUCTIONS: Read each statement carefully and using the following scale, indicate to what degree each statement describes you and how you view yourself now and in the future: Please be sure to transfer your responses to the computer card provided.

$\begin{array}{ccccc}1 & 2 & 3 & 4 & 5 \\ \begin{array}{c}\text { not very much } \\ \text { like me }\end{array} & & \begin{array}{c}\text { somewhat } \\ \text { like me }\end{array} & \begin{array}{c}\text { very much } \\ \text { like me }\end{array}\end{array}$

11. When I think of the person I want to be someday, this possible self is very much like the person I am today.

12. It is important for me to achieve this possible self.

13. Who I am today is very much like the person I see myself becoming.

14. I am very capable of becoming the person I hope to be.

15. My hoped-for self is a long way off.

16. My future self is basically the same as who I am now. 
INSTRUCTIONS: Below you will find a number of statements and beliefs, attitudes and/or ways of dealing with issues. Read each carefully and indicate to what degree that item describes you using the following scale:

Please be sure to transfer your responses to the computer card provided.

$\begin{array}{ccccc}1 & 2 & 3 & 4 & 5 \\ \begin{array}{c}\text { not very much } \\ \text { like me }\end{array} & & \begin{array}{c}\text { somewhat } \\ \text { like me }\end{array} & & \begin{array}{c}\text { very much } \\ \text { like me }\end{array}\end{array}$

93. I've spent a great deal of time thinking about what I should do with my life.

94. I've more or less always operated according to the values with which I was brought up.

95. Many times by not concerning myself with personal problems, they work themselves out.

96. I've always had purpose in my life; I was brought up to know what to strive for.

97. I'm not really thinking about my future right now; it's still a long way off.

98. I believe it's better to have a firm set of beliefs than to be open-minded.

99. When I have a personal problem, I try to analyze the situation in order to understand it.

100. It's best for me not to take life too seriously; I just try to enjoy it.

101. I think it's better to have fixed values than to consider alternative value systems.

102. I try not to think about or deal with problems as long as I can.

103. When I have to make a decision, I like to spend a lot of time thinking about my options.

104. When making important decisions I like to have as much information as possible.

INSTRUCTIONS: Please read the following statements and indicate how well they describe you by rating them as either true (1) or false (2).

Please be sure to transfer your responses to the computer card provided.

$$
1=\text { TRUE } \quad 2=\text { FALSE }
$$

105. I worry about what people will think of me even when I know it doesn't make any difference.

106. I become tense and jittery if I know someone is sizing me up.

107. I am unconcerned even if I know people are forming an unfavourable impression of me.

108. The opinions that important people have of me cause me little concern.

109. I am frequently afraid of other people noticing my shortcomings. 
110. The disapproval of others would have little effect on me.

111. I rarely worry about what kind of impression I am making on someone.

112. Other people's opinions of me do not bother me.

113. I am usually worried about what kind of impression I make.

114. I worry very little about what others may think of me.

115. Sometimes I think I am too concerned with what other people think of me.

116. I am usually confident that others will have a favourable impression of me.

INSTRUCTIONS: For each of the following statements please choose the response that best fits for you.

Please be sure to transfer your responses to the computer card provided.

117. Does your opinion of yourself tend to change a good deal or does is always continue to remain the same?

$$
1=\text { Changes somewhat or a great deal } 2=\text { Changes very little or not at all }
$$

118. Do you ever find that on one day you have one opinion of yourself and on another day you have a different opinion?

$1=$ Yes, this happens sometimes or often $2=$ No, this never or rarely happens

119. I have noticed that my ideas about myself seem to change very quickly.

$$
1=\text { Agree } 2=\text { Disagree }
$$

120. Some days I have a good opinion of myself; other days I have a very poor opinion of myself.
$1=$ Agree
$2=$ Disagree

121. I feel that nothing, or almost nothing, can change the opinion I currently hold of myself.
1 = Agree
2 = Disagree 
INSTRUCTIONS: For each of the following statements, circle the number that would be most nearly true for you. Note that the numbers always extend from one extreme feeling to its opposite kind of feeling. "Neutral" implies no judgment either way - try to use this rating as little as possible.

Please be sure to transfer your responses to the computer card provided.

122. In life I have:

$\begin{array}{lcc}1 & 2 & 3 \\ \text { no goals or } & & \text { (neutral) } \\ \text { aims at all } & \end{array}$
4 5
very clear goals and aims

123. My personal existence is:

$\begin{array}{lcccc}1 & 2 & 3 & 4 & 5 \\ \text { y meaningless } & & \text { (neutral) } & & \begin{array}{c}\text { very purposeful and } \\ \text { meaningful }\end{array}\end{array}$

124. In achieving life goals I have:

1

2

made no progress whatever

125. I am a:

1
very irresponsible
person

2

3

(neutral)

3

(neutral)
4

$$
\text { progressed to }
$$
complete fulfillment

4 very responsible
person

126. My life is:

$\begin{array}{lcc}1 & 2 & 3 \\ \text { empty, filled } & & \text { (neutral) } \\ \text { only with despair } & & \end{array}$

127. I have discovered:

$\begin{array}{lcc}1 & 2 & 3 \\ \text { no mission or } & & \text { (neutral) } \\ \text { purpose in life } & & \end{array}$

4 running over with exciting good things 
128) Do you identify as:

129) What year of study are you currently enrolled in?

$\mathrm{a}=$ female

$\mathrm{a}=$ first year

$\mathrm{b}=$ male

$c=$ transgender

$\mathrm{b}=$ second year

$\mathrm{c}=$ third year

$\mathrm{d}=$ fourth year

$\mathrm{e}=$ Other -- please specify:

130) Which category best represents the age group to which you belong?

$a=18$ or under

$\mathrm{b}=19$ to 20 years

$\mathrm{c}=21$ to 22 years

$\mathrm{d}=23$ to 25 years

$\mathrm{e}=26$ years or over

131) To what racial or ethnic group do you belong? (If you are bi/multiracial please select all that apply)
$\mathrm{a}=$ White/European
$\mathrm{b}=$ Black/African/Caribbean
$\mathrm{c}=$ East Asian/Chinese/Japanese
$\mathrm{d}=$ South Asian/Indian/Pakistani
$\mathrm{e}=$ Other (please specify)

132) What are your current living arrangements?

$\mathrm{a}=\mathrm{I}$ live on campus/in residence (alone)

$\mathrm{b}=\mathrm{I}$ live on campus/in residence with housemate(s)

$\mathrm{c}=\mathrm{I}$ live off campus (alone)

$\mathrm{d}=\mathrm{I}$ live off campus with housemate(s)

$\mathrm{e}=$ Other (please specify)

\section{UNIVERSITY OF GUELPH STUDENTS:}

133) To which college/faculty do you belong?

$\mathrm{a}=$ Arts (e.g., English, Fine Arts, History, Languages/Literatures, Philosophy, etc.)

b = Biological Science (e.g., Botany, Human Biology/Nutritional Sciences,

Microbiology, Zoology, etc.)

c = Physical and Engineering Science (e.g., Chem/Biochem, Computing, Env. Sci., Physics)

d = Social \& Applied Human Sciences (e.g., FRAN, Consumer Studies, Econ, Psych, etc.)

$\mathrm{e}=$ Other (please specify)

\section{UNIVERSITY OF WATERLOO STUDENTS:}

133) To which college/faculty do you belong?

$\mathrm{a}=$ Arts (e.g., English, History, Geography, Languages, Philosophy, Psych, Soc, SMF, etc.)

b = Applied Health Sciences (e.g., Health Studies, Gerontology, Kinesiology, Rec \& Leisure)

$\mathrm{c}=$ Engineering $\underline{\mathrm{OR}}$ Science (e.g., Chem/Civil/Electrical/Comp Engineering; Bio, Chem, Physics, etc.) 


\section{Appendix D}

\section{Recruitment Email}

\section{Dear Professor:}

My name is Toni Serafini and I am a Doctoral Candidate in the department of Family Relations and Applied Nutrition at the University of Guelph. I am currently in the process of collecting data for my doctoral research and am writing to inquire whether you would consider allowing me to recruit participants for my study from your class this semester. I have been recruiting participants from both the University of Guelph and the University of Waterloo campuses. If you agree, this would involve my making a short presentation (3-4 minutes) at either the beginning or end of class, whichever is more convenient for you, to present the study and distribute questionnaire packages. In order to make participation in the study more convenient for students, I would also like to be available at your class one week later to collect completed questionnaire packages and to issue a brief reminder. Students may also return completed questionnaire packages via campus mail, or drop them off at my Essay Drop Box at St. Jerome's University.

A bit about my research: My research is in the area of identity development. Specifically, I am working on refining an assessment tool (The Functions of Identity Scale) that I created for a previous research project. The instrument has been used in three studies thus far and this stage of the validation research involves conceptual refinements to the tool, with a focus on construct and external validity.

Students who wish to participate in this project will be asked to complete a package of psychological questionnaires that assess various aspects of the "self". The package should take between 30 to 45 minutes to complete, and students are asked to do so on their own time. Participation in this study is completely voluntary, but those who choose to participate will receive "compensation" via entry into a draw for two chances to win a $\$ 200$ cash prize. The research study has been approved by the University of Guelph's Research Ethics Board (REB \#04DE006) and the University of Waterloo's Office of Research Ethics (ORE \#12315).

I thank you for your time and your consideration. If you are willing and able to assist me in this matter, please reply directly to this email with a day and time that is convenient for you.

Best regards, Toni

Toni Serafini, Doctoral Candidate

Department of Family Relations \& Applied Nutrition

University of Guelph

519-824-4120 x56325

toni@golden.net 
Appendix E

Sample Recruitment Script: In-Class Recruitment Presentation, University of Waterloo

Introduction:

- Thank you to professor

- My name is Toni Serafini

- Doctoral Candidate, Department FRAN at the University of Guelph

- Currently conducting my doctoral research (thesis research)

- I'm here to see if you'd be interested in participating in my study ...

- My research area: study of "the self" - how we construct our sense of self, theory-testing, and creation and validation of assessment tools that assess the self

- I am here to ask for your participation in this research endeavour

- You do not need any previous knowledge or experience

- Participation in my research requires you to answer questions about YOU - your thoughts, opinions, beliefs, etc. by rating statements on a 4- or 5-point scale.

- There are no right or wrong answers - I'm interested in you, what you think

What does participation involve?

- Completing a package of questionnaires

- Takes about 30-45 minutes of your time

- Package includes a detailed information letter. If you have any questions, you may contact me directly (contact information on the information letter enclosed)

- Record answers on computer/Scantron sheet

- NO NAMES OR ID numbers - just circle oval responding to your answer choice.

- Responses are confidential and anonymous

- You may withdraw at any time - simply do not complete/return the questionnaire package.

- You may leave questions blank, if you wish. Just watch numbering ... shading in correct oval.

- Your participation in this research is not related to this, or any other course you are taking. It is completely voluntary on your part.

- I have approached students from both the University of Guelph and the University of Waterloo campuses with this opportunity to participate in my research.

- Research has been approved by both the University of Waterloo's Office of Research Ethics and the University of Guelph's Research Ethics Board

- Those interested can take a package today.

- You may return it directly to me (or my research assistant) next week in class will come by to pick it up, OR

- Can return it via campus mail (provide location) or at my Essay Drop Box at St. Jerome's University (for UW students). 


\section{Why Participate?}

- You will be contributing to social science research, supporting research component of university institutions

- Financial incentive: As a fellow student, I understand that students can always use a little extra money, so if they wish, those who participate will have their ticket number (enclosed in the envelope) entered into a draw for 2 chances to win a \$200 cash prize. The draw will take place in September, once all the data has been collected and analyzed (see info letter for details about the draw and for the website where results of draw will be posted). 


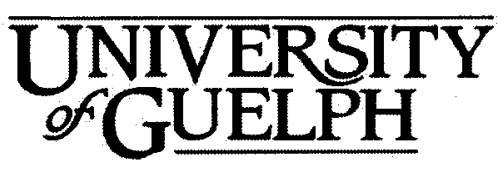

\section{CONSENT TO PARTICIPATE IN RESEARCH}

Research Project Title:

The Self: Understanding and Assessment

You are asked to participate in a research study conducted by Toni Serafini, Doctoral Candidate, and her advisory committee: Doctors Adams, Maitland, and MacMartin of the Department of Family Relations \& Applied Nutrition and Dr. Newby-Clark of the Psychology Department, all of the University of Guelph. The results of this study will form the basis of Toni Serafini's Doctoral Dissertation Project, which has received external funding from a Social Science and Humanities Research Council (SSHRC) Doctoral Fellowship.

If you have any questions or concerns about the study, please feel free to contact Toni Serafini (x63525) or Dr. Gerald Adams (x 53967), at the University of Guelph (519-8244120).

\section{PURPOSE OF THE STUDY:}

We are conducting a study to develop an empirically sound assessment device. The area of our research is the assessment of self. The study consists of responding to various questions that deal with how you view aspects of the self. Some items may seem repetitious, but this repetition is built into the assessment device. We ask that you respond to each item as fresh and unique.

PROCEDURE: If you agree to participate in this study, we ask that you do the following things:

Consent: You would need to read and sign this information and consent form in order to indicate that you understand the study and are willing to participate. You may withdraw from the project at any time during the course of this study, even once consent has been given.

Questionnaires: You are asked to respond to several short scales or questionnaires provided to you in a "questionnaire package". You are to do this outside of class, on your own time, unless your instructor provides class time. Please read the instructions for 
each scale carefully and follow the directions as they are stated. You may leave any items blank, if you do not wish to respond. Some of the items may seem a bit repetitious, but this repetition is part of the process of creating a measurement tool (or scale). Please try to respond to each question as though it is new.

If you decide to participate in this study, please complete the enclosed scales as honestly as possible. Feel free to leave any questions blank if they upset you in any way, or to ask questions of clarification should you need to do so.

Time commitment: The whole questionnaire package should take between 30 and 45 minutes to complete. This is a one-time event. You will not be contacted to take part in any additional procedures related to this study.

Compensation for participation: All participants are also invited to enter their name in a lottery for a chance at winning one of two $\$ 200$ cash prizes. Instructions for entering the lottery are provided in the consent form. The draw will occur after the data collection phase is completed (i.e., sometime in the fall of 2005).

Returning completed packages: Once the scales have been completed, please place them in the self-addressed envelope provided and either hand them in at your next class where Toni Serafini will come to collect them, or place them in the inter-campus mail (envelope is addressed to Toni Serafini, FRAN Box \#79).

Feedback/Results: At the end of data collection and once the data have been analyzed and interpreted (August, 2005), a summary of the findings will be posted on Dr. Adams' website (www.uoguelph.ca/ gadams/adamsweb/) so that you may see what your participation has helped to produce. Results of this study will be formally submitted to a scholarly journal for publication, once the Doctoral Thesis has been accepted.

Effects of Participation in this Study: Participation in this study is not expected to cause participants any harm. You may, however, experience feeling more introspective and more likely to think about your "self" and "who you are" after completing the questionnaires (since they are all about you). The benefit of participating in this research study is that you are contributing to scholarly research in the social science field. Specifically, your participation will help to construct a sound, reliable, and valid measurement instrument that can be useful in future research and possibly clinical settings.

\section{CONFIDENTIALITY:}

Every effort will be made to ensure confidentiality of any identifying information that is obtained in connection with this study. If you agree to participate in this study, your signed consent form will be filed separate from your questionnaire package to ensure confidentiality (and some anonymity) of responses and to ensure that no one will be able to connect an individual person to an individual response. The documents will be coded so that should you choose to withdraw your participation once data has already been collected, the researcher will be able to locate your original questionnaire package and 
return it to you. In this case, all computerized data will also be erased. Note that only the researcher will have access to the completed questionnaires and the coding scheme in order to protect participants' confidentiality.

For those who choose to participate in this research project, the questionnaire packages will be stored in a locked office on the University of Guelph campus. Data will held until the project is complete (i.e., December, 2005); it will then be shredded and disposed of.

\section{PARTICIPATION AND WITHDRAWAL:}

You can choose whether to be in this study or not. If you volunteer to be in this study, you may withdraw at any time without consequences of any kind. Your may exercise the option of removing your data from the study. You may also refuse to answer any questions you don't want to answer and still remain in the study. The investigator may withdraw you from this research if circumstances arise that warrant doing so.

\section{RIGHTS OF RESEARCH PARTICIPANTS:}

You may withdraw your consent at any time and discontinue participation without penalty. You are not waiving any legal claims, rights, or remedies because of your participation in this study. This study has been reviewed and received Ethics clearance through the University of Guelph Research Ethics Board and the University of Waterloo Office of Research Ethics. If you have any questions regarding your rights as a research participant, contact:

Research Ethics Officer

University of Guelph

437 University Centre

Guelph, ON, N1G 2W1

(519) 824-4120, ext. 56606

e-mail: sauld@uoguelph.ca

Fax: (519) 821-5236
Director, Office of Research Ethics

University of Waterloo

(519) 888-4567, ext. 6005 


\section{$\overline{\text { UNIVERSITY }}$}

\section{SIGNATURE OF RESEARCH PARTICIPANT}

I have read the information provided for the study, "The Self: Understanding and Assessment" as described herein. My questions have been answered to my satisfaction, and I agree to participate in this study.

Name of Participant (please print)

Name of Witness (please print)

Note: - anyone may witness your signature

Signature of Participant

Signature of Witness

Date

Date

\section{Participation in Lottery}

If you would like to be entered into the lottery for a chance to win one of two $\$ 200$ cash prizes, please provide the following information so that you may be contacted if your name is drawn:

NAME (please print):

TELEPHONE NUMBER:

(Where you can be reached in the fall):

ADDRESS:

E-MAIL ADDRESS: 


\section{Appendix G \\ On-line Recruitment Email to University of Guelph \\ Distance Education Course Instructors}

Dear Professor:

My name is Toni Serafini and I am a Doctoral Candidate in the Department of Family Relations and Applied Nutrition at the University of Guelph. I am currently in the process of collecting data for my doctoral research and am writing to inquire whether you would consider allowing me to recruit participants for my study from your Distance Education class(es) this semester. If you agree, this would involve forwarding the attached note (see below) to students who are enrolled in your course(s) (via the "mail everyone in the class list" option on your course website). Students who are interested in participating in the proposed research study may contact me directly via email.

For your own information: A bit about my research My research is in the area of identity development. Specifically, I am working on refining an assessment tool (The Functions of Identity Scale) that I created for a previous research project. The instrument has been used in three studies thus far and this stage of the validation research involves conceptual refinements to the tool, with a focus on construct and external validity.

Students who wish to participate in this project will be required to complete a package of psychological questionnaires that assess various aspects of the "self". The package should take between 30 to 45 minutes to complete, and students are asked to do so on their own time. Participation in this study is completely voluntary, but those who choose to participate will receive "compensation" by having their names entered into a lottery to win one of two $\$ 200$ cash prizes. The research study has been approved by the University of Guelph's Research Ethics Board (REB \#04DE006).

Instructions Summary:

1. Forward the clip below to students in your course(s) using the "mail everyone in the class list" option located in the 'Class List' section of your course website.

2. Attach the enclosed information letter as an attachment.

3. Please use the subject line: Research Opportunity.

I thank you for your time and your consideration. Your support for my research would be greatly appreciated.

Best regards,

Toni

Toni Serafini, Doctoral Candidate

Department of Family Relations \& Applied Nutrition

University of Guelph

x56325, toni@golden.net 


\section{Instructors: PLEASE SEND THE FOLLOWING NOTE TO STUDENTS ALONG WITH THE ENCLOSED ATTACHMENT*}

\section{Greetings online learner!}

My name is Toni Serafini and I am a Doctoral Candidate in the department of Family Relations and Applied Nutrition at the University of Guelph. I am currently in the process of collecting data for my doctoral dissertation research and am wondering if you would be interested in participating in this research.

I am studying "the self" in an effort to understand how we construct our sense of self and to create and validate measurement tools that assess aspects of the self. This is part of an ongoing program of research that began six years ago and has received approval from the University of Guelph's Research Ethics Board.

Participation would involve completing a series of questionnaires containing statements about your beliefs, opinions, values, etc. The entire package takes about 30 to 45 minutes to complete. If you choose to participate in the study, your name will be entered into a draw to win one of $2, \$ 200$ cash prizes, as my way of thanking you for your time and your support.

If you are interested in knowing more about the study, please read the attached information letter. After reading the letter, if you would like to participate, please contact me directly at: toni@golden.net. I will send a questionnaire package to you directly.

\section{PLEASE NOTE:}

1. You have been sent this email via your course instructor, but participation in this study is completely voluntary and is not at all related to this course.

2. Please do not contact your instructor about participation in this study.

3. Contact me, Toni Serafini, directly at: toni@golden.net -- using the subject line: Research Opportunity.

4. In your email, please include either:

a) your $U$ of $G$ campus mailbox information (so that I can send you the questionnaire package via campus mail), or

b) your mailing address, including postal code, if you do not have a $U$ of $G$ campus mailbox.

5. If you'd prefer not to provide your mailing address and you are local to Guelph, you may pick up a questionnaire package from my office door (MINS 123) and return it by sliding it under the door. 
Thanks for your time and all the best for a successful semester!

Cheers,

Toni

Toni Serafini, Doctoral Candidate

Department of Family Relations \& Applied Nutrition

University of Guelph

x56325

toni@golden.net

*Note: The "attachment" referred to in this email is a copy of the "information letter" found in Appendix E 
Appendix $\mathrm{H}$

Order of Scales in Questionnaire Package

\begin{tabular}{|c|c|}
\hline Version 1 & Version 2 \\
\hline Info/Consent Form & Info/Consent Form \\
\hline Functions of Identity Scale (FIS, 39 items) & Functions of Identity Scale (FIS, 39 items) \\
\hline $\begin{array}{l}\text { Social Desirability Scale } \\
\text { (Short Form, } 13 \text { items) }\end{array}$ & Stability of Self Scale ( 5 items) \\
\hline OMEIS (24 items) & OMEIS (24 items) \\
\hline General Self-Efficacy Scale (10 items) & $\begin{array}{l}\text { Social Desirability Scale } \\
\text { (Short Form, } 13 \text { items) }\end{array}$ \\
\hline $\begin{array}{l}\text { Current - Future/Possible Self Scale } \\
\text { (6 items) }\end{array}$ & General Self-Efficacy Scale (10 items) \\
\hline Identity Styles Inventory (ISI, 12 items) & $\begin{array}{l}\text { Fear of Negative Evaluation Scale } \\
\text { (12 items) }\end{array}$ \\
\hline $\begin{array}{l}\text { Fear of Negative Evaluation Scale } \\
\text { (12 items) }\end{array}$ & Purpose In Life Scale (6 items) \\
\hline Stability of Self Scale (5 items) & $\begin{array}{l}\text { Current - Future/Possible Self Scale } \\
\text { (6 items) }\end{array}$ \\
\hline Purpose In Life Scale (6 items) & Identity Styles Inventory (ISI, 12 items) \\
\hline Demographics & Demographics \\
\hline
\end{tabular}




\begin{abstract}
Appendix I
The Functions of Identity Initial Five Latent Factor Model:

Indicators for Each Latent Variable (Identity Function) Prior to Model Trimming
\end{abstract}

Structure Items:

S 1: I accept who I am.

S 6: I am certain that I know myself.

S 12: I feel a sense of peace with my self and my identity.

S 14: I feel I have a consistent sense of self from one day to the next.

Harmony Items:

H 3: My values and beliefs say a lot about who I am.

H 15: My values and beliefs reflect of who I am.

H 31: My values and beliefs are consistent with the commitments that I make in my life at this time.

H 39: My values and beliefs fit with the person I am.

Goals Items:

G 9: Self-motivation, based on my sense of self, is one of my strengths.

G 17: I have clear life goals.

G 21: I have constructed my own personal goals for myself.

G 22: I tend to set goals and then work towards making them happen.

G 35: I am a goal-directed person. 
Future Items:

F 2: I have a good idea of what my future holds for me.

F 7: My sense of an achievable future ahead of me guides my current choices and actions.

F 11: I am undecided about where I will be in the future.

F 24: I do not have a sense of a tangible future ahead of me (e.g.,. career).

F 29: I am clear about who I will be in the future.

F 36: Thinking about my future gives me a sense of direction.

New Control Items:

NC 4: I am able to control my emotions if I choose to.

NC 5: When what I'm doing isn't working, I am able to find different approaches to meeting my goal(s).

NC 8: I am responsible for my actions.

NC 10: My sense of free will and personal control guide my behaviours.

NC 16: When I'm faced with options, I can pick the one that fits best for me.

NC 19: I monitor my progress when working toward a goal.

NC 26: I can control myself when I am faced with temptation.

NC 28: Making my own decisions is something I am good at.

NC 30: The decisions I make about how to behave and act are based on my personal choices.

NC 32: I am self-directed when I set my goals.

NC 33: When I am working toward a goal, I don't really actively monitor my progress.

NC 37: The decisions I make about how to behave and act are influenced by others.

NC 38: If I chose to, I am able to change my response to a given situation. 


\section{Appendix J}

The OMEIS Items per Latent Variable (Identity Status)

\section{$\underline{\text { Diffusion }}$}

D53 I haven't really considered politics. They just don't excite me much.

D55 When it comes to religion I just haven't found any that I'm really into myself.

D58 I don't give religion much thought and it doesn't bother me one way or the other.

D60 I haven't chosen the occupation I really want to get into, but I'm working toward becoming a until something better comes along.

D63 I really never was involved in politics enough to have to make a firm stand one way or the other.

D68 I'm sure it will be pretty easy for me to change my occupational goals when something better comes along.

\section{Foreclosure}

F54 I might have thought about a lot of different things, but there has never really been a decision since my parents said what they wanted.

F56 My parents had it decided a long time ago what I should go into and I'm following their plans.

F59 I guess I'm pretty much like my folks when it comes to politics. I follow what they do in terms of voting and such.

F69 My folks have always had their own political and moral beliefs about issues like abortion and mercy killing and I've always gone along accepting what they have. 
F73 I attend the same church as my family has always attended. I've never really questioned why.

F75 I've never really questioned my religion. If it's right for my parents it must be right for me.

Moratorium

M57 There are so many different political parties and ideals. I can't decide which to go with until I figure it all out.

M64 I'm not so sure what religion means to me. I'd like to make up my mind but I'm not done looking yet.

M67 Religion is confusing to me right now. I keep changing my views on what is right and wrong to me.

M71 I'm not sure about my political beliefs, but I'm trying to figure out what I can truly believe in.

M72 I just can't decide how capable I am as a person and what jobs I'll be right for.

M74 I just can't decide what to do for an occupation. There are so many possibilities.

\section{Achieved}

A61 A person's faith is unique to each individual. I've considered and reconsidered it myself and know what I can believe.

A62 It took me a long time to decide but now I know for sure what direction to move in for career.

A65 I've thought my political beliefs through and realize I may or may not agree with many of my parent's beliefs.

A66 It took me a while to figure it out, but now I really know what I want for a career. 
A70 I've gone through a period of serious questioning about faith and can now say I understand what I believe in as an individual.

A76 Politics are something that I can never be too sure about because things change so fast. But I do think it's important to know what I believe in. 


\section{Appendix K}

The Identity Styles Inventory (ISI): Scale Items per Latent Variable

Information Oriented Identity Processing Style:

Info 93 I've spent a great deal of time thinking about what I should do with my life.

Info 99 When I have a personal problem, I try to analyze the situation in order to understand it.

Info 103 When I have to make a decision, I like to spend a lot of time thinking about my options.

Info 104 When making important decisions I like to have as much information as possible.

Diffuse-Avoidant Identity Processing Style:

DiffAv 95 Many times by not concerning myself with personal problems, they work themselves out.

DiffAv 97 I'm not really thinking about my future right now; it's still a long way off.

DiffAv 100 It's best for me not to take life too seriously; I just try to enjoy it.

DiffAv 102 I try not to think about or deal with problems as long as I can. 